\title{
A PROTOTYPE OF PROPANE REFRIGERANT BASED ASHP WITH HEAT RECOVERY VENTILATION (HRV) SYSTEM
}

by

\author{
Ali Karevan \\ Bachelor of Mechanical Engineering, \\ K.N.Toosi University of Technology, Iran, 1996 \\ A Major Research Project \\ presented to Ryerson University \\ in partial fulfillment of the \\ requirements for the degree of \\ Master of Building Science \\ in the program of \\ Building Science
}

Toronto, Ontario, Canada, 2019

(C) Ali Karevan, 2019 


\section{AUTHOR'S DECLARATION}

I hereby declare that I am the sole author of this MRP. This is a true copy of the MRP, including any required final revisions.

I authorize Ryerson University to lend this MRP to other institutions or individuals for the purpose of scholarly research.

I further authorize Ryerson University to reproduce this MRP by photocopying or by other means, in total or in part, at the request of other institutions or individuals for the purpose of scholarly research.

I understand that my MRP may be made electronically available to the public. 


\title{
ABSTRACT
}

\section{A PROTOTYPE OF PROPANE REFRIGERANT BASED ASHP WITH HEAT RECOVERY VENTILATION (HRV) SYSTEM}

\author{
Ali Karevan \\ Master of Building Science, \\ Building Science, \\ Ryerson University, 2019
}

In recent years, an increased focus has been given to replacing high Global Warming Potential (GWP) refrigerants with relatively low GWP alternatives. Energy efficiency, carbon reduction and HFC phase-down will push the heat pump market towards natural refrigerants. Propane (R-290) is a type of hydrocarbon refrigerant with zero ozone depletion potential and very low GWP $(<4)$. R-290 is a pure refrigerant and has excellent thermodynamic properties. The research presented in this project is a study of the refrigerant side of an ASHP to analyze the thermodynamic performance of the propane refrigerant under different operating conditions. For this purpose, a test rig was designed and constructed in a single packaged air source heat pump unit. In addition, the air side of the tested heat pump was designed for energy recovery in cooling and heating modes. The compactness of the system and installation of air dampers allows its placement for coupling to the building renewable air sources, such as a building integrated photovoltaic/thermal (BIPV/T) system. 


\section{ACKNOWLEDGEMENTS}

I would first like to thank my supervisor, Dr. Zaiyi Liao, for his guidance and support throughout the development of this project. I would also like to thank Centennial College and and Mr. Donald Wang, the chair of the Advanced Manufacturing \& Automation Technology Department (AMAT), for his support. I would like to thank the all companies and specialists for their participation and recommendations to improve my research project. Finally, I am grateful to my wife, for providing me with unfailing support and continuous encouragement throughout my study.

I would also like to extend my thanks to Stephen Manson (Tecumseh Canada), Danilo Yaksich (RefPlus), Mike Podd (Sporlan Canada), Ali Maki (Ecotherm) and Jeff Hedden (Alltemp Products) who generously supported this research project. This accomplishment would not have been possible without them. 


\section{Table of Contents}

AUTHOR'S DECLARATION ............................................................................ ii

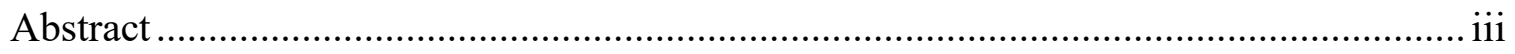

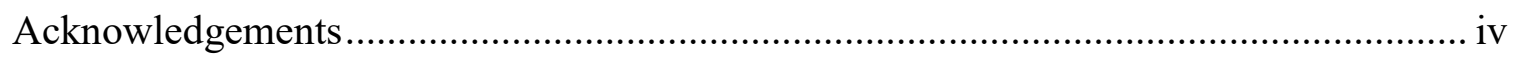

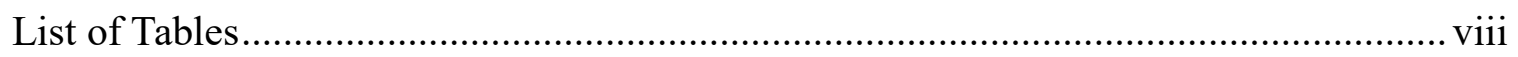

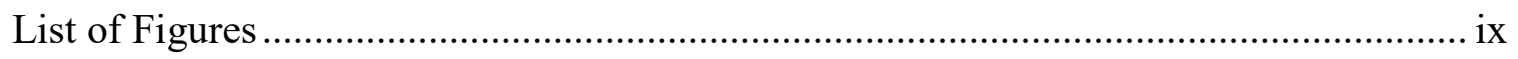

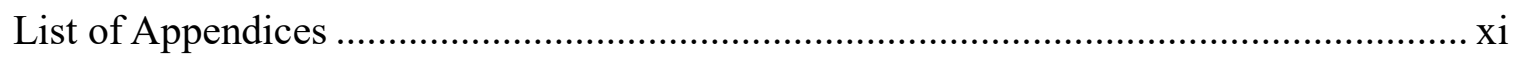

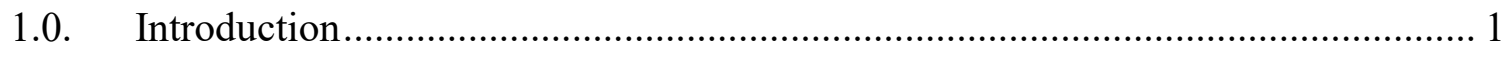

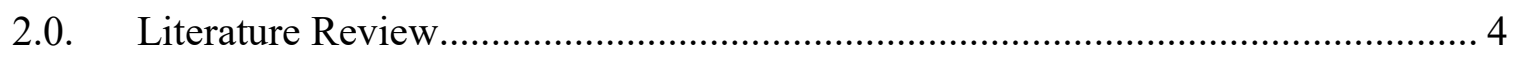

2.1. Air Source Heat Pumps for Cold Climates ................................................ 5

2.2. Selection and Performance Metrics of ASHPs ............................................. 6

2.3. Cold Climate Heat Pump Design ................................................................ 7

2.4. The Future of Refrigerants ............................................................... 11

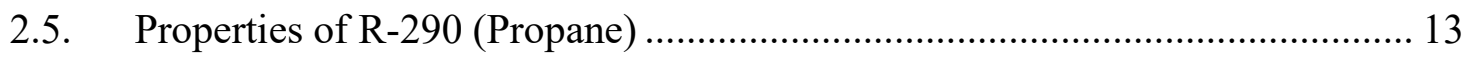

2.6. Literature on Experimental Test Results for R-290 .................................... 14

2.7. Challenges, Flammability and Safety of HC Refrigerants............................ 17

2.8. Life-Cycle Climate Performance of ASHPs ............................................... 19

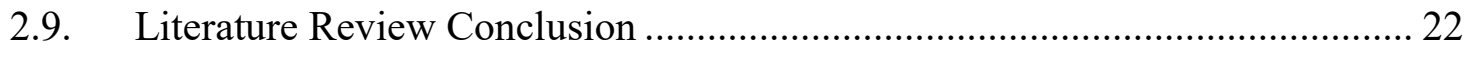

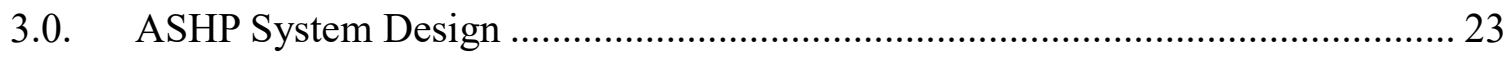

3.1. ASHP Refrigeration Cycle and Components .......................................... 23

3.2. Thermodynamic Analysis of Refrigerants ........................................... 24

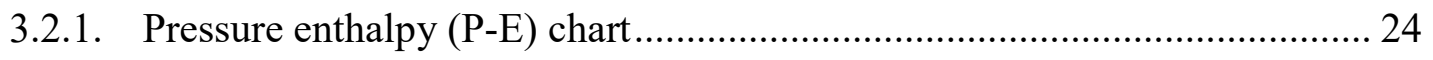

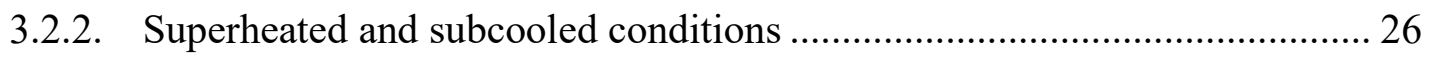

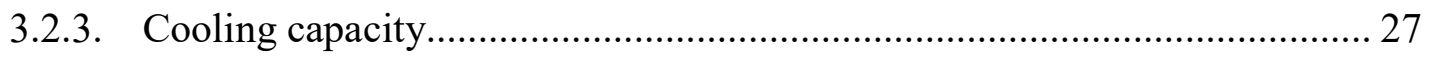




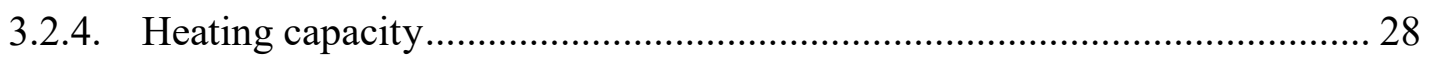

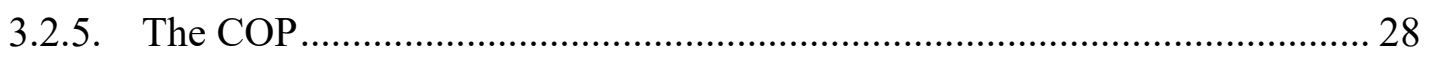

3.3. Heat Pump Performance with Different Refrigerants........................................ 30

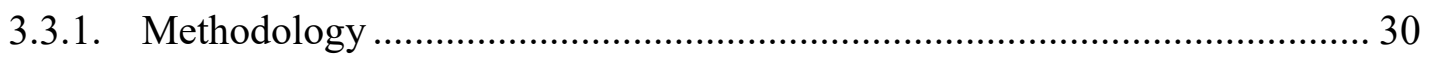

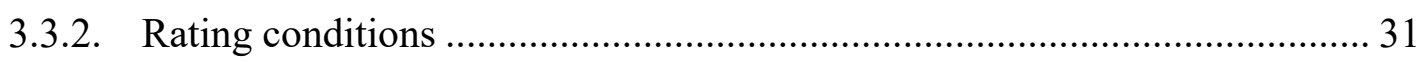

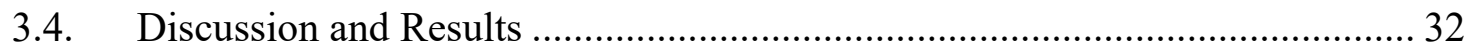

3.4.1. Variation in heating and cooling performances........................................... 32

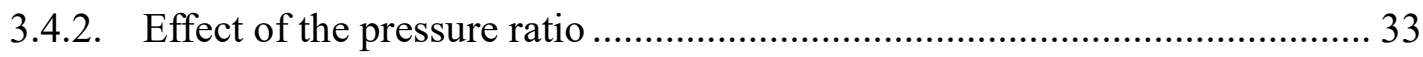

3.4.3. Compressor discharge superheat temperature............................................. 34

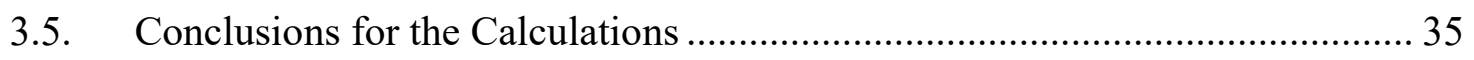

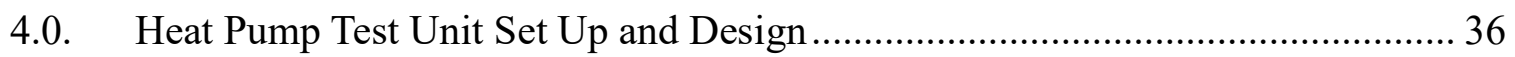

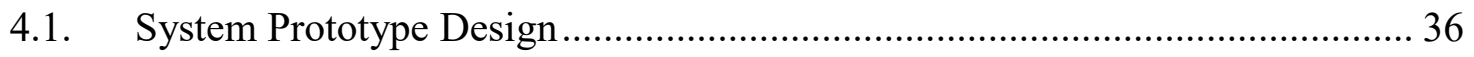

4.1.1. Framing and panels ................................................................................ 36

4.1.2. Refrigeration cycle design and rating conditions......................................... 37

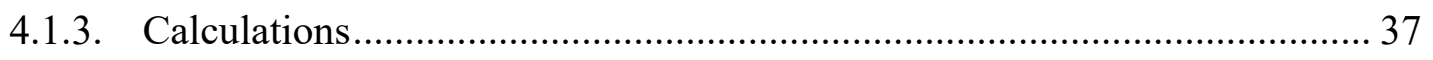

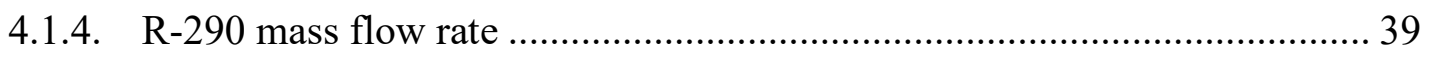

4.2. System Prototype Components ………………............................................... 40

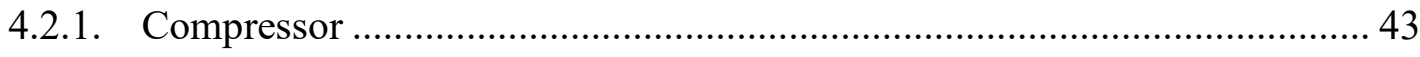

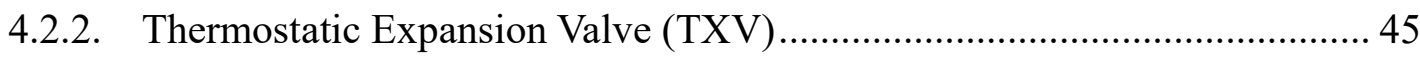

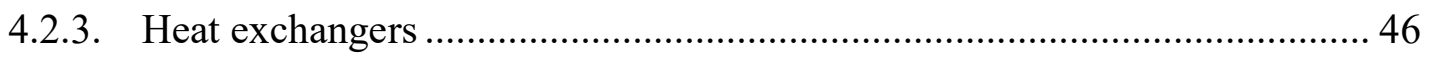

4.2.4. Refrigerant piping and accessories............................................................. 47

4.2.5. Electrical, Controllers and Instrumentation ................................................. 48

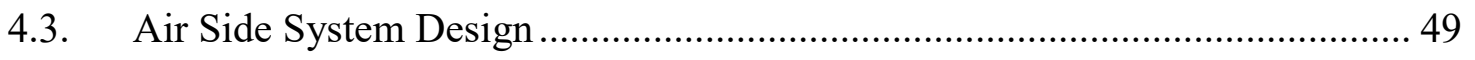

4.3.1. Air side system components ................................................................. 50

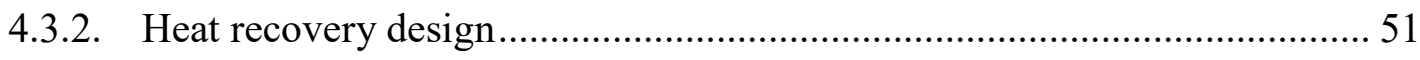


4.3.3. Example of heat pump Installation ................................................. 52

4.4. Photographic Overview - Construction of the Heat Pump ............................. 53

5.0. Starting Up and Testing the Prototype ASHP ............................................ 55

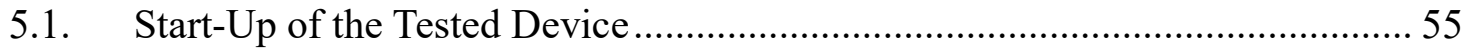

5.2. Description of Test Setup ................................................................. 56

5.2.1. Temperature and pressure measurements......................................... 57

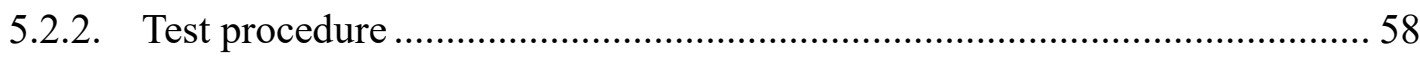

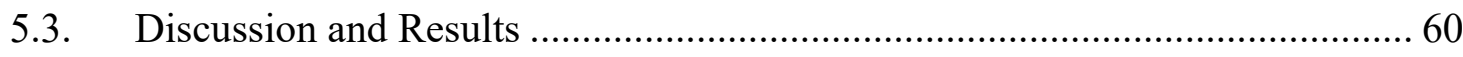

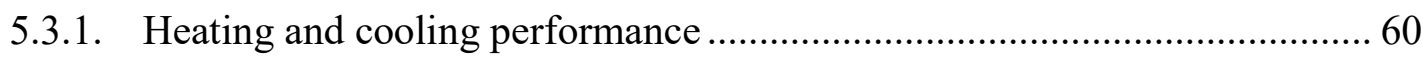

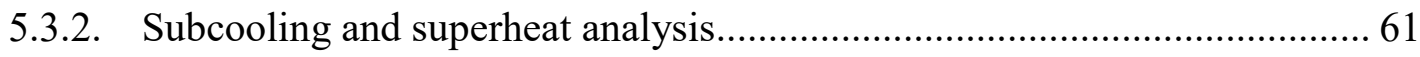

5.3.3. Compressor performance and discharge temperature effect ..................... 62

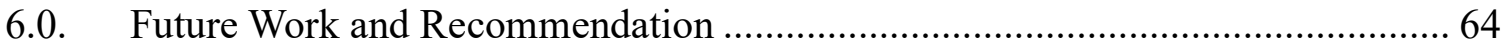

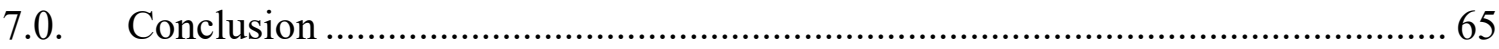

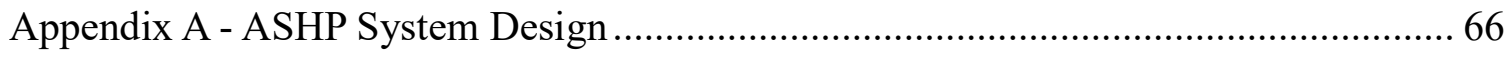

Appendix B - ASHP Test Results and Conditions .................................................... 71

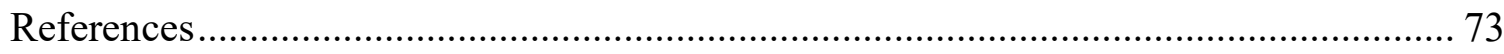




\section{LIST OF TABLES}

Table 2-1: Refrigerants tested, with compositions and (GWPs) (Schultz et al., 2015) .............. 12

Table 2-2: Refrigerant production footprints from UNEP RTOC (Johnson, 2011) ................... 21

Table 3-1: Refrigerant properties (ANSI/ASHRAE standard 34, REFPROP 9.1) ................... 30

Table 3-2: Rating conditions for R22, R134a, R410a and R290 refrigerants ......................... 31

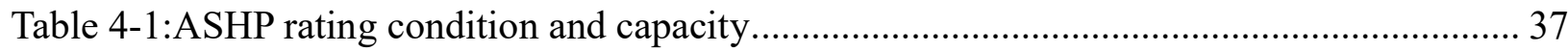

Table 4-2: Theoretical results of R-290 refrigeration cycle for design conditions ..................... 38

Table 4-3: Comparison of R-22 and R-290 under design condition $\left(7.22 / 37.8^{\circ} \mathrm{C}\right) \ldots \ldots \ldots \ldots \ldots \ldots . . . . . . .40$

Table 4-4: Refrigeration cycle components of the experimental heat pump unit ...................... 41

Table 4-5: Specifications of the R-290 compressor Model AK4482U-XA3B (Tecumseh

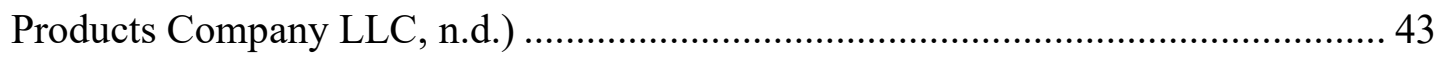

Table 4-6: Compressor performance data (Tecumseh AK4482U-XA3B) ............................... 44

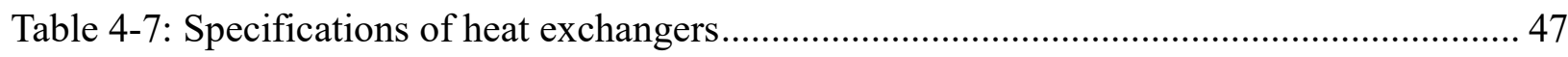

Table 4-8: Specifications of electrical components, controllers, and instrumentation. .............. 49

Table 4-9: Specifications of the air side components of the of the tested ASHP..................... 51

Table 5-1: Specifications and location of temperature sensors ............................................. 57 


\section{LIST OF FIGURES}

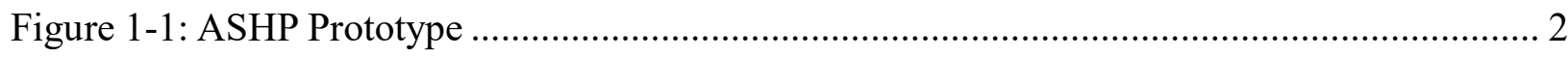

Figure 2-1: Refrigeration Cycle of ASHP in Cooling and Heating modes (ASHRAE, 2016b) ..... 4

Figure 2-2: Variation of cooling COP of ASHP with outdoor air temperature (Safa et al., 2015)

Figure 2-3: ASHP experimental test unit with EVI system and PE diagram (Chen et al., 2018) 8

Figure 2-4: Schematic of BIPV/T system integrated with ASHP and thermal energy storage system(Kamel R et al., 2015). 10

Figure 2-5: Variations in COP in the reported heat pump with refrigerant charge for given heat source and heat sink temperatures. (Fernando et al., 2007) 14

Figure 2-6: Air- to -water heat pump Test set up by (Stöben et al., 2016) 15

Figure 2-7: Performance of alternative refrigerants compared with R-22 at AHRI A test (Abdelaziz \& Shrestha, 2017) 16

Figure 2-8: COPs of the refrigerator when using the different refrigerants (Yu \& Teng, 2014) 16

Figure 2-9: Schematic of leakage test apparatus for R-290. (Li, 2014)..................................... 18

Figure 2-10: Velocity contour of the $\mathrm{Y}=2.2 \mathrm{~m}$ plane. (Maojuan et al., 2018)............................ 19

Figure 2-11: Refrigerant contribution to the heat-pump footprint is significant (Johnson, 2011) 21

Figure 3-1: (a) Refrigeration cycle and four main components; (b) Pressure-Enthalpy Chart (Afshari, 2017) 25

Figure 3-2: Variation of cooling performance of refrigerants .................................................... 32

Figure 3-3: Variation of heating performance of refrigerants ...................................................... 33 
Figure 3-4: Variation of pressure ratio under different rating conditions 34

Figure 3-5: Variation of compressor discharge temperature .............................................. 35

Figure 4-1: Picture of ASHP cabinet and framing .......................................................... 36

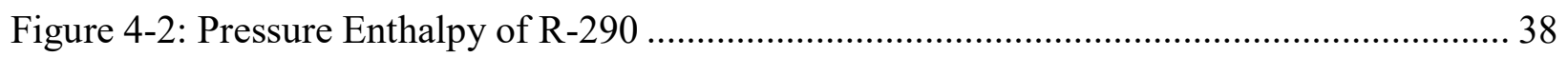

Figure 4-3: Comparison of refrigerant flow rate for the mass-flow-independent models

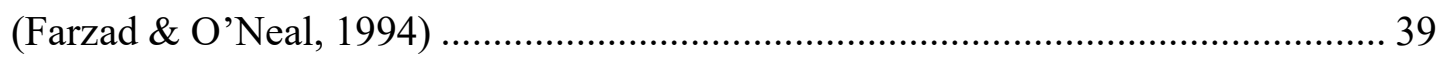

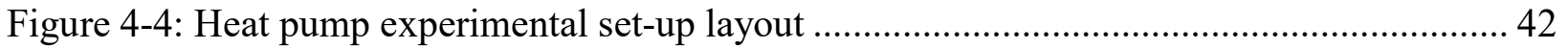

Figure 4-5: Effect of condensing and evaporating temperatures on R-290 compressor

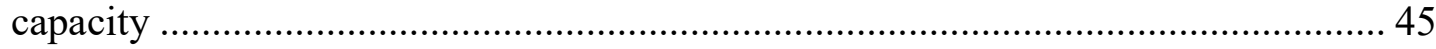

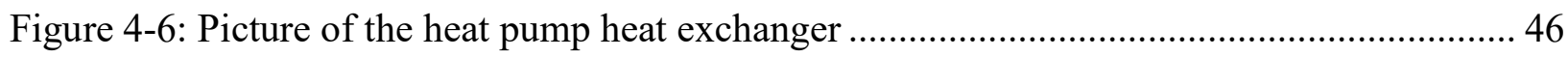

Figure 4-7: Picture of the blower fan, EC motor and fan outlet ............................................ 50

Figure 4-8: Connecting the ASHP prototype to a (BIPV/T) system ..................................... 52

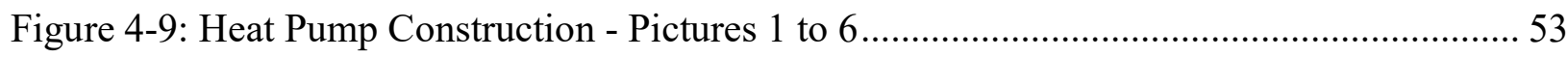

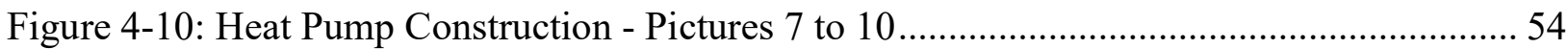

Figure 5-1: Flexible air ducts connecting outdoor unit and thermocouples connected to refrigerant pipes and air side of heat exchangers ............................................. 56

Figure 5-2: R-290 Refrigerant saturation temperatures of the ASHP test unit ......................... 59

Figure 5-3: Heating and cooling COPs vs. evaporating and condensing temperatures ............... 60

Figure 5-4: Variation of Heating mode COP vs. superheat and subcooling ............................. 61

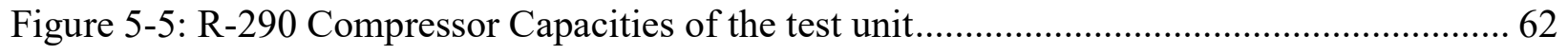

Figure 5-6: Compressor discharge temperatures vs. pressure ratios..................................... 63 


\section{LIST OF APPENDICES}

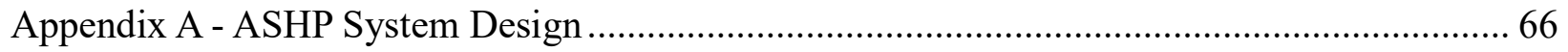

Appendix A Tables:

Table A-1: Suction and Discharge Temperature Condition (AHRI Handbook of low GWP

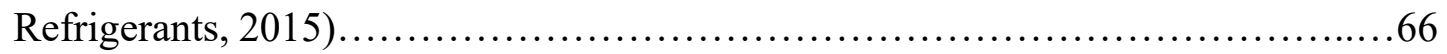

Table A:2: Comparison of R-22, R-410A, R-134A and R-290 Refrigerants under different

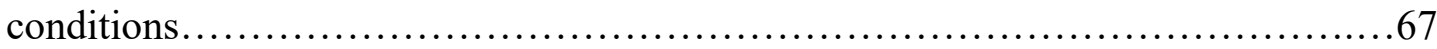

Table A-3: R-290 Compressor Performance Sheet.........................................68

Appendix A Figures:

Figure A-1: TXV election (Sporlan Valve selection program v5)............................69

Figure A-2: Electrical Diagram of the heat pump prototype.................................. 70

Appendix B - ASHP Test Results and Conditions ……………................................................ 71

Appendix B Tables:

Table B-1: Cooling performance of the test heat pump with R290 working fluids.................71

Table B-2: Heating performance of the heat pump with R290 as working fluid.................72 


\subsection{Introduction}

Increasing the energy efficiency of buildings is an important environmental goal. Recent research indicates that Canadian residential houses consume 17\% of domestic energy and emit 70 million tons of $\mathrm{CO}_{2}$. It was estimated that $57 \%$ of the emissions in residential buildings are for space heating purposes and come primarily from the use of natural gas to provide comfort and water heating (National Resources Canada (NRCan), 2017).

Heat pumps have potential for use in sustainable heating systems as alternatives to conventional heating systems and may yield reductions in the level of greenhouse gas (GHG) emissions. However, current heat pumps have an environmental footprint that can be reduced. Power generation accounts for most of a heat pump's greenhouse gas emissions, while its refrigerant footprint and footprint energy efficiency (in $\mathrm{kg} \mathrm{CO}_{2} \mathrm{e}$ emitted per $\mathrm{kWh}$ delivered) are the other major contributors to its overall pump footprint fuels (Johnson, 2011). In this study an air source heat pump (ASHP) was designed, built and tested to investigate the performance of the unit with a natural refrigerant in cold climates. It also combines renewable energy and technologies with the ASHP with the goal of achieving net zero energy in a building. For the study, the equipment uses Propane (R-290) as this refrigerant in the ASHP and heat recovery methods are investigated to increase the heat pump's efficiency.

Issues regarding the environmental impact of common refrigerants have been recognized for several decades, as many are both ozone-depleting substances (ODSs) and green house gases (GHGs). With the Montreal Protocol (1987), the ozone-depletion potential (ODP) of chlorofluorocarbons (CFCs) and hydrochlorofluoro-carbons (HCFCs) was acknowledged. These refrigerants were phased out on an accelerated basis and are no longer in use in industrialized countries. Hydrofluorocarbons (HFCs) became widely established over several years in residential and commercial air conditioning and heat pump systems as replacement refrigerants for the CFCs and HCFCs, since they are chlorine-free zero ozone depletion potential (ODP) refrigerants. However, new challenges have emerged, primarily because of increasing concerns with the greenhouse effect. In 1998, the Kyoto Protocol (United Nations) set obligations for the reduction of GHGs, including the high GWP refrigerants. In the future, HFC refrigerants with high GWP will be restricted and substitutes will become necessary. Presently, because of their direct warming impact, these high GWP refrigerants are only considered transitional alternatives (Chen, Liu, Yang, 
\& Chen, 2018). In recent years, use of natural refrigerants $\left(\mathrm{CO} 2, \mathrm{NH}_{3}\right.$, Hydrocarbons) has increased in commercial and residential refrigeration and air conditioning systems.

This study focuses on the design and building of a prototype air source heat pump (ASHP) unit for use under Canadian climate conditions, with R-290 (Propane) natural refrigerant as its working fluid. The performance of the heat pump was experimentally investigated with the optimum refrigerant charge. Figure 1-1 shows a schematic diagram of the tested heat pump. The heat pump was designed in a single packaged unit and consists of three sections: the indoor unit, the outdoor unit and the compressor and electric panel section. The unit was built with aluminum extrusion frames and insulated double skin coated panels, suitable for outdoor installation. The refrigeration cycle consists of a hermetic reciprocating compressor, indoor and outdoor fin and tube heat exchangers, a bi- flow thermostatic expansion valve, and a four-way reversing valve. All major components and accessories were selected based on R-290 refrigerant. The pipe layout and equipment selection are based on the minimum system refrigerant charge. In the air side, using two air inlet dampers in each section makes the heat pump an energy recycling system.

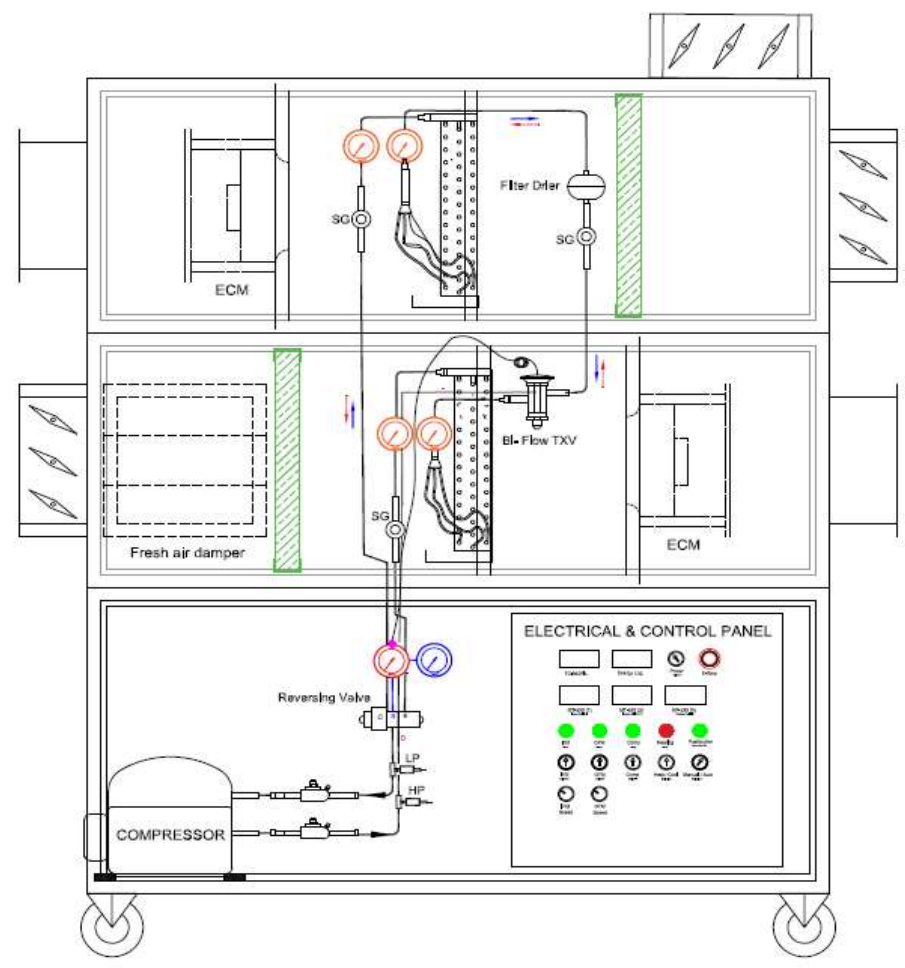

Figure 1-1: ASHP Prototype 
Many studies have focused on different ways to generate the warm air for air source heat pumps during the winter such as using wasted energy of building exhaust air, combining an air source heat pump with building integrated photovoltaic, and solar thermal (BIPV/T) and thermal energy storage systems (TES). In order to increase the air source temperature in the winter before the evaporator, an air duct system must be installed and connected to the outdoor unit. Connecting the split type of ASHPs which exist in the current market remains a challenge. In this study, the presented packaged ASHP with dedicated air dampers allows the heat pump to connect with any air system configuration. Two air dampers were installed in the inlet of the indoor and outdoor units. They can connect to any air duct system from different air sources. In winter, the wasted energy from building exhaust air or generated energy by renewable systems (e.g. solar thermal air) can improve the performance of the ASHP. The air side design of this system can also bypass the heat pump and use only renewable energy sources when the temperature is warm enough and supply the air directly to the building. Additionally, this module can improve indoor air quality and maintaining a comfortable and healthy indoor environment by introducing fresh air to the building. The objective of this work is to present enhancements that will increase the performance of the air source heat pump as well as decrease the carbon emissions by using a low GWP natural refrigerant. 


\subsection{Literature Review}

Heat pumps are used in residential and commercial buildings to fulfill the functions of space heating and cooling as well as domestic hot water heating as a single piece of equipment. The design concept of a heat pump is moving heat energy from one point to another, extracting heat from the heat source and rejecting heat to the heat sink. The heat source and heat sink are normally air or water, air-to-air, water-to-air, and water-to-water. Outdoor or exhaust air can be used as the energy source of an ASHP. These air source heat pumps are more economic than groundwater heat pumps (GWHP) and are widely used for residential buildings. Using air as a source of energy has excellent properties in terms of availability and ease of use compared to the other sources. An ASHP can provide cooling in summer and heating in winter. In the cooling mode, the indoor coil (evaporator) absorbs heat from a building and remove it outside by means of the outdoor (condenser) coil. In the heating mode, refrigerant moves in the reverse cycle via the fourway reversing valve. Refrigerant absorbs heat from ambient air in the outdoor coil (evaporator) and removes heat into the building by the indoor coil (condenser). Figure 2-1 shows the schematic of the refrigeration cycle in cooling and heating modes (ASHRAE, 2016b).
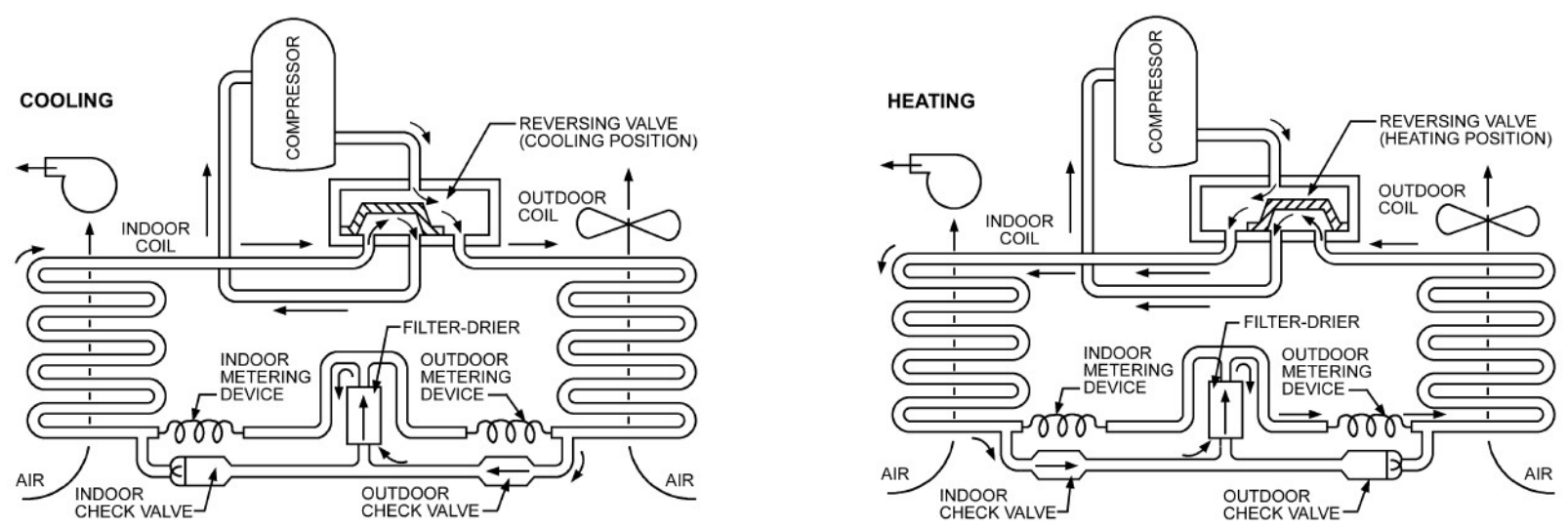

Figure 2-1: Refrigeration Cycle of ASHP in Cooling and Heating modes (ASHRAE, 2016b)

Ground source heat pumps (GSHP) are also used in residential buildings but are mostly found in commercial buildings. They take the heat from soil, groundwater or lake water, which is more stable at temperature compared with outdoor air, as a heat source in winter. This enables the GSHP to have a greater coefficient of performance (COP) than the ASHP. Lower operating costs 
and higher life expectancy (20 to 25 years) are other benefits of GSHPs (NRCan, 2017). The disadvantages of GSHPs are higher installation costs and unavailability of the energy sources.

\subsection{Air Source Heat Pumps for Cold Climates}

In the winter, the ambient temperature usually plays a critical role in determining the heating capacity and efficiency of the heat pump. A lower heat source temperature in winter reduces the heating capacity and the COP of the heat pump system (Fernando, Palm, Lundqvist, \& Granryd, 2007). The COP of an ASHP is typically about 3.3 at $10^{\circ} \mathrm{C}$ and drops to 2.3 at $-8.3^{\circ} \mathrm{C}$ (NRCan, 2017). Recently, manufacturers are using different technologies to increase the efficiency of ASHPs for cold climate regions, including offering cold-climate air source heat pumps (CCASHP) suitable for the Canadian market. Safa, Fung, \& Kumar (2015) experimentally compared the performance of a variable capacity ASHP and a horizontal ground loop GSHP at the archetype sustainable twin houses at the Kortright Centre, Woodbridge, Ontario, Canada. They compared two types of heat pumps in two side-by-side semi-detached houses. Both houses were 3-storey, south-facing with similar floor areas with the same internal volumes. Heat pumps were compared in heating and cooling modes for different weather conditions. They also simulated the performance of the systems for major Canadian cities. According to their research, in the heating and cooling modes, in mild climate conditions (e.g. Vancouver) the ASHP performed with higher efficiency and in cold cities (e.g. Edmonton) the ASHP revealed relatively weak performance during the heating season. In Ontario, the results showed that the COP ranges of ASHP and GSHP for cooling modes were close together at $33{ }^{\circ} \mathrm{C}$ to $16{ }^{\circ} \mathrm{C}$ outdoor temperature (4.7 to 5.7 for ASHP and 4.9 to 5.6 for GSHP). In heating mode, COP ranges were from 1.79 to 5.0 for ASHP and from 3.05 to 3.44 for GSHP at outdoor temperatures of $-19^{\circ} \mathrm{C}$ to $9^{\circ} \mathrm{C}$. Figure 2-2 portrays the cooling COPs experimentally obtained from ASHP. 


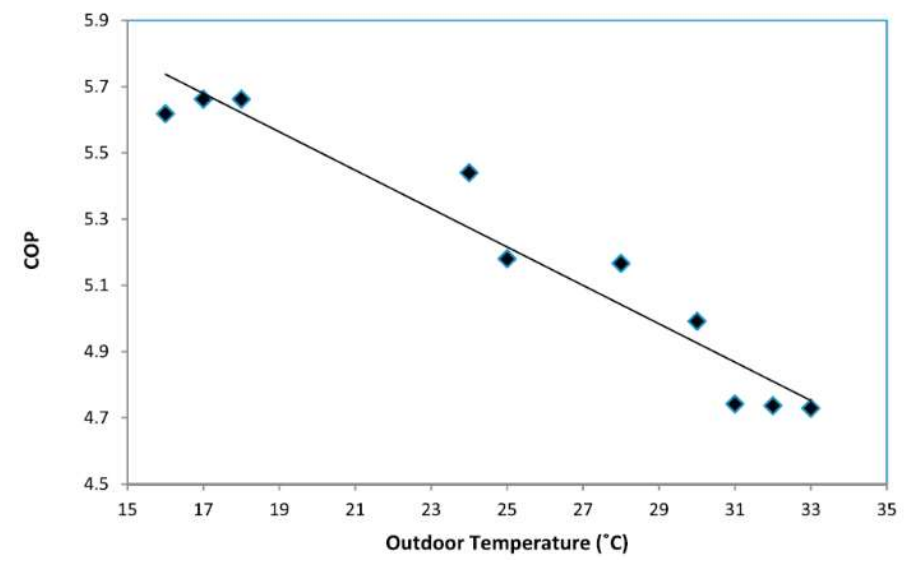

Figure 2-2: Variation of cooling COP of ASHP with outdoor air temperature (Safa et al., 2015)

\subsection{Selection and Performance Metrics of ASHPs}

For purposes of heat pump sizing, it is essential that the building heating and cooling load estimates are calculated in accordance with generally accepted engineering standards and handbooks such as ASHRAE Handbook-Fundamentals (ASHRAE, 2017) and CSA F280 (CSA, 2012). The load calculation should include both the capacity for meeting space loads and the capacity for the ventilation air. For heating, the outdoor air temperature must be heated to the room temperature and the heat required added to the building heat loss. The minimum supply airflow for ventilation must comply with local codes, ASHRAE Standard 62.1 (ASHRAE, 2016a), and should be considered when calculating heating loads.

In cold climate regions, the ASHP should be sized based on the heating loads which are larger than cooling loads. If the heat pump is sized to match the heating load, it will be too large for the cooling requirement, and will operate intermittently in the cooling mode. This may lead to excessive cycling and reduce performance and decrease the unit's ability to provide dehumidification in the summer. In addition, as the outdoor air temperature drops so does the capacity and efficiency of an ASHP. Cold ambient air as a heat source for heat pumps presents technical challenges in maintaining a high COP (Hewitt, Huang, Anderson, \& Quinn, 2011).The 
balance point of the building load and heat pump capacity needs to be calculated. When the outdoor temperature is below the balance point, supplemental heat (e.g. electric resistance) must be added to make up the difference.

In Canada, heating loads dominate most of the year and it does not make economic sense to meet all heating needs with an air-source heat pump. An air-source heat pump should be sized to provide no more than 125 percent of the cooling load. A selected heat pump for cold climates would meet about 80 to 90 percent of the annual heating load (National Resources Canada (NRCan), 2004). Roth, Dieckmann, \& Brodrick (2009) stated that "Using multiple or modulating compressors addresses mismatched loads by sizing compressor capacity to meet heating design loads at full capacity, while part-load operation efficiently satisfies cooling loads and dehumidification." They also investigated using carbon dioxide (CO2) natural refrigerant in ASHPs, finding that it increases capacity up to $35 \%$ at low ambient temperatures $\left(-8.3^{\circ} \mathrm{C} / 17^{\circ}\right.$ F) and decreases the use of auxiliary heaters in heating mode.

\subsection{Cold Climate Heat Pump Design}

The ambient temperature plays a critical role in the heating capacity and efficiency of ASHP. Introducing new technologies in cold climate ASHPs such as applying two compressors that operate in series, or two-stage units, or incorporating a refrigerant economizer in the refrigeration cycle would increase the $\mathrm{COP}$ of the heat pump at very cold ambient temperatures.

An Economized Vapour Injection system (EVI) can improve the performance of the heat pump in cold ambient climates. Using an EVI system reduces the compressor discharge temperature and raises the fluid mass and enthalpy difference. Chen et al., (2018) examined the performance of an ASHP hot water heating system with an EVI on a test bench. As shown in Figure $2-3$, a scroll compressor was used in the heating mode of the refrigeration cycle in conjunction with the economizer. Two metering devices (EXVs) were used in the system. The P-E diagram of the cycle was divided into two parts, injection circuit and the main circuit. The refrigerant flow rate is effectively increased in this cycle and the discharge temperature can be lowered. 
Heating mode
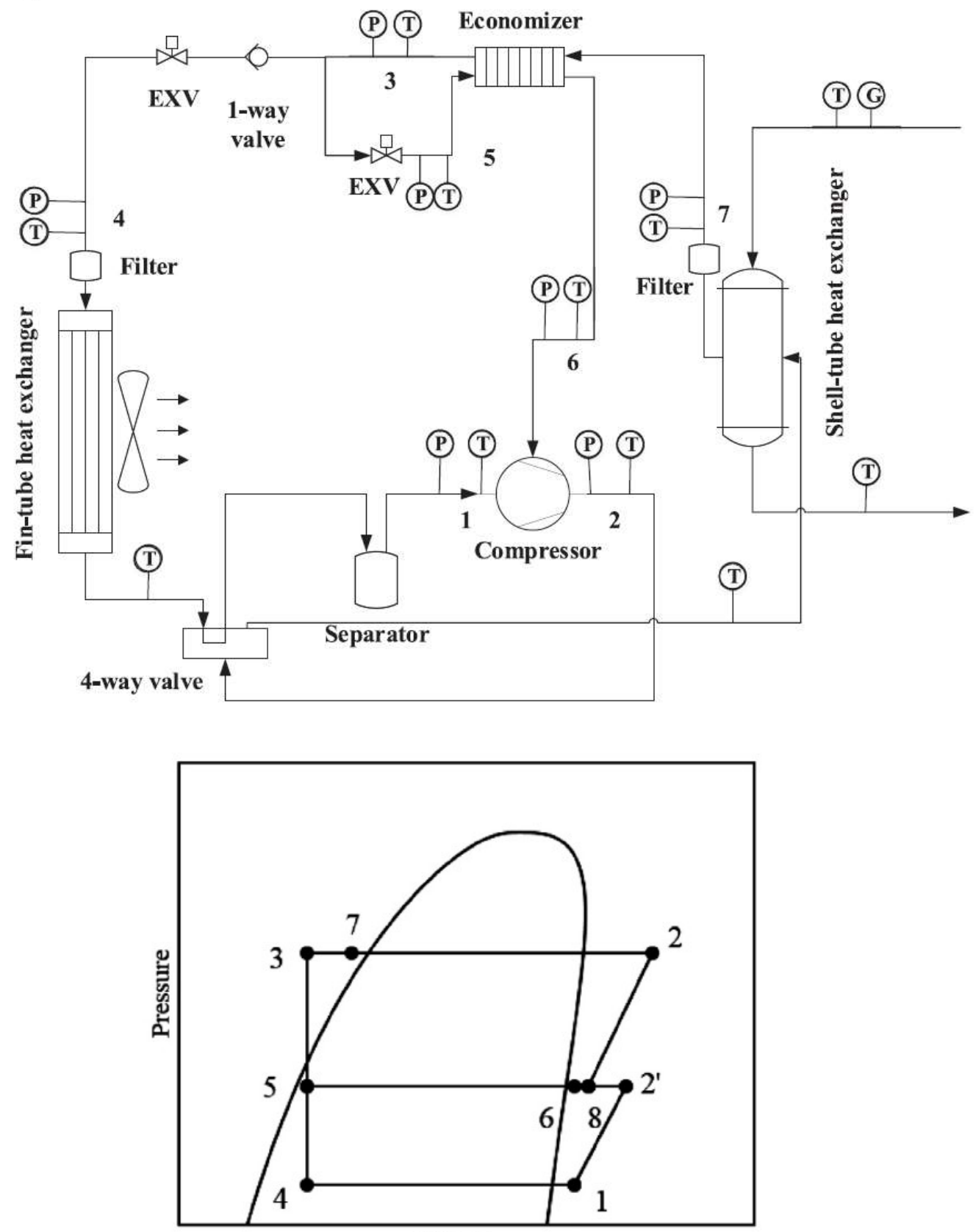

Enthalpy

Figure 2-3: ASHP experimental test unit with EVI system and PE diagram (Chen et al., 2018) 
The unit was charged and tested with four different refrigerants (R-22, R-427A, R-161 and R-290). The test conditions were set in the steady heating performances from 7 to $-20{ }^{\circ} \mathrm{C}$ ambient temperatures. The results showed that the amount of the refrigerant charge for R-290 decreased by $55 \%$ of the baseline refrigerant (R-22), which reduced the direct equivalent carbon dioxide emissions. They also found that under $-20{ }^{\circ} \mathrm{C}$ outdoor conditions with an R-290 refrigerant system and using the EVI system, the heating capacity increased $38 \%$ and the COP of the heat pump increased $20 \%$.

As mentioned earlier in this report, an increase in air temperature before the outdoor coil of the ASHP will increase the efficiency during extremely cold weather conditions. There are different ways to achieve this. In net-zero energy (NZE) or near NZE homes this can be achieved by integrating a BIPV/T coupled ASHP system. Kamel R, Ekramia, Dasha, Funga, \& Hailub (2015) modified the TRANSYS model of Safa et al., (2015) by integrating an ASHP and a BIPV/T to achieve near net-zero annual energy consumption at the Kortright Centre in Ontario, Canada.

The solar PV system provides electrical energy in winter as well as improving the COP of the heat pump by preheating the ambient temperature before the evaporator. They also added a concrete slab and gravel bed under the floor as a Thermal Energy Storage System (TES) to enhance the performance of the heat pump during night time. The analysis showed that an increase in the seasonal COP from 2.74 to 3.45 for direct coupling of BIPV/T+ASHP without the use of TES provided a $20 \%$ reduction of electricity consumption in winter. Figure $2-4$ shows the mechanical system with duct connections. Kamel R et al., (2015) found that the ducting design and connection of a PV/T system with a split type air source heat pump is a challenge, and for such integration a custom designed heat pump and control is necessary to satisfy the required functions. 


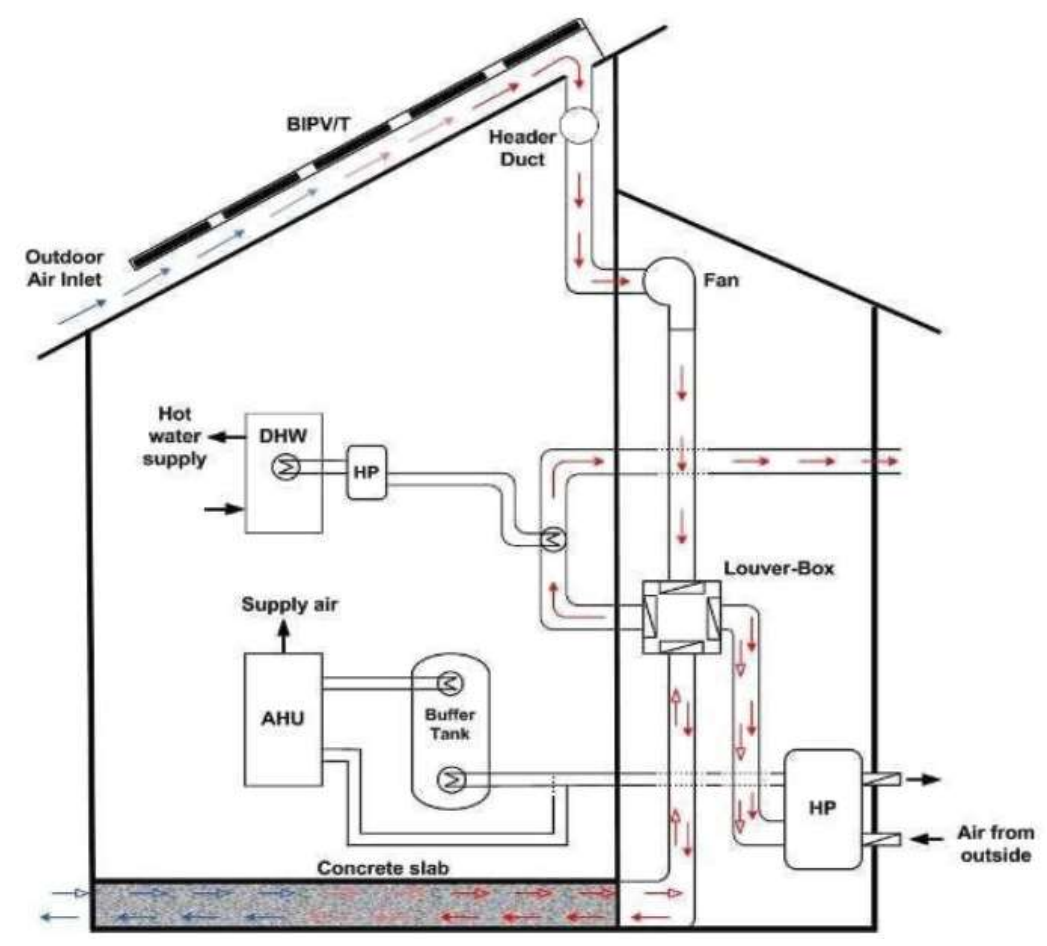

Figure 2-4: Schematic of BIPV/T system integrated with ASHP and thermal energy storage system (Kamel R et al., 2015).

Vuong (2017) presented enhancements that would increase the efficiency of the overall integrated BIPV/T coupled variable capacity ASHP systems in an NZE and an energy efficient house in Toronto, Canada. The collector arrangements, internal air channel, and emissivity parameters were modified and simulated in EnergyPlus V8.0. The simulation result showed 82 $\mathrm{kWh}(7 \%)$ reduction of electricity consumption for NZE and $107 \mathrm{kWh}(3.6 \%)$ for the energy efficient house. Vuong (2017) recommended further works on BIPV/T system coupling with a variable speed outdoor fan of ASHP. Developing the design of a heat pump with variable capacity of the outdoor unit increases the additional air flow that enhances the performance of the system. 


\subsection{The Future of Refrigerants}

Energy efficiency, carbon reduction, and HFC phase-down will push the heat pump market towards alternative refrigerants. Most of the air conditioners and heat pumps currently use HFCs and they contribute significantly to greenhouse gas (GHG) emissions. Environmentally friendly refrigerants with zero Ozone Depletion Potential (ODP) and low global warming effects were substituted for CFCs, HCFCs and HFCs when the Montreal protocol and Kyoto Protocol were signed in 1987 and 1997 respectively. ODP of a chemical is the relative amount of degradation to the stratospheric ozone layer around the earth, compared to CFC, R-11 (ODP =1). Global Warming Potential (GWP) is based on the time-integrated global mean radiative forcing of a pulse emission of $1 \mathrm{~kg}$ of some compound relative to that of $1 \mathrm{~kg}$ of the reference gas $\mathrm{CO}_{2}$ over the span of 100 years. In other words, GWP is a relative measure of how much heat a greenhouse gas traps in the atmosphere. The Montreal Protocol was adapted with the signing of the Kigali Amendment (United Nations Environment Programme (UNEP), 2016), in order to phase down the use of HFCs in developed countries to $15 \%$ of the average consumption for a 2011 to 2013 baseline by 2036 . The European Union (EU) also directed the phase out of R-134a in automobile air conditioning by 2017. Shifting to lower GWP refrigerants in refrigeration and air conditioning systems helps to reduce the total emissions and negative environmental impacts of these systems.

The new generation of refrigerants must offer high energy efficiency in addition to low GWP. A substantial amount of research has investigated alternative refrigerants which will not only perform efficiently but will also maintain the integrity of the environment. The use of the low GWP refrigerants (N-40 and L-41a) as substitutes for HFCs (R-410A and R-404 A) in commercial refrigeration and residential HVAC systems results in a reduction of more than $30 \%$ in the total emissions (in $\mathrm{kg} \mathrm{CO}_{2} \mathrm{eq}$ ) (Beshr, Aute, Abdelaziz, Fricke, \& Radermacher, 2017).

In recent years, new refrigerants have been examined as transitional alternatives in ASHP systems due to their low GWPs. The alternatives to HCFCs and HFCs include in natural refrigerants such as $\mathrm{CO}_{2}$ (R- 744), Hydrocarbons (R-290, R- 600a), Hydrofluoroolefins (HFO) or blends of these refrigerants. R-290 (propane) and hydrocarbon blends offer zero ODP and very low GWP with higher efficiency than R-22 and R-410a and have been commercialized as alternative refrigerants (Corberán, Martínez-Galván, Martínez-Ballester, Gonzálvez-Maciá, \& Royo-Pasto, 2011). 
The Air-Conditioning, Heating and Refrigeration Institute (AHRI) launched the Low GWP Alternative Refrigerants Evaluation Program (Low GWP AREP) in March 2011. Alternative refrigerants with low GWP were chosen for selective commercial air conditioning units. The program provides laboratory tests on "natural and low GWP refrigerants" with comparisons to the performance of an HCFC or HFC as a "baseline". The program provided guidelines and testing procedures for compressors, drop-in tests, and soft optimization tests of forty low GWP refrigerants as potential Low GWP options. The alternative Low GWP refrigerants were placed in existing systems using baseline refrigerants with minor modifications (drop-in tests), and the systems were modified and tested based on the latest industry standards (soft optimization tests) (Stöben, Wesch, Jepsen, \& Jessen, AHRI Test Report \#61, 2016). Many refrigeration systems and components such as compressors, chillers, air-conditioners and heat pumps were tested based on AHRI standards 210/240 and ASHRAE standard 37.

Schultz, Perez-Blanco, \& Kujak (2015) performed drop in tests for low GWP refrigerants (DR-55, R32, and DR-5A) on a 48,500 Btu/hr (4.04 RT, $14.2 \mathrm{~kW}$ ) rooftop heat pump unit with HFC (R-410A) base refrigerant. The unit was operated in cooling mode at ambient temperatures from $65^{\circ} \mathrm{F}$ to $125^{\circ} \mathrm{F}\left(18^{\circ} \mathrm{C}\right.$ to $\left.52^{\circ} \mathrm{C}\right)$ and tests were performed for cooling in controlled ambient chambers. The heat pump was modified with an adjustable TXV and a variable frequency drive (VFD) was also installed to allow the compressor speed to be varied for R-410A and chosen refrigerants. The air side capacities were calculated with constant $1600 \mathrm{cfm}$ and inlet and outlet temperature measurements based on ASHRAE 37 (ASHRAE, 1978). Capacities were also calculated from refrigerant side measurements around the indoor coil, providing a check on energy balance. The heat pump was charged based on the subcooling method $\left(8.33^{\circ} \mathrm{C} / 15^{\circ} \mathrm{F}\right)$. The results indicated that all three alternative refrigerants shown in Table 2-1 had improvements in EER over R410A.

Table 2-1: Refrigerants tested, with compositions and (GWPS) (Schultz et al., 2015)

\begin{tabular}{|llcc|}
\hline name & composition (\%wt) & GWP (AR4) & GWP (AR5) \\
\hline R410A & $50 \% \mathrm{R} 32 / 50 \% \mathrm{R} 125$ & 2088 & 1924 \\
\hline DR-55 & $67 \% \mathrm{R} 32 / 7 \% \mathrm{R} 125 / 26 \% \mathrm{R} 1234 \mathrm{yf}$ & 698 & 675 \\
\hline R32 & $100 \% \mathrm{R} 32$ & 675 & 677 \\
\hline DR-5A & $68.9 \% \mathrm{R} 32 / 31.1 \% \mathrm{R} 1234 \mathrm{yf}$ & 466 & 466 \\
\hline
\end{tabular}


R-22 is one of the most commonly used HCFCs in air conditioning and heat pump systems. Chang, Kim, \& Ro (2000) experimentally compared the performance of an R-22 heat pump system to hydrocarbon $(\mathrm{HC})$ refrigerants. In their research, the performance of single component $\mathrm{HC}$ refrigerants (Propane R-290, Isobutane R-600a, Butane R-600 and Propylene R-1270) was examined. Mixtures of propane/isobutane and propane/butane were also investigated. The experimental results showed that the cooling and heating capacities of R-290 are slightly smaller than R-22 and the COP was higher than R-22. The test reports showed that $\mathrm{HC}$ refrigerants potentially have higher heat transfer coefficients in the evaporator and condenser than R22, because of the higher thermal conductivity and lower viscosity of HCs. However, the flammability and safety of $\mathrm{HC}$ refrigerants are still potential challenges for use in heat pump systems.

\subsection{Properties of R-290 (Propane)}

R-290 (propane), in the Hydrocarbons (HCs) category, has a negligible GWP and is a natural refrigerant available all over the world. In the past, R-290 has been used in refrigeration and industrial plants and is still used in small hermetic systems such as commercial refrigerators and freezers. R-290 is a flammable refrigerant with the safety level of A3 and is not a toxic refrigerant according to the ASHRAE 34 classification. Its risk can be minimized by keeping the equipment with lower charge and containing propane in a ventilated room or in outdoors applications. However, propane has high feasibility to be the working fluid for the next generation of air conditioners because of its environmental fitness, unique thermo-physical properties, and price. In Germany, R-290 has been used in residential heat pumps and air conditioners for several years.

R-290 is a pure refrigerant with good thermodynamic properties. It can be used as a working fluid in refrigeration systems down to $-40{ }^{\circ} \mathrm{C}$. The normal boiling point of propane is close to R22 $\left(-40.8{ }^{\circ} \mathrm{C}\right)$. The saturation pressures of the two fluids are close to each other in the temperature range $-40{ }^{\circ} \mathrm{C}$ to $60^{\circ} \mathrm{C}$. The pressure level and critical temperature are very similar to $\mathrm{R} 22$ (The critical temperature of propane $206.6^{\circ} \mathrm{F}, 96.7^{\circ} \mathrm{C}$ ), and the discharge temperature is much lower. This gives the opportunity to work at higher pressure ratios, meaning lower evaporating temperatures, which allows for work at higher suction gas temperatures. The density of propane is approximately half of that of R22. Therefore, about half of the mass of refrigerant is 
needed in a specific system if propane is used instead of R22. It is reported that the maximum refrigerant charge of R-290 is $150 \mathrm{~g}$ in accordance with ISO, IEC, UL and EU standards (Abas et al., 2018).

\subsection{Literature on Experimental Test Results for R-290}

Fernando et al., (2007) experimentally investigated the performance (COP) of R-290 refrigerant in a domestic air source heat pump with different working conditions and with different amounts of refrigerant. They used a $5-\mathrm{kW}$ capacity heat pump for the test, consisting of two microchannel aluminum heat exchangers, a scroll compressor, and an electronic expansion valve. The heat pump was charged with the minimum amount of propane refrigerant ( $230 \mathrm{~g}, 224 \mathrm{~g}, 215$ $\mathrm{g}$, and $205 \mathrm{~g}$ ) for stable operation. The optimum charge of refrigerant depends on the operating conditions, such as evaporating and condensing temperature. Figure 2-5 depicts the variations in $\mathrm{COP}$ of refrigerant R-290 charge for the heat source temperatures $\left(-10^{\circ} \mathrm{C},-2^{\circ} \mathrm{C},+6^{\circ} \mathrm{C}\right.$, and 12 $\left.{ }^{\circ} \mathrm{C}\right)$ and a given heat sink temperature $\left(40^{\circ} \mathrm{C}\right)$.

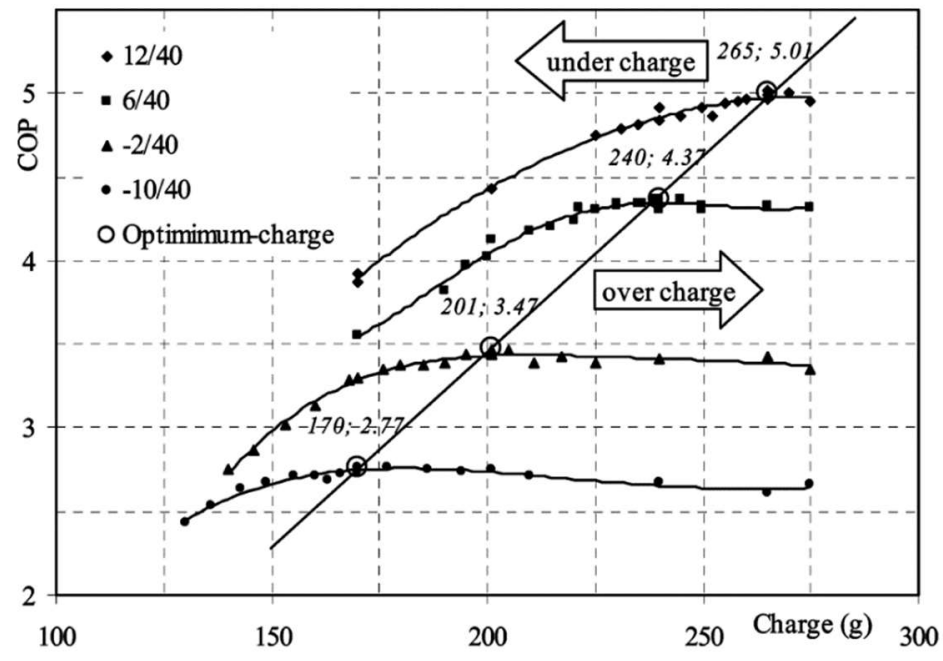

Figure 2-5: Variations in COP in the reported heat pump with refrigerant charge for given heat source and heat sink temperatures. (Fernando et al., 2007) 
Stöben, Wesch, Jepsen, \& Jessen (2016) also evaluated the cycle performance of R-290 refrigerant in an air to water residential heat pump unit manufactured by Danfoss. The rated capacity of the heat pump was $15 \mathrm{~kW}$ with R-407C refrigerant (HFC blend with $1526 \mathrm{GWP}$ ) as the base line refrigerant. The unit was equipped with a scroll compressor charged by POE oil and pressure and temperature sensors were installed in the positions shown in Figure 2-6. The purpose of the tests was to gain knowledge of capacity and efficiency of low GWP refrigerants including R-290 (GWP =3).

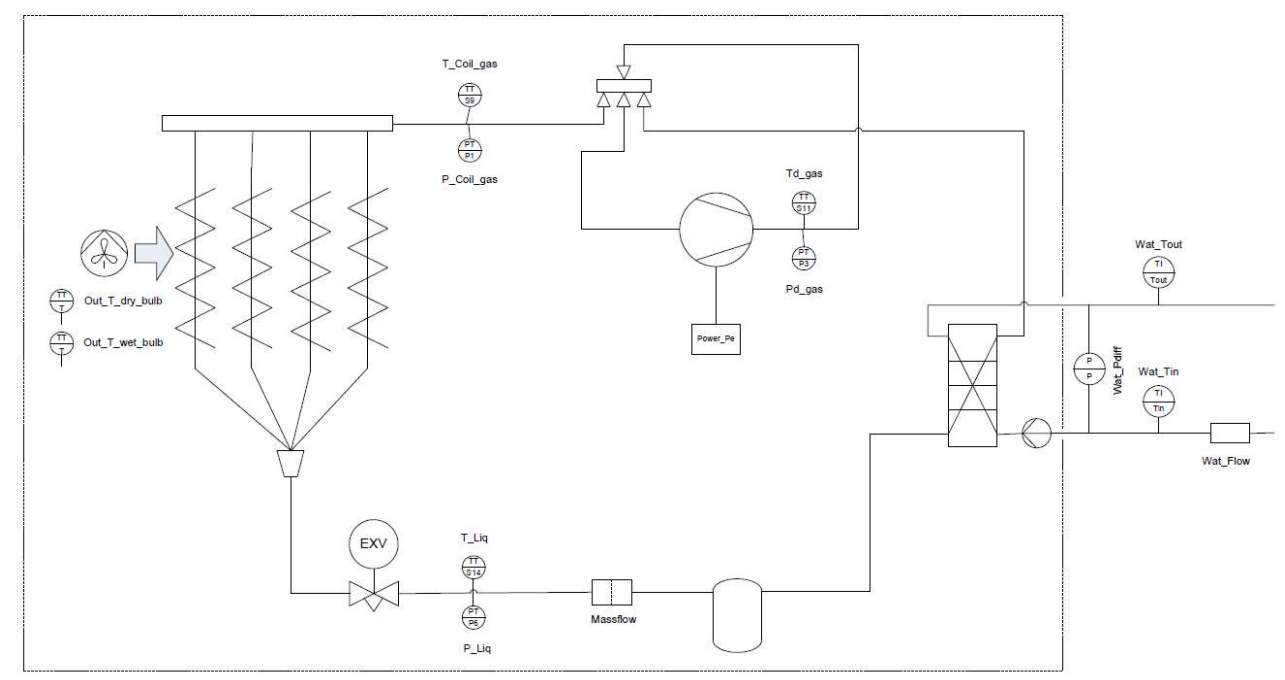

Figure 2-6: Air- to -water heat pump Test set up by (Stöben et al., 2016)

The tests were performed in a psychrometric test chamber based on EN14511 and EN14825 (2013) conditions for calculating and testing the capacities, COPs, and Seasonal Coefficient of Performance (SCOP). Test conditions were set up for heating season $\left(-15,-7,2,7,12{ }^{\circ} \mathrm{C}\right.$ ambient temperature) and $35^{\circ} \mathrm{C}$ water outlet. The heat pump was charged gradually (test condition Air $7^{\circ}$ $\mathrm{C} /$ Water $35^{\circ} \mathrm{C}$ ) until the rated capacity was reached. The system was charged $5.2 \mathrm{~kg}$ for R-407C and $2.6 \mathrm{~kg}$ for R-290. According to the results R-290 showed lower capacities (-7\% to $-15 \%)$ and the SCOP showed a 9\% increase in efficiency compared to R-407C.

Abdelaziz \& Shrestha (2017) evaluated alternative refrigerants for two baselines, R-22 and R-410A.The tests were performed according to ANSI/ASHRAE Standard 37 (ASHRAE, 1978), and AHRI 210-240 (AHRI, 2017), and ISO 5151 (2010) for mini-split air conditioners. R-290 was one of the six alternative refrigerants that were compared to the R-22 baseline. The system COP was evaluated based on the air-side capacity and power measurements. Figure 2-7 shows the 
relative performance of these alternative refrigerants to the baseline (R-22) at the AHRI conditions for cooling mode. Propane was the only refrigerant showing higher COP at all conditions, although its cooling capacity was $5 \%$ to $10 \%$ below the baseline.

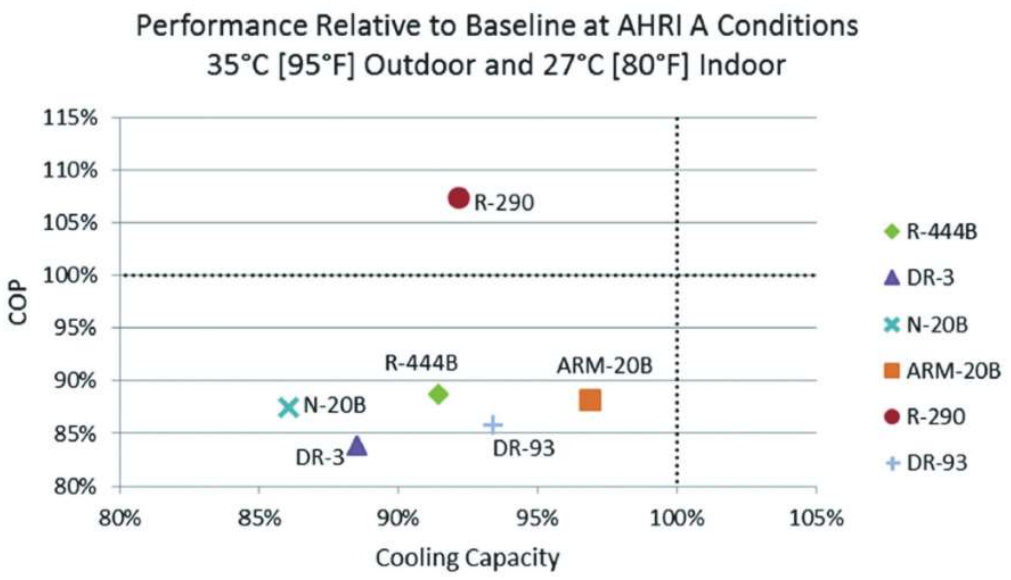

Figure 2-7: Performance of alternative refrigerants compared with $R-22$ at AHRI A test (Abdelaziz \& Shrestha, 2017)

Yu \& Teng (2014) investigated the use of R-600a and R-290 refrigerants with different mixed mass ratios and charging masses in a small $\mathrm{R} 134 \mathrm{a}$ refrigerator to evaluate the refrigeration performance. They modified the capillary tubes for different refrigerant charges. The results indicated that the refrigerant charge of the system with HCs was $40 \%$ of R-134a and lower electricity consumption. The EFs (energy factors, $\mathrm{L} / \mathrm{kW}-\mathrm{h} / \mathrm{month}$ ) of all $\mathrm{HC}$ mixtures were higher than for R134a. Figure 2-8 shows the COP differences calculated by enthalpy of each test point from NIST REFPROP 9.1 (Lemmon, Huber, \& McLinden, Natl Std. Ref. Data Series [NIST NSRDS], 2013). A mixture 65\% R-290 and 35\% R-600a (HC1) had a maximum COP.

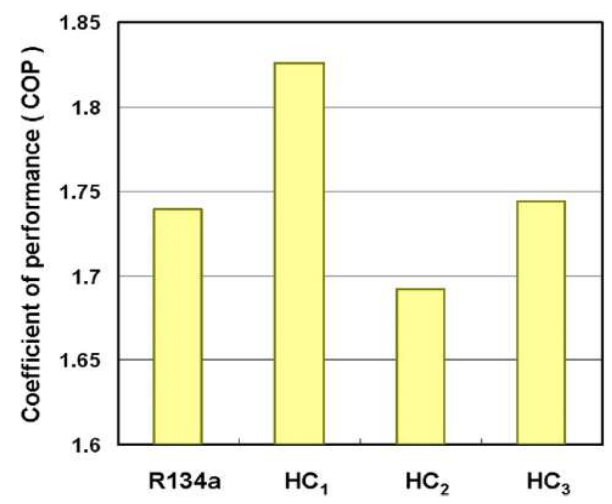

$\mathrm{HC} 1=65 \% \mathrm{R} 290$ and $35 \% \mathrm{R} 600 \mathrm{a}$ $\mathrm{HC} 2=50 \% \mathrm{R} 290$ and $50 \% \mathrm{R} 600 \mathrm{a}$ $\mathrm{HC} 3=0 \% \mathrm{R} 290$ and $100 \% \mathrm{R} 600 \mathrm{a}$

Figure 2-8: COPs of the refrigerator when using the different refrigerants (Yu \& Teng, 2014) 


\subsection{Challenges, Flammability and Safety of HC Refrigerants}

Propane, with its good thermal performance and environmental characteristics, is an alternative refrigerant to HFCs. The main disadvantage is the risk based in its flammability. This leads to the necessity for very careful handling and safety precautions on the appliance itself and in the manufacturing factory. According to the safety standard IEC 60 335-2-24 (2005), the maximum refrigerant charge of R-290 is set to be $150 \mathrm{~g}$. In a refrigeration system charged with propane, all electrical elements and switching can be potential sources of ignition. This includes the thermostat, door contacts for lighting, on/off and other switches, compressor relays, defrost timers, and so on. Refrigerant containing parts such as the evaporator, the condenser, the tubing, and the compressor are taken to be possible sources of refrigerant through leaks.

For an accident to occur, there need to be two essential preconditions which must be present together for combustion when leakage happens. The first condition is the presence of the flammable mixture of gas and air and the second condition is an ignition source of a certain energy level or temperature. The minimum ignition temperature for R-290 is $470{ }^{\circ} \mathrm{C}$. In order to reduce the risk of combustion, the refrigerant mass needs to be limited for a given room area according to the following formula.

$\mathrm{M}_{\max }=2.5 \mathrm{LFL}^{5 / 4} \mathrm{~h}_{\mathrm{o}} \mathrm{A}^{1 / 2}$

LFL: The lower flammable limit $\left(\mathrm{kg} / \mathrm{m}^{3}\right)$

$\mathrm{M}_{\text {max: }}$ the allowable maximum mass of refrigerant $(\mathrm{kg})$

A: the room volume $\left(\mathrm{m}^{3}\right)$

$\mathrm{h}_{\mathrm{o}}$ : the installation height of the appliance $(\mathrm{m})$

The lower flammable limit (LFL) of propane refrigerant is approximately $0.038 \mathrm{~kg} / \mathrm{m}^{3}$. The basis of the formula is to ensure that the concentration of leaked refrigerant that settles at floor level does not exceed the LFL. Li (2014) experimentally investigated the effect of refrigerant leak rate, leak point location, equipment airflow, and installation height of a split-type air conditioner. A capillary tube was connected from the R-290 cylinder into the indoor unit housing and into the refrigerant line as shown in Figure 2-9. The refrigerant concentration was measured by infra-red flammable gas detectors placed in a room at different positions. 


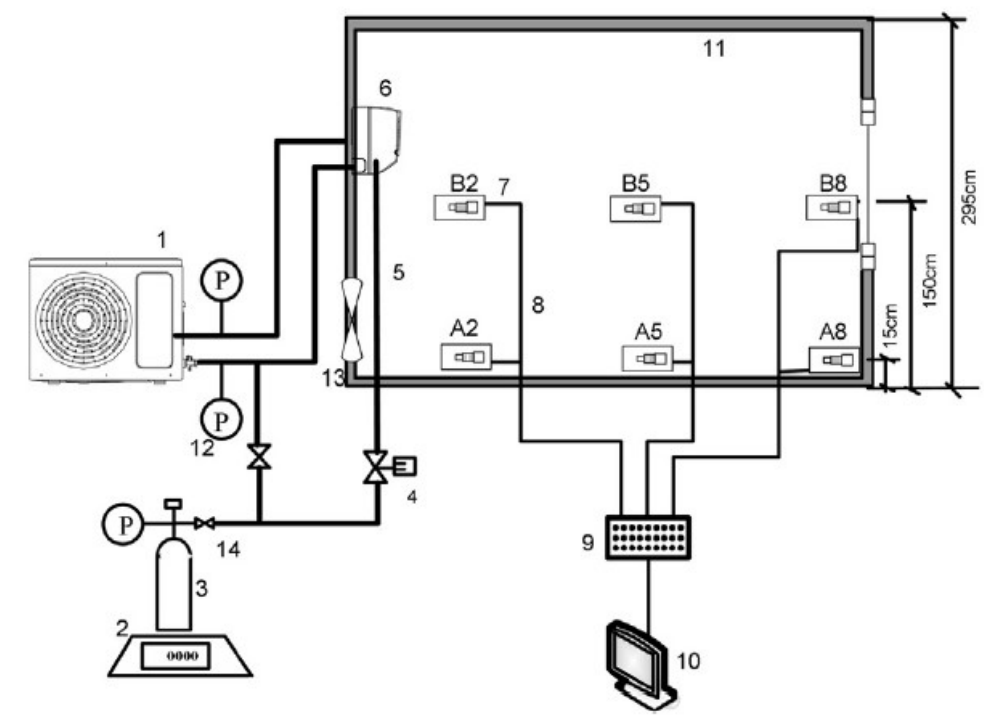

Figure 2-9: Schematic of leakage test apparatus for R-290. (Li, 2014)

The results of R-290 leakage indicated that the maximum concentration was less than two thirds of the LFL and the leak concentration was underneath the leak position. It can be concluded that the location of potential ignition sources, such as switches and electrical appliances near the floor, should not be directly below indoor units. Li (2014) also found that the leak rate has a major influence on the refrigerant concentration distribution. The effect of the fan operation and location of the leak position have minor effect on the maximum concentration, but air flow has a major effect on reducing the concentrations across the room floor.

Jin, Gao, \& Zheng (2017) studied the effect of concentration distribution of R32 when leaking from a floor type air conditioner. Through experiment, they also analyzed mechanical ventilation on refrigerant leak. It was found that the position below the leak hole had high risk and mechanical ventilation from the down exhaust could help diffuse leaked R32.

Maojuan, Jinbo, Zhe, \& Tingxun (2018) tested and analyzed different masses of R-290 (propane) leaked into the room from the inside and the outside of a split type air conditioner indoor unit. The refrigerant concentration was measured by infrared gas sensors and a computational fluid dynamics (CFD) mode for the indoor unit was developed and verified by the test data. The influences of installation height, leak point location, airflow rate and different airflow angles of the indoor unit were tested and analyzed. The experimental and simulation results indicated that 
higher installation height was helpful for refrigerant dispersion. However, refrigerant in the region with lower flow velocity (less than $0.2 \mathrm{~m} / \mathrm{s}$ ) diffused only under the function of the concentration difference and gravity, and the more homogeneous distribution would be with higher airflow rate, as illustrated in Figure 2-10. The airflow angle could only influence the refrigerant dispersion when the airflow rate was low. The indoor unit was installed at a height of $2.2 \mathrm{~m}$.

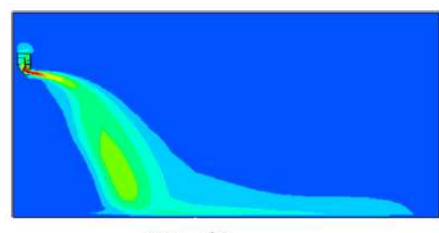

$214 \mathrm{~m}^{3} / \mathrm{h}$

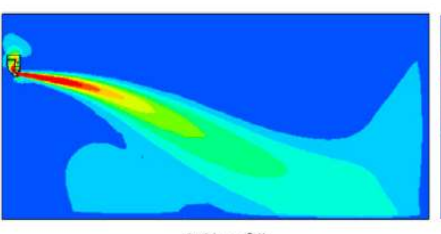

$369 \mathrm{~m}^{3} / \mathrm{h}$

$\begin{array}{lllllllll}0.0 & 0.1 & 0.2 & 0.3 & 0.4 & 0.5 & 0.6 & 0.7 & 0.8\end{array}$

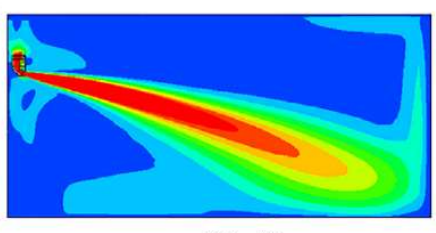

$582 \mathrm{~m}^{3} / \mathrm{h}$

Figure 2-10: Velocity contour of the $Y=2.2 \mathrm{~m}$ plane. (Maojuan et al., 2018)

\subsection{Life-Cycle Climate Performance of ASHPs}

As previously mentioned, heat pumps reduce the demand for fossil fuel, with a corresponding reduction of $\mathrm{CO} 2$-emissions for heating and cooling in residential, commercial and industrial applications. Based on practical experience, heat pumps can reduce the primary energy consumption by between 15 and 50\% when compared with conventional oil- and gas-fired boilers (Laue, 1994).

The annual performance of a heat pump is defined as the ratio of useful heat output to the total power input over a one-year period, $\mathrm{Q}_{\text {out. yr }} / \mathrm{W}_{\mathrm{yr}}$ known as the Seasonal Performance Factor (SPF). Many heat pumps operate on the vapour-compression cycle and the use of electric motor drives in the compressor dominates such units. Therefore $\mathrm{CO} 2$-emissions of electric heat pumps are directly related to their power generation emissions. The high electrical energy consumption, efficiency of power generation, low performance of heat pumps during the cold ambient air, and the production of non-fossil fuel electricity in individual countries made strong arguments against heat pumps. The research stated that heat pumps have little or even negative impact on the protection of the environment related to the $\mathrm{CO} 2$-emissions of the whole energy chain for power generation. In addition, refrigerants as a working fluid in the compression cycle of heat pumps 
have negative impact on the ozone depletion and greenhouse effect for climate. The approach of this problem is to compile the carbon footprint of a heat pump from production of the raw materials and energy used in the heat pump through disposal. In order to find cradle-to-grave gas emission of the heat pumps, the Life-Cycle Climate Performance (LCCP) calculates direct and indirect impacts including emissions from manufacture, energy used, energy embodied in components, operating energy, and disposal or recycle (HFC/PFC Task Force of the Technology and Economic Assessment Panel (UNEP/TEAP), 1999).

The work done by Johnson (2011) calculates carbon footprints of a residential ASHP with an HFC refrigerant in the UK. The refrigerant base was R-410 in his study. The footprint was calculated according to the lifetime of the heat pump and per $\mathrm{kWh}$ of heat delivered. Johnson observed that heat pump footprints (in $\mathrm{kg} \mathrm{CO} 2 \mathrm{e}$ emitted per $\mathrm{kWh}$ of heat delivered) are the same or higher than footprints of gaseous fuels used in heating. Johnson (2011) concluded that refrigerant adds $20 \%$ to the heat pump footprint. The carbon footprints were analyzed based on the lifetime and $\mathrm{kWh}$ of heat delivered.

In Johnson's (2011) study, the "cradle-to-grave" assessment was calculated in five parts: raw materials production; electricity production and transmission; manufacture installation and use of the ASHP; refrigerant leakage during operation and disposal; and energy used in the heat pump through disposal of components. Table 2-2 shows the present heat pump refrigerant production footprints based on 2010 dataset for Refrigerant production footprints being used by the United Nations Environment Program Refrigeration, Air Conditioning and Heat Pumps Technical Options Committee (UNEP RTOC) used by Johnson. Refrigerants, metal and plastic components are the main raw materials in a heat pump's production. R-290 refrigerant has a very low production foot print (mean $1.2 \mathrm{~kg} \mathrm{CO} 2 \mathrm{~kg}$ refrigerant), below that of other selected refrigerants. 
Table 2-2: Refrigerant production footprints from UNEP RTOC (Johnson, 2011)

\begin{tabular}{|c|c|c|c|c|c|}
\hline \multirow[b]{2}{*}{ Refrigerant } & \multicolumn{2}{|c|}{ Estimates } & \multicolumn{3}{|c|}{ Production footprint ${ }^{\mathrm{a}} \mathrm{kg} \mathrm{CO}_{2} \mathrm{e} / \mathrm{kg}$ refrigerant } \\
\hline & Value & Source & Minimum & Mean & Maximum \\
\hline \multirow{2}{*}{ R22 } & 205.3 & Frischknecht (1999) & 205 & 299 & 393 \\
\hline & 393 & Little (2002) & & & \\
\hline R32 & 190 & Frischknecht (1999) & 86 & 190 & 295 \\
\hline R125 & 160 & Frischknecht (1999) & 72 & 160 & 248 \\
\hline \multirow[t]{5}{*}{ R134a } & 38.8 & Banks and Sharratt (1996) & 10 & 49 & 87 \\
\hline & 84.5 & Campbell and McCulloch (1998) & & & \\
\hline & 72 & Frischknecht (1999) & & & \\
\hline & 87 & Little (2002) & & & \\
\hline & 10 & McCulloch and Lindley (2003) & & & \\
\hline R143a & 120 & Frischknecht (1999) & 54 & 120 & 186 \\
\hline R227ea & 120 & Banks et al. (1998) & 54 & 120 & 185 \\
\hline R404A & 136 & Frischknecht (1999) & 61 & 136 & 211 \\
\hline $\mathrm{R} 407 \mathrm{C}$ & 142 & Frischknecht (1999) & 64 & 142 & 220 \\
\hline $\mathrm{R} 410 \mathrm{~A}$ & 173 & Frischknecht (1999) & 78 & 173 & 268 \\
\hline \multirow[t]{2}{*}{ R290 } & 1.5 & Gover et al. (1996) & 0.9 & 1.2 & 1.5 \\
\hline & 0.95 & Frischknecht (1999) & & & \\
\hline \multirow[t]{2}{*}{$\mathrm{R} 600 \mathrm{a}$} & 1.5 & Campbell and McCulloch (1998) & 0.9 & 1.2 & 1.5 \\
\hline & 1.5 & Gover et al. (1996) & & & \\
\hline \multirow[t]{2}{*}{ R717 } & 2.0 & McCulloch et al. (2003) & 2.0 & 2.3 & 2.5 \\
\hline & 2.53 & Frischknecht (1999) & & & \\
\hline $\mathrm{R} 744\left(\mathrm{CO}_{2}\right)$ & 1.62 & Frischknecht (1999) & 0.7 & 1.6 & 2.5 \\
\hline
\end{tabular}

${ }^{a}$ Where only one value was found in the literature, the minimum and maximum values were based on the average variation found for R22 and R134a, which are determined by a larger number of sources.

Figure 2-11 captures the carbon footprint of the heat pump. The carbon footprint model accounted for the 15-year lifetime of the ASHP. Manufacturing, installation, refrigerant leakage and some maintenance were considered. The results indicated that the power is the major contributor to the heat pump footprint with $80-83 \%$ of the total, on average the refrigerant contributes $15-18 \%$, and metal and plastic components make a minor contribution at $2-3 \%$ of the overall heat-pump footprint.

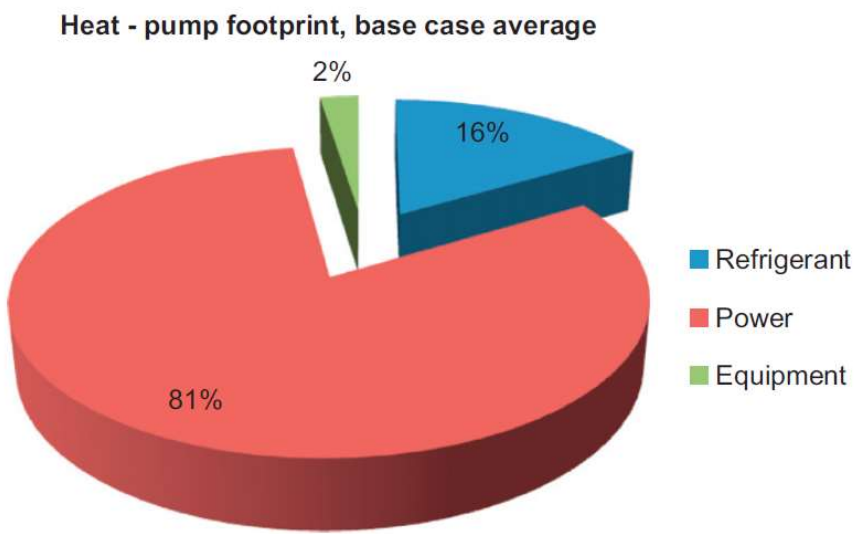

Figure 2-11: Refrigerant contribution to the heat-pump footprint is significant (Johnson, 2011) 


\subsection{Literature Review Conclusion}

From the various literature sources, multiple studies have demonstrated how recent efforts have improved heat pump energy efficiency for cold climate areas. It was determined that the ambient temperature plays a critical role in the heating capacity and efficiency of an ASHP. Various recently developed technologies have further improved the efficiency of the heat pumps such as use of Economized Vapour Injection system (EVI), multi-stage compressors with variable capacities, and connecting the heat pump to renewable air sources and exhaust air systems. Further improvement is needed in order to satisfy the required function and efficiency of ASHPs in cold climate regions.

In addition, application of natural refrigerants for heat pumps was reviewed. The new generation of refrigerants must offer high energy efficiency in addition to low environmental impacts. Propane refrigerant with zero ozone depletion and very low GWP is a good candidate for a heat pump system. Many studies investigated the use of propane in air to water heat pumps. However, in the literature to date there is limited research data on air to air heat pump systems using R-290 refrigerant. The life cycle, flammability issue, and challenges for use of propane as a refrigerant were also studied.

This research aims to analyze the thermodynamic performance of R-290 refrigerant in an air source heat pump with consideration of an air side energy recovery system. 


\subsection{ASHP System Design}

The specific objective of this chapter is to discuss the method of refrigeration cycle design and the thermodynamic characteristics of refrigerants using in a heat pump system. The selective refrigerants will be compared with R-290 under different operating conditions. In the literature review, it was concluded that there is limited data available for propane refrigerant when it used in an air source heat pump application. This chapter focuses on the refrigerant side of the heat pump with working fluid of R-290 to determine important factors such as: heating and cooling capacity, coefficient of performance (COP), the performance of the compressor and metering device, and refrigerant charge optimization.

The following topics will be presented in this chapter:

- the refrigeration system components and thermodynamic analysis of the ASHP;

- the R-290 refrigeration system design, performance evaluation, method of calculation and pressure- enthalpy chart; and

- comparison of different types of refrigerant with R-290.

\subsection{ASHP Refrigeration Cycle and Components}

The refrigeration circuit of a heat pump is very similar to that of an air conditioner or a refrigerator. The compressor maintains a difference in pressure between the evaporator and the condenser. The expansion valve separates the high-pressure part of the system from the lowpressure part. The liquid that flows through the evaporator is entirely vaporized by the heat flowing through the walls of the evaporator. This heat has been removed from the ambient air in the heating mode of an air source heat pump. A reversing valve changes the flow of refrigerant in the cooling mode and makes the indoor coil function as an evaporator. The heat transfers from return air of the building to the refrigerant. The amount of the heat transfer depends on the enthalpy difference between the inlet saturated liquid refrigerant and superheated outlet vapour. While absorbing the heat, the refrigerant temperature does not change except at the end of the evaporator coil when the refrigerant is completely vaporized. The superheated refrigerant then flows to the compressor after leaving the evaporator, where its pressure is raised after being compressed. The vapour then flows 
to the condenser so that it can be condensed by the air. The latent heat of condensation is transferred from the refrigerant to the air through the wall of the condenser. The liquid refrigerant flows back to the expansion valve and the cycle is repeated.

\subsection{Thermodynamic Analysis of Refrigerants}

Refrigerants with different thermodynamic properties have been chosen for cooling and heating applications through four generations since 1830 (Calm, 2008). In this chapter, the theoretical performance of R-290 and selected candidate refrigerants are analyzed and compared in heating and cooling mode of an ASHP. The focus of the study is on R-290 low GWP refrigerant as a replacement for HCFCs and HFCs. In many studies, the performance of new refrigerants was investigated under different working conditions. According to the multinational manufacturers of refrigerants, the new generation of refrigerants have been developed to meet the GWP limit of 150 (Dupont and Honeywell, 2007).

In order to determine the performance of the heat pump, the temperature and pressure of the refrigerant need to be measured at critical points of the refrigerant line. The rating condition and the amount of the refrigerant charge influence the efficiency, compressor power, and total energy consumption (Afshari, Comakli, Adiguzel, \& Ghasemi Zavaragh, 2017).

\subsubsection{Pressure enthalpy (P-E) chart}

The pressure-enthalpy chart ( $\mathrm{p}-\mathrm{E}$ chart) is helpful in the study of refrigeration cycles. The chart displays physical properties of a given refrigerant and can be used for calculating the total capacity and the COP of the heat pump. Figure 3-1 (a) shows the schematic of a refrigeration cycle with four major components (compressor, condenser, expansion valve, and evaporator), while the p-E chart of the cycle on the two scales of pressure (p) and enthalpy (E) is plotted in Figure 3-1 (b). The chart is convenient because columns of figures from physical properties of a refrigerant are shown graphically. Thus, it is easy to visualize the changes that take place as the refrigerant flows from one part of the cycle to another. 

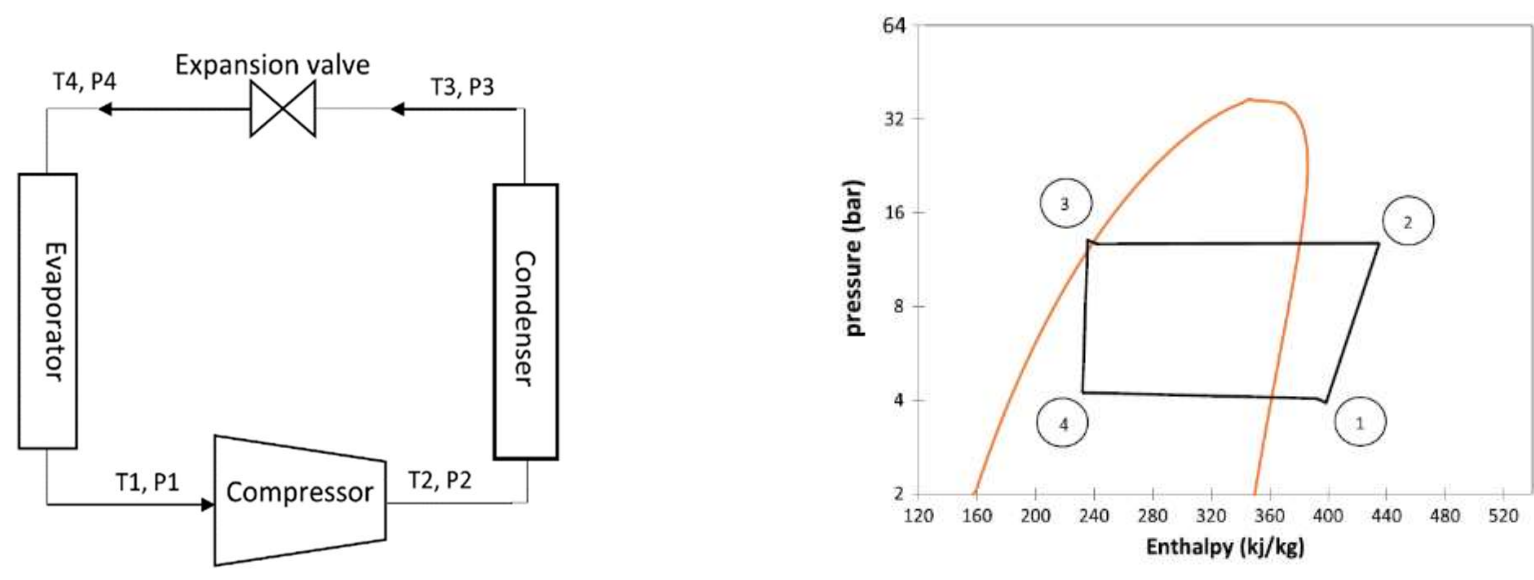

Figure 3-1: (a) Refrigeration cycle and four main components; (b) Pressure-

Enthalpy Chart (Afshari, 2017)

The P-E chart is divided into three general areas: the saturated area under the curve, the superheated region (the area to the right of the saturated vapour), and the subcooled region (the area to the left of the saturated liquid line). The ideal refrigeration cycle of the heat pump consists of an isentropic compression process, an isobaric heat rejection process, an adiabatic expansion process, and an isobaric evaporation process. The process shows in the path 1-2-3-4 of Fig. 3-1 (b). Refrigerant is superheated after the evaporator and absorbs more heat in the suction line before entering the compressor (point 1). The compression process requires energy to raise the vapour from the low-pressure suction in the evaporator to a higher-pressure discharge in the condenser. The refrigerant vapour absorbs this energy, called the heat of compression. This process is shown as line 1-2, figure 3-1 (b). The condenser and evaporator processes occur at a constant pressure and are represented by lines 2-3 and 4-1, respectively. The expansion valve drops the pressure from discharge to suction pressure (point 3 to 4 ) in a constant enthalpy process. 


\subsubsection{Superheated and subcooled conditions}

When liquid refrigerant is admitted to a cooling coil (evaporator), it will usually be completely vaporized before it reaches the outlet connection. The cold vapour continues to absorb heat and becomes superheated before entering the compressor. The amount of the superheat is important factor for compressor safety. In addition, the amount of the refrigerant charge can be affected by superheat in heat pumps with the capillary tube system. In general, a constant superheat can optimize the performance of the heat pump at design conditions (Choi \& Kim, 2002). The amount of the superheat recommended by manufacturers depends on the system design and evaporator temperature range. Sporlan (2011) suggested an (8-12 $\left.{ }^{\circ} \mathrm{F}\right)$ optimal superheat setting for typical design of air conditioning and heat pump applications. The system superheat degree can be calculated using Eq. (3.1).

$\mathrm{SH}=\mathrm{T}_{\text {evap out }}-\mathrm{SST}$

where:

$$
\begin{aligned}
\mathrm{SH}= & \text { Superheat degree }\left({ }^{\circ} \mathrm{C} /{ }^{\circ} \mathrm{F}\right) ; \\
T_{\text {evap out }}= & \text { Evaporator outlet temperature }\left({ }^{\circ} \mathrm{C} /{ }^{\circ} \mathrm{F}\right) ; \text { and } \\
\mathrm{SST}= & \text { Saturation suction temperature or evaporating } \\
& \text { temperature }\left({ }^{\circ} \mathrm{C} /{ }^{\circ} \mathrm{F}\right) .
\end{aligned}
$$

Subcooling refers to the cooling of a liquid refrigerant in the condenser, at constant pressure, to a point below the temperature at which it was condensed (Corberán et al., 2011). To calculate the total amount of the subcooling, the difference between the refrigerant liquid temperature and its saturation temperature needs to be measured as per Eq. (3.2). A certain amount of subcooling prevents the formation of vapour in the liquid line (flash gas), increasing the refrigerant effect and the heat pump system capacity. The subcooling can be increased by adding refrigerant charge. Based on experimental investigation, Corberán et al., (2011) found that that an optimum subcooling degree range of $5-7^{\circ} \mathrm{C}\left(9-12.6^{\circ} \mathrm{F}\right)$ is required for a heat pump unit system with a thermostatic metering device (TXV). The heat pump with a TXV metering device needs to be charged based on the optimum amount of subcooling. 
The amount of the subcooling can be calculated by the following equation.

$\mathrm{SC}=\mathrm{SDT}-\mathrm{T}$ cond out

where:

$$
\begin{aligned}
\mathrm{SC}= & \text { Subcooling degree }\left({ }^{\mathrm{o}} \mathrm{C} /{ }^{\circ} \mathrm{F}\right) ; \\
T_{\text {cond out }}= & \text { Condenser outlet temperature }\left({ }^{\circ} \mathrm{C} /{ }^{\circ} \mathrm{F}\right) ; \text { and } \\
\mathrm{SDT}= & \text { Saturation discharge temperature or condensing } \\
& \text { temperature }\left({ }^{\mathrm{o}} \mathrm{C} /{ }^{\circ} \mathrm{F}\right) .
\end{aligned}
$$

\subsubsection{Cooling capacity}

The heat added to each pound of refrigerant in the evaporator is the difference between the enthalpy of the vapour leaving the evaporator and the enthalpy of the liquid-vapour mixture entering the evaporator (Eq. 3.3). In this study, the cooling capacity of the heat pump was determined based on the refrigerant enthalpy drop across the evaporator. The refrigerant enthalpy was quantified by using the PE chart. The secondary quantities such as enthalpy could be calculated through measuring temperature and pressure at every state point of the refrigerant loop. Capacities were calculated by multiplying the refrigerant flow rate and inlet and outlet enthalpy difference of the indoor heat exchanger.

$\dot{\mathrm{Q}}_{\mathrm{c}}=\dot{\mathrm{m}}_{\mathrm{r}}\left(\mathrm{h}_{\text {evap out }}-\mathrm{h}_{\text {evap in }}\right)$

where:

$$
\begin{array}{ll}
\dot{\mathrm{Q}}_{\mathrm{c}} & =\text { Cooling capacity, } \mathrm{kW}(\mathrm{btu} / \mathrm{h}) ; \\
\dot{\mathrm{m}}_{\mathrm{r}} & =\text { refrigerant mass flow rate, } \mathrm{kg} / \mathrm{s}(\mathrm{lb} / \mathrm{h}) ; \\
h_{\text {evap out }} & =\text { the outlet enthalpy of the evaporator, } \mathrm{kJ} / \mathrm{kg}(\mathrm{Btu} / \mathrm{lb}) ; \text { and } \\
h_{\text {evap in }} & =\text { the inlet enthalpy of the evaporator, } \mathrm{kJ} / \mathrm{kg}(\mathrm{Btu} / \mathrm{lb}) .
\end{array}
$$




\subsubsection{Heating capacity}

In the case of heating capacity, the difference between the enthalpy of the vapour entering the condenser and the enthalpy of the liquid leaving the condenser was calculated. To calculate the work done by the compressor, the heat of compression was added to the enthalpy of the vapour. Enthalpies were determined by drawing vertical lines downward from the inlet and outlet of the condenser.

The heating capacities were determined by the following equation.

$$
\dot{\mathrm{Q}}_{\mathrm{h}}=\dot{\mathrm{m}}_{\mathrm{r}}\left(\mathrm{h}_{\text {cond, in }}-\mathrm{h}_{\text {cond, out }}\right)
$$

where:

$$
\begin{array}{ll}
\dot{\mathrm{Q}}_{\mathrm{h}} & =\text { Heating capacity, } \mathrm{kW}(\mathrm{btu} / \mathrm{h}) ; \\
\dot{\mathrm{m}}_{\mathrm{r}} & =\text { refrigerant mass flow rate, } \mathrm{kg} / \mathrm{s}(\mathrm{lb} / \mathrm{h}) ; \\
h_{\text {cond out }} & =\text { the outlet enthalpy of the condenser, } \mathrm{kJ} / \mathrm{kg}(\mathrm{Btu} / \mathrm{lb}) ; \text { and } \\
h_{\text {cond in }} & =\text { the inlet enthalpy of the condenser, } k J / k g(\mathrm{Btu} / \mathrm{lb}) .
\end{array}
$$

\subsubsection{The COP}

The coefficient of performance (COP) is a number indicating the efficiency of the refrigeration cycle. The cooling COP corresponds to the ratio of the enthalpy removed by evaporation to the enthalpy added to the refrigerant vapour during the compression phase. The heating COP can be obtained by the ratio of the condenser inlet and outlet enthalpy differences during the compression phase. 
The heating and cooling COP is calculated by Equations 3.5 and 3.6.

$$
\begin{array}{ll}
\mathrm{COP} \text { cooling } & =\left(\left(\mathrm{h}_{\text {evap out }}-\mathrm{h}_{\text {evap in }}\right) /\left(\mathrm{h}_{\text {comp out }}-\mathrm{h}_{\text {comp in }}\right)\right. \\
\mathrm{COP}_{\text {heating }} & =\left(\mathrm{h}_{\text {cond in }}-\mathrm{h}_{\text {cond out }}\right) /\left(\mathrm{h}_{\text {comp out }}-\mathrm{h}_{\text {comp in }}\right)
\end{array}
$$

where

$$
\begin{array}{ll}
h_{\text {comp out }} \text { and } h_{\text {comp in }} & \begin{array}{l}
\text { represent the outlet and inlet enthalpies } \\
\text { of the compressor; }
\end{array} \\
h_{\text {evap out } \text { and } h_{\text {evap in }}} & \begin{array}{l}
\text { represent the outlet and inlet enthalpies } \\
\text { of the evaporator; and }
\end{array} \\
h_{\text {cond in } \text { and } h_{\text {cond out }}} & \begin{array}{l}
\text { represent the inlet and outlet enthalpies } \\
\text { of the condenser. }
\end{array}
\end{array}
$$

The above formulas indicate the theoretical value of COP. In the actual case, the COP which can directly evaluate the system efficiency will be less than this value due to the energy consumed by the compressor and fans (Chen et al., 2018). The actual heating COP is calculated by Eq. (3.7).

$$
C O P=\frac{\dot{m r}(h \text { cond,in }- \text { h cond,out })}{W}
$$

Where

$\dot{\mathrm{m}}_{\mathrm{r}}, h_{\text {cond,in, }} h_{\text {cond,out }}$ and $\mathrm{W}$ represent refrigerant mass flow rate, the inlet and outlet enthalpies of the condenser, and total power consumption respectively. 


\subsection{Heat Pump Performance with Different Refrigerants}

In this part, ASHP is analyzed for different climates, refrigerants and operating conditions.

\subsubsection{Methodology}

The performance of R22, R134a, R410a and R290 were investigated under typical airconditioning and heat pumping conditions as per information available from the Low GWP AREP Handbook (AHRI, Heating, 2015). The standard parameters and physical properties of candidate refrigerants were utilized, as listed in Table 3-1. The performance of refrigerant candidates was analyzed on the P-H chart, and their capacities and COPs were calculated. All refrigerants were analyzed under the same conditions of evaporating and condensing temperatures and the same amount of superheating and subcooling. Compressor isentropic efficiency of $70 \%$ and zero suction and discharge line pressure losses were assumed. Different amounts of compressor suction superheat conditions were considered due to the heat gain from ambient air. The important performance factors such as heating and cooling capacities, COPs, pressure ratios, and compressor discharge temperatures were evaluated and compared. The capacity measurements were based on the refrigerant enthalpy differences obtained from the pressure-enthalpy chart for each type of refrigerant. The thermodynamic properties of refrigerants were calculated according to SOLKANE 8.0 (Solvay Fluor GmbH, n.d.) and NIST REFPROP 9.1 (Lemmon et al., 2013) software.

Table 3-1: Refrigerant properties (ANSI/ASHRAE standard 34, REFPROP 9.1)

\begin{tabular}{|c|c|c|c|c|}
\hline Parameter & R22 & R134a & R410a & R290 \\
\hline Chemical formula & $\mathrm{CHCLF}_{2}$ & $\mathrm{CH}_{2} \mathrm{FCF}_{3}$ & $\begin{array}{l}\mathrm{CH}_{2} \mathrm{~F}_{2} / \mathrm{CHF}_{2} \mathrm{CF}_{3} \\
50 / 50 \% \text { BY WEIGHT }\end{array}$ & $\mathrm{CH}_{3} \mathrm{CH}_{2} \mathrm{CH}_{3}$ \\
\hline Liquid density at $30^{\circ} \mathrm{C}\left(\mathrm{kg} / \mathrm{m}^{3}\right)$ & 1292.7 & 1187.5 & 1036.2 & 484.39 \\
\hline Critical pressure (bar) & 49.9 & 40.5 & 49.2 & 42.5 \\
\hline Critical temperature $\left({ }^{\circ} \mathrm{C}\right)$ & 96.15 & 101.08 & 72.13 & 96.74 \\
\hline Normal boiling point $\left({ }^{\circ} \mathrm{C}\right)$ & -41 & -26.07 & -51.58 & -42.11 \\
\hline Safety classification & A1 & A1 & A1 & A3 \\
\hline ODP & 0.05 & 0 & 0 & 0 \\
\hline $\mathrm{GWP}_{\text {(100-Years) }}$ & 1810 & 1430 & 2088 & $4^{1}$ \\
\hline
\end{tabular}

1. GWP value based on IPCC AR4, 100-year ITH (AHRI Hand book of Low GWP refrigerants) 


\subsubsection{Rating conditions}

Acceptable standards need to be specified in order to evaluate the thermodynamic performance of refrigerants under different environmental conditions. The Air-Conditioning, Heating and Refrigeration Institute (AHRI) initiated an industry-wide research program called AHRI Low GWP Alternative Refrigerants Evaluation Program (Low GWP AREP).

The program lists AHRI standard 210/240 (AHRI, 2017) and ASHRAE standard 37 (ASHRAE, 1978) for testing HVAC equipment. The rating conditions were obtained from AHRI standard tests for space heating and cooling conditions of air source heat pumps (see Appendix A, Table A-1). Rating conditions are explained in Table 3-2 below. The following rating conditions are based on the operating conditions in Appendix A, Table A-2 of the first-round testing of the alternative refrigerant candidates listed in AHRI Handbook of low GWP Refrigerants (AHRI, 2015). The results of the calculations for R-290 refrigerant and comparisons to other alternative refrigerants were performed.

Table 3-2: Rating conditions for R22, R134a, R410a and R290 refrigerants

\begin{tabular}{|l|l|l|l|l|l|}
\hline \multirow{2}{*}{} & \multicolumn{5}{|c|}{ Operating Conditions } \\
\cline { 2 - 6 } & \multicolumn{1}{|c|}{ Point 1 } & \multicolumn{1}{|c|}{ Point 2 } & Point 3 & \multicolumn{1}{|c|}{ Point 4 } & \multicolumn{1}{c|}{ Point 5 } \\
\hline Evaporator Temperature $\left({ }^{\circ} \mathrm{C}\right)$ & 4.4 & 7.2 & -6.7 & -17.8 & -31.7 \\
\hline Condenser Temperature $\left({ }^{\circ} \mathrm{C}\right)$ & 37.8 & 54.4 & 43.3 & 43.3 & 40.6 \\
\hline Evaporator Outlet Superheat $\left({ }^{\circ} \mathrm{C}\right)$ & 5.6 & 5.6 & 5.6 & 5.6 & 5.6 \\
\hline Compressor Suction Superheat $\left({ }^{\circ} \mathrm{C}\right)$ & 5.6 & 11.1 & 11.1 & 5.6 & 22.2 \\
\hline Subcooling $\left({ }^{\circ} \mathrm{C}\right)$ & 5.6 & 8.3 & 0.00 & 0.00 & 0.00 \\
\hline
\end{tabular}

The theoretical performance and calculations of the thermodynamic cycle of R22, R134a and $\mathrm{R} 410 \mathrm{a}$ refrigerants were derived with SOLKANE version 8.0 software (Solvay Fluor GmbH, n.d.) based on single stage compressor process. The properties and enthalpies of R290 refrigerant were calculated with the REFPROP 9.1 software program available from the National Institute of Standards and Technology (NIST) (Lemmon et al., 2013). 


\subsection{Discussion and Results}

For R-290 and all candidate refrigerants, Table A-2 in Appendix A lists various operating and calculated system parameters such as discharge and suction temperatures and pressures, superheat and subcooling degrees, pressure ratios, and COPs.

\subsubsection{Variation in heating and cooling performances}

Figure 3-2 and Figure 3-3 present a comparison of the theoretical cooling and heating COPs of the refrigerants respectively and illustrate that R-290 had better COPs. The calculations show that the theoretical coefficient of performance of R290 is up to $40 \%$ higher than other candidate refrigerants. The best performance is achieved at condition $1\left(4.44{ }^{\circ} \mathrm{C} \mathrm{SST} / 37.78^{\circ} \mathrm{C} \mathrm{SDT}\right)$ for both heating and cooling modes, with a COP of 8.25.

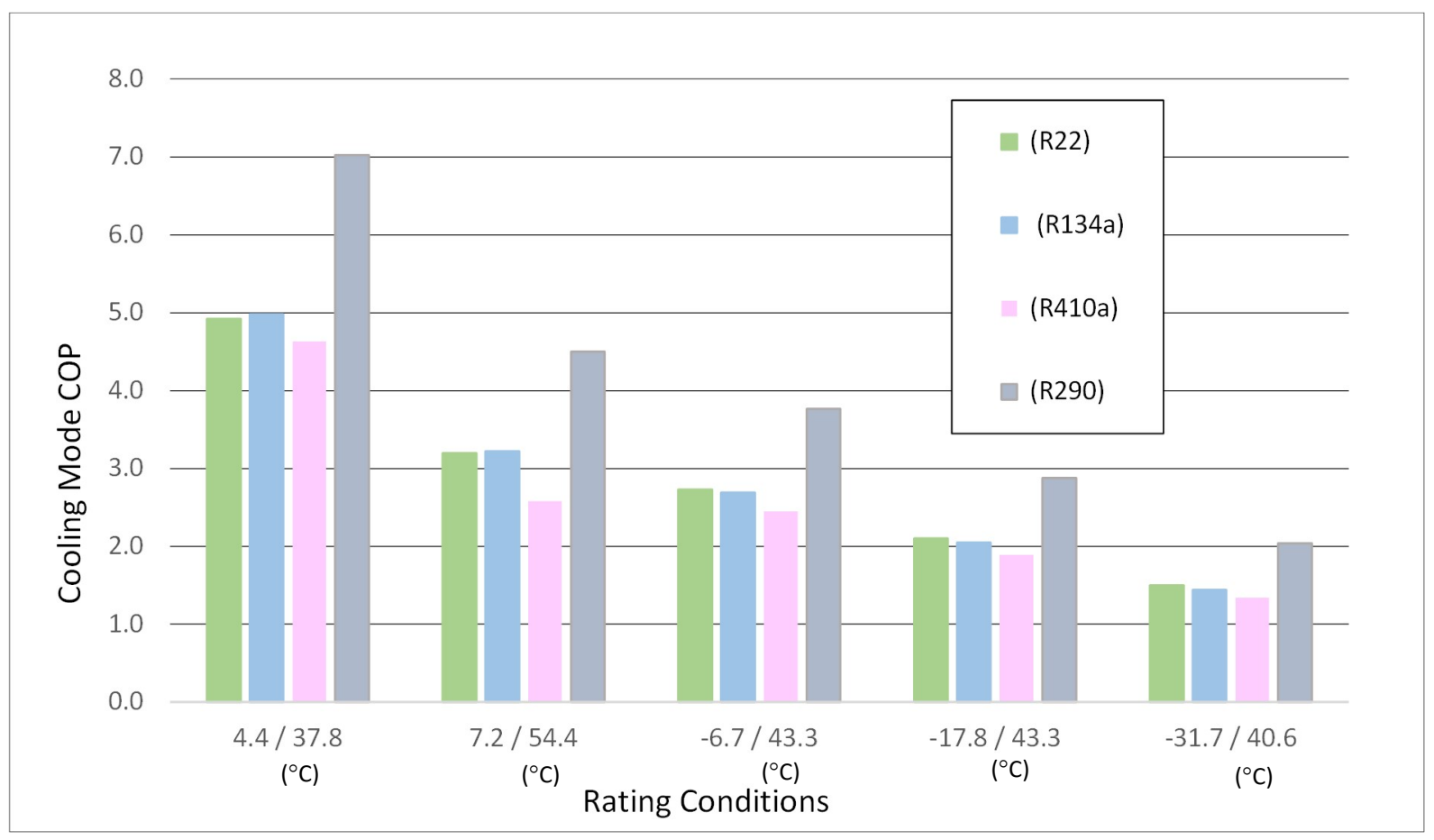

Figure 3-2: Variation of cooling performance of refrigerants 


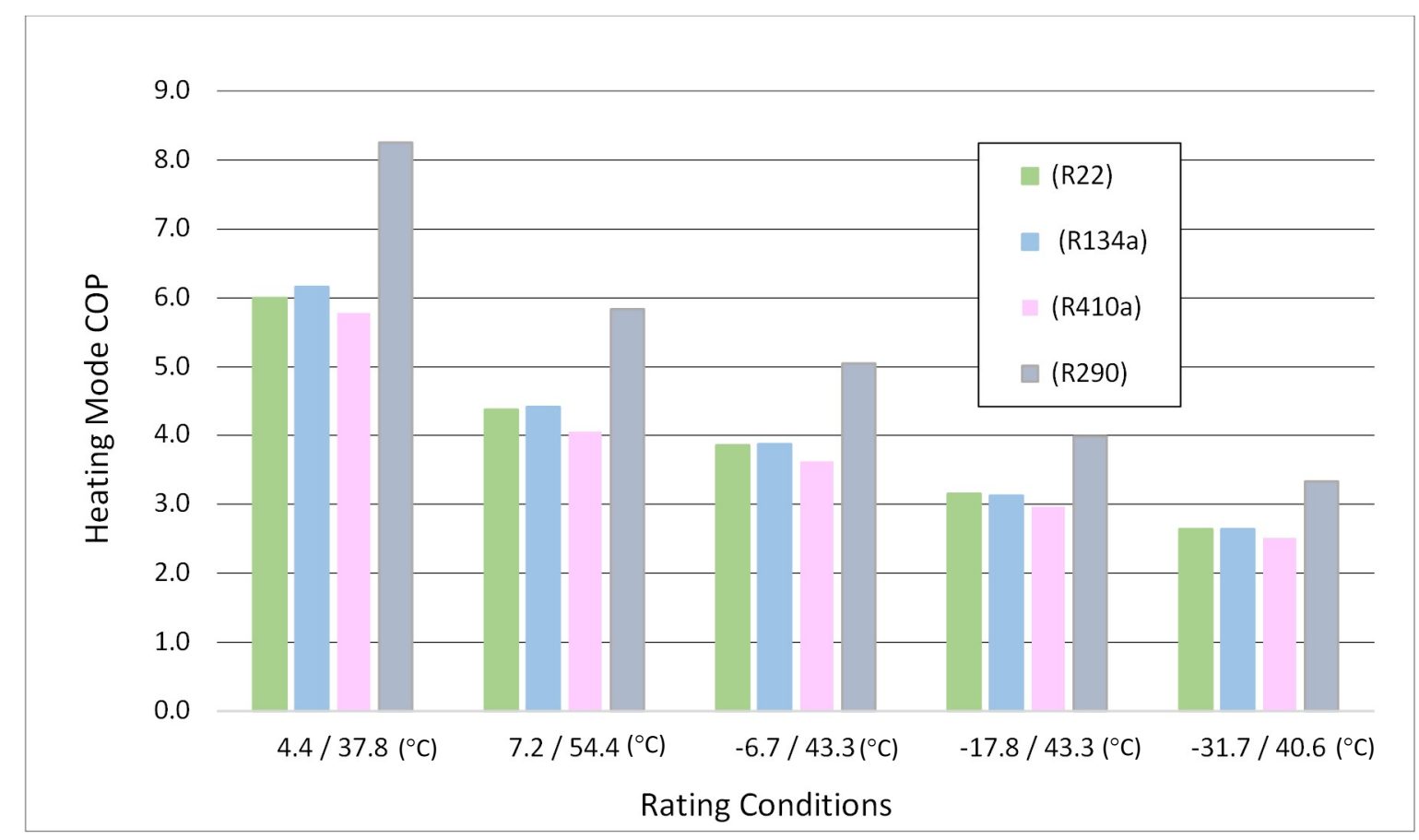

Figure 3-3: Variation of heating performance of refrigerants

\subsubsection{Effect of the pressure ratio}

The pressure ratio, or the ratio of absolute discharge pressure to suction pressure, is an important factor in the refrigeration cycle as it affects the volumetric efficiency of any type of compressor (Trane Air Conditioning Manual, 1965). A higher-pressure ratio decreases the efficiency of the compressor. The compression ratio is strongly related to gas type and amount and to both condenser and evaporator operating conditions (Afshari et al., 2017). Figure 3-4 shows that R-290 has up to a $25 \%$ lower pressure ratio compared to the other candidates. R-134a shows the higher pressure ratio curve. 


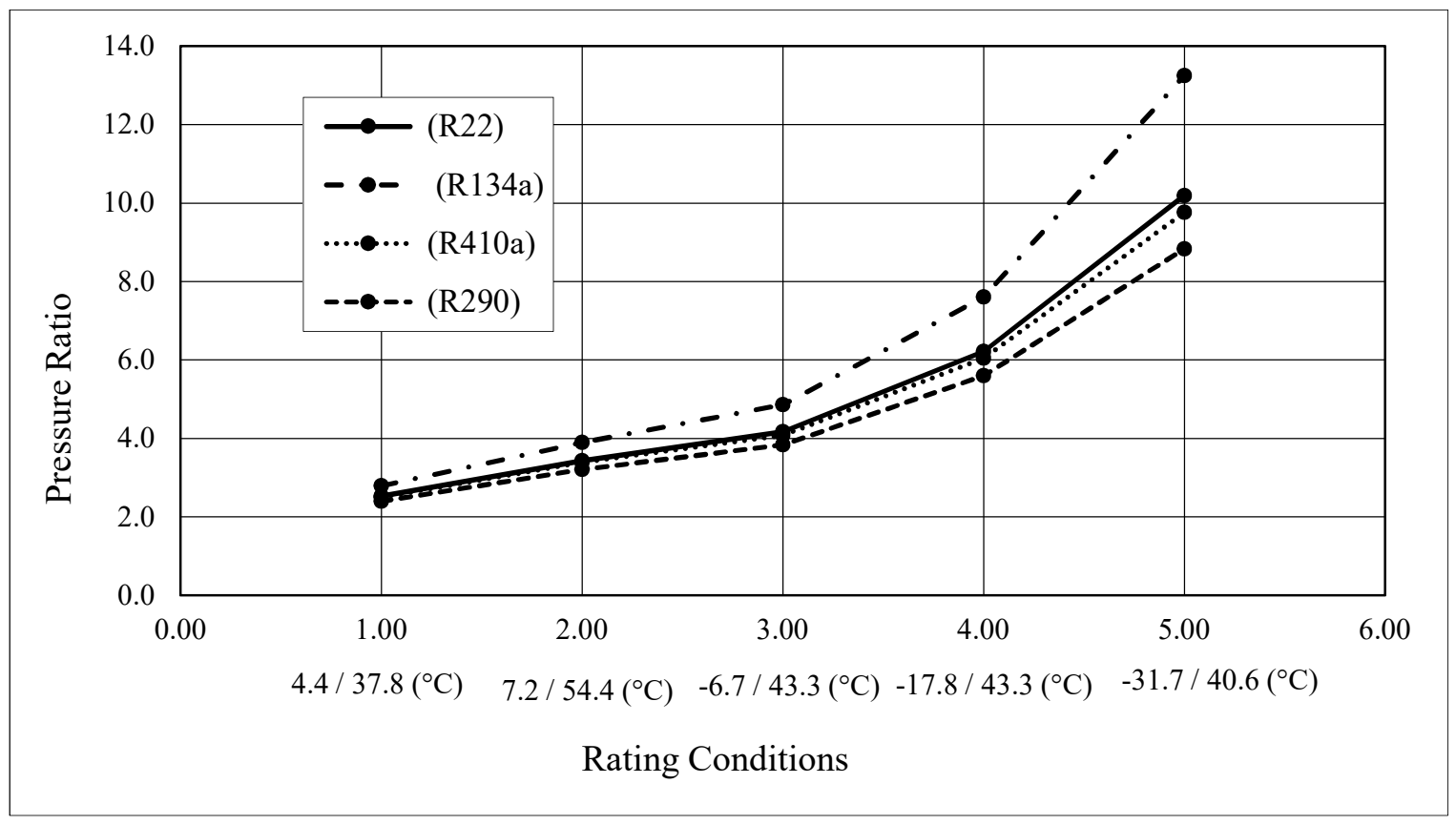

Figure 3-4: Variation of pressure ratio under different rating conditions

\subsubsection{Compressor discharge superheat temperature}

Cooling of the compressor shell causes isothermal compression, providing reversibility in the system so that power consumption during compression can be reduced. Under some conditions, the isentropic assumption does not apply, meaning that the compressor consumes more power than it does in steady-state mode. Figure 3-5 shows the influence of operating conditions on the compressor discharge superheat temperature. R-22 and R-410 refrigerants had the highest discharge superheat temperatures compared to R-290 which falls by 50\%. This means that R-290 systems use less energy and are less likely to burn out the lubricant and compressor. 


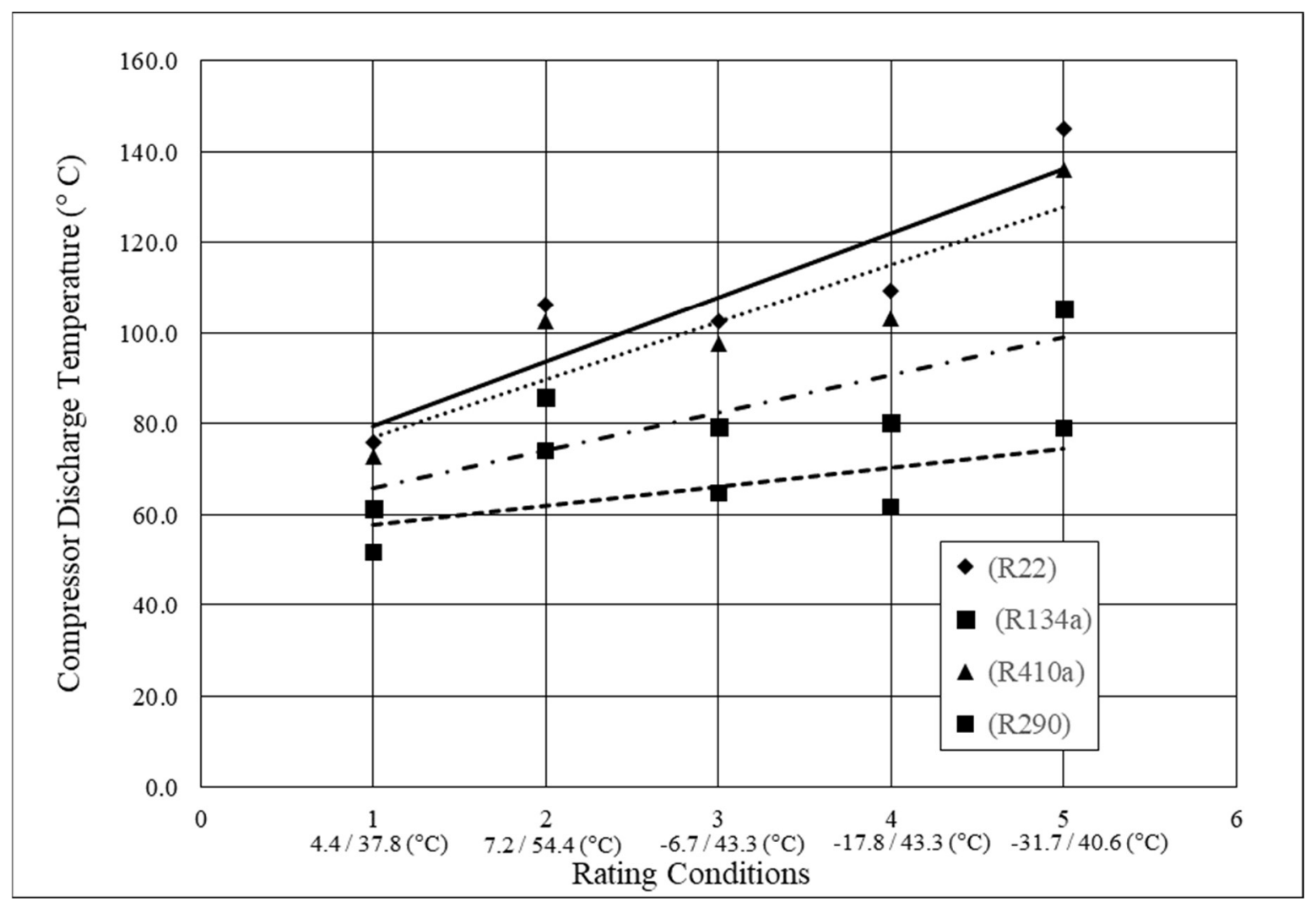

Figure 3-5: Variation of compressor discharge temperature

\subsection{Conclusions for the Calculations}

Based on the theoretical calculation results, R-290 had better COPs on both heating and cooling conditions compared to the other refrigerants. At $-31.7 / 40.6{ }^{\circ} \mathrm{C}$ conditions, the COP of R290 increases by 32\% and has superiority in low ambient temperature conditions. R-290 is also considered as the most beneficial refrigerant in high pressure ratio conditions, which has great influence on the system safety control and the compressor lifetime. In addition, compared to the other refrigerants R-290 presents a lower compressor discharge temperature. From all of the above considering system efficiency, discharge temperature, performance for extreme conditions, and the warming impact R-290 is the most synthetically beneficial alternative. 


\subsection{Heat Pump Test Unit Set Up and Design}

As explained in the introduction section, the research presented in this project is a study of the influence of the propane refrigerant on the performance of ASHP under different operating conditions. For this purpose, a test rig was designed and constructed in a single packaged air source heat pump unit. Most air source heat pumps consist of an indoor fan coil unit and an outdoor fan coil unit with the compressor that usually installed in the outdoor unit. In this system, a single packaged unit was presented, designed and constructed for the purpose of space heating and cooling.

\subsection{System Prototype Design}

\subsubsection{Framing and panels}

The heat pump cabinet was designed in a single packaged unit including three sections: outdoor unit, indoor unit and heat pump components with an electric panel enculture. The overall dimensions of the unit are 74" (H) X 60" (W) X 25" (D). Figure 4-1 shows a picture of the framing and panels.

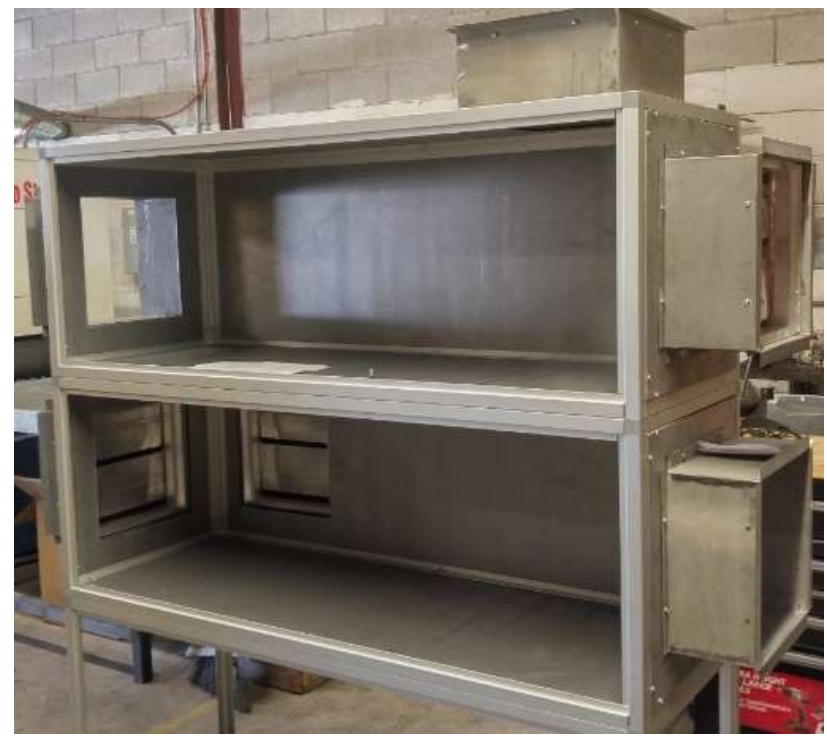

Figure 4-1: Picture of ASHP cabinet and framing 
The supporting frames were built by joining extruded aluminum profiles together with plastic made corners. The panels were constructed double-skinned with non-inflammable, noise and temperature fiberglass insulation. All steel panels were coated white in colour.

The insulated panels reduce heat transfer between the sections and ambient air. Insulated panels also prevent excessive sweating in high humidity ambient conditions. Air leakage around panels and at cabinet joints was minimized by rubber gaskets.

\subsubsection{Refrigeration cycle design and rating conditions}

The refrigerant side design and selection of components was evaluated based on R-290 refrigerant. Its rating condition and capacity are shown in Table 4-1. The heat pump is rated at a cooling capacity of $2.5 \mathrm{~kW}(8530 \mathrm{BTU} / \mathrm{hr})$. Thermodynamic analysis of the heat pump has been carried out for heating and cooling modes under AHRI standard rating conditions for Unitary Air Source Heat Pump (Low GWP AREP Handbook (AHRI, 2015) and Standard 210/240 (AHRI, 2017)). Compressor capacity, efficiency, and mass flow rate were calculated by enthalpy method equations. Accurate enthalpies and physical properties of R-290 were obtained from NIST REFPROP 9.1 (Lemmon et al., 2013). Analysis of heat pump operation has been carried out for different climates in Chapter 3.

Table 4-1:ASHP rating condition and capacity

\begin{tabular}{|l|l|}
\hline Refrigeration capacity & $2.5^{\mathrm{kW}}(8530 \mathrm{BTU} / \mathrm{hr})$ \\
\hline Evaporating temperature & $7.22^{\circ} \mathrm{C}\left(45^{\circ} \mathrm{F}\right)$ \\
\hline Evaporator outlet superheat & $5.6^{\circ} \mathrm{C}\left(10^{\circ} \mathrm{F}\right)$ \\
\hline Condensing temperature & $37.8^{\circ} \mathrm{C}\left(100^{\circ} \mathrm{F}\right)$ \\
\hline Subcooling & $8.3^{\circ} \mathrm{C}\left(15^{\circ} \mathrm{F}\right)$ \\
\hline Return Gas Temperature (RGT) & $18^{\circ} \mathrm{C}\left(65^{\circ} \mathrm{F}\right)$ \\
\hline
\end{tabular}

\subsubsection{Calculations}

Key calculated values for the ideal R-290 refrigerant cycle are shown in Table 4-2, including the heat of compression, COP, and compressor power consumption. The software program NIST REFPROP 9.1 (Lemmon et al., 2013) was used to calculate other values including suction and 
discharge pressure, enthalpy and entropy. The pressure-enthalpy diagram of the refrigeration cycle was plotted in Figure 4-2 based on the design rating condition, with the refrigerant mass flow rate based on the $2.5 \mathrm{~kW}$ refrigeration capacity of the heat pump.

Table 4-2: Theoretical results of $R-290$ refrigeration cycle for design conditions

\begin{tabular}{|l|l|}
\hline \multicolumn{2}{|c|}{ R-290 System Design } \\
\hline Suction Pressure (bar) & 5.88 \\
\hline Discharge Pressure (bar) & 13.01 \\
\hline Pressure Ratio & 2.21 \\
\hline Compressor discharge temperature $\left({ }^{\circ} \mathrm{C}\right)$ & 51.22 \\
\hline CE-Condenser Effect $(\mathrm{kJ} / \mathrm{kg})$ & 364.22 \\
\hline NR- Net Refrigerant Effect $(\mathrm{kJ} / \mathrm{kg})$ & 315.43 \\
\hline HO- Heat of Compression $(\mathrm{kJ} / \mathrm{kg})$ & 39.34 \\
\hline Cooling Efficiency (COP) & 8.02 \\
\hline Heating Efficiency $(\mathrm{COP})$ & 9.26 \\
\hline Mass Flow Rate $(\mathrm{g} / \mathrm{sec})$ & 7.93 \\
\hline Power consumption of the compressor $(\mathrm{kW})$ & 0.31 \\
\hline Condenser Capacity $(\mathrm{kW})$ & 2.89 \\
\hline Evaporator capacity $(\mathrm{kW})$ & 2.5 \\
\hline
\end{tabular}

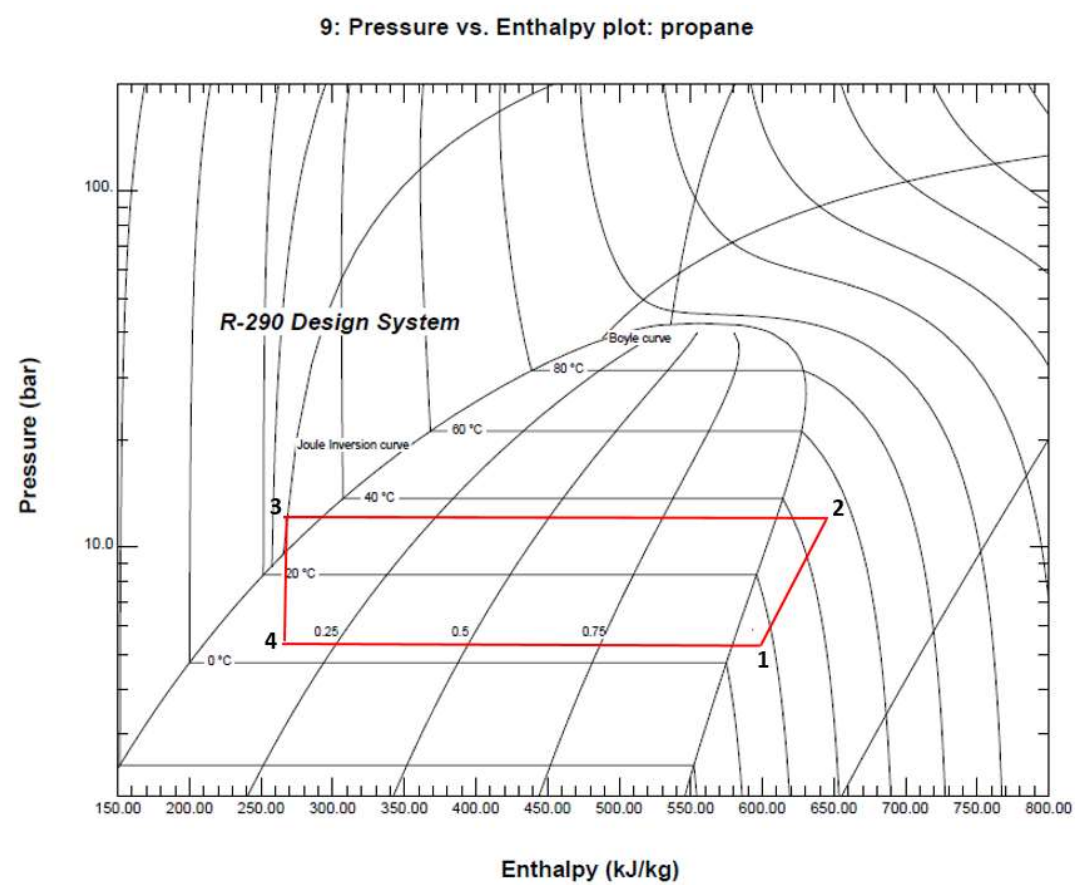

Figure 4-2: Pressure Enthalpy of R-290 


\subsubsection{R-290 mass flow rate}

For the system, the appropriate refrigerant mass charge is linked to the system performance. The method of the refrigerant charge depends on the type of metering device. A thermostatic expansion valve (TXV) is used in the test unit to regulate refrigerant flow from the high side pressure to the low side pressure of the refrigerant line. The system needs to be charged by refrigerant at standard rating conditions when the actual subcooling at the exit of the condenser is set at $5.6^{\circ} \mathrm{C}\left(10^{\circ} \mathrm{F}\right)$ for the expansion valve systems (AHRI Standard 210/240, 2017).

Many authors evaluated and compared the effect of refrigerant charge on the heat pump performance. The optimal charge is determined when the heat pump operates with maximized refrigerating system performance (COP). Farzad \& O’Neal (1994) studied the effect of the important system variables such as capacity, mass flow rate, superheat and subcooling as a function of refrigerant charging. They used eight void fraction models in a refrigeration system of a heat pump. Figure 4-3 shows the effect of mass flow rate.

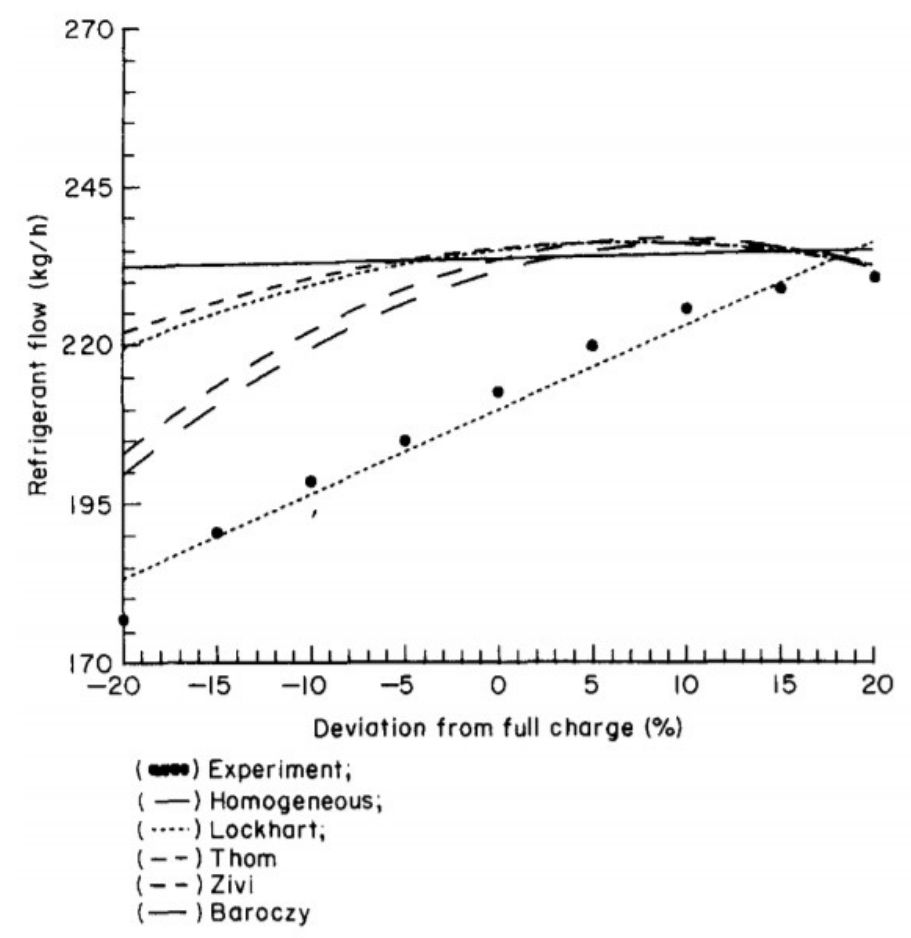

Figure 4-3: Comparison of refrigerant flow rate for the mass-flow-independent models (Farzad \& O’Neal, 1994) 
Most hydrocarbons have smaller liquid densities than most halocarbons, meaning that the amount of charge decreases significantly with hydrocarbons. The performance of R-290 and R-22 at design conditions was calculated and compared in Table 4-3. The calculations show that compared to R22, for R-290 under design conditions the mass flow rate decreased to $44 \%$ with the same amount of heating and cooling capacities. The R-290 compressor discharge temperature is $16 \%$ cooler than for the R-22 system.

Table 4-3: Comparison of $R-22$ and $R-290$ under design condition $\left(7.22 / 37.8^{\circ} \mathrm{C}\right)$

\begin{tabular}{|l|l|l|}
\hline & R-22 & R-290 \\
\hline Suction Pressure (bar) & 6.26 & 5.88 \\
\hline Discharge Pressure (bar) & 14.53 & 13.01 \\
\hline Pressure Ratio & 2.32 & 2.21 \\
\hline Compressor discharge temperature $\left({ }^{\circ} \mathrm{C}\right)$ & 60.63 & 51.22 \\
\hline CE-Condenser Effect $(\mathrm{kJ} / \mathrm{kg})$ & 200.58 & 364.22 \\
\hline NR- Net Refrigerant Effect $(\mathrm{kJ} / \mathrm{kg})$ & 175.70 & 315.43 \\
\hline HOC-Heat of Compression $(\mathrm{kJ} / \mathrm{kg})$ & 21.83 & 39.34 \\
\hline Cooling Efficiency (COP) & 8.05 & 8.02 \\
\hline Heating Efficiency (COP) & 9.19 & 9.26 \\
\hline Mass Flow Rate (g/sec) & 14.23 & 7.93 \\
\hline Power consumption of the compressor $(\mathrm{kW})$ & 0.31 & 0.31 \\
\hline Condenser Capacity (kW) & 2.85 & 2.89 \\
\hline Evaporator capacity (kW) & 2.50 & 2.50 \\
\hline
\end{tabular}

\subsection{System Prototype Components}

This section explains component selection and the construction process of the $2.5 \mathrm{~kW}$ heat pump test unit. The refrigeration cycle consists of a hermetic reciprocating R-290 compressor with a CSR motor type, fin and tube evaporator and condenser, a bi-flow thermostatic expansion valve (TXV), and a four-port reversing valve to switch the operation of the heat pump between heating and cooling modes. Three sight glasses were installed in the refrigerant lines to observe the quality of the refrigerant in the suction, discharge, and liquid piping. A bi-flow filter drier catches the contaminants and absorbs the moisture from the refrigerant. Six pressure gauges were installed in critical points of the refrigerant line to monitor R-290 pressures. 
All major components and accessories were selected based on propane refrigerant. To keep the amount of propane charge within the minimum range, refrigerant piping and the heat exchangers were designed and selected with the minimum amount of internal volume. Both indoor and outdoor coils were designed with internal diameter (ID) copper tubes of $6.8 \mathrm{~mm}(5 / 16$ " nominal size). The suction, discharge, and liquid lines were laid out as short as conditions would permit with the minimum number of fittings and pipe sizes. The main refrigeration components of the experimental unit are summarized in Table 4-4.

Table 4-4: Refrigeration cycle components of the experimental heat pump unit

\begin{tabular}{|l|l|}
\hline Compressor & Reciprocating, Single speed, AK4482U-XA3B \\
\hline Expansion Device & Thermostatic expansion valve, ERVE-1/2-GA \\
\hline Evaporator & Fin and tube, 3 rows, DKC \\
\hline Condenser & Fin and tube, 3 rows, CKC \\
\hline 4-Way reversing valve & STF-02U2G \\
\hline Refrigerant line accessories & Filter drier, service valves, sight glasses \\
\hline Refrigerant & R-290 (Propane) \\
\hline Oil Type & Polyolester \\
\hline
\end{tabular}

Figure 4-4 shows the schematic of the experimental unit set up and main components of the refrigeration circuit. The main components are:

- A hermetic single speed R-290 compressor,

- Two high efficiency fin and tube heat exchangers (coils),

- A bi-flow TXV for cooling and heating modes,

- A four- ported reversing valve,

- a filter drier, and

- $\quad$ three sight glasses. 


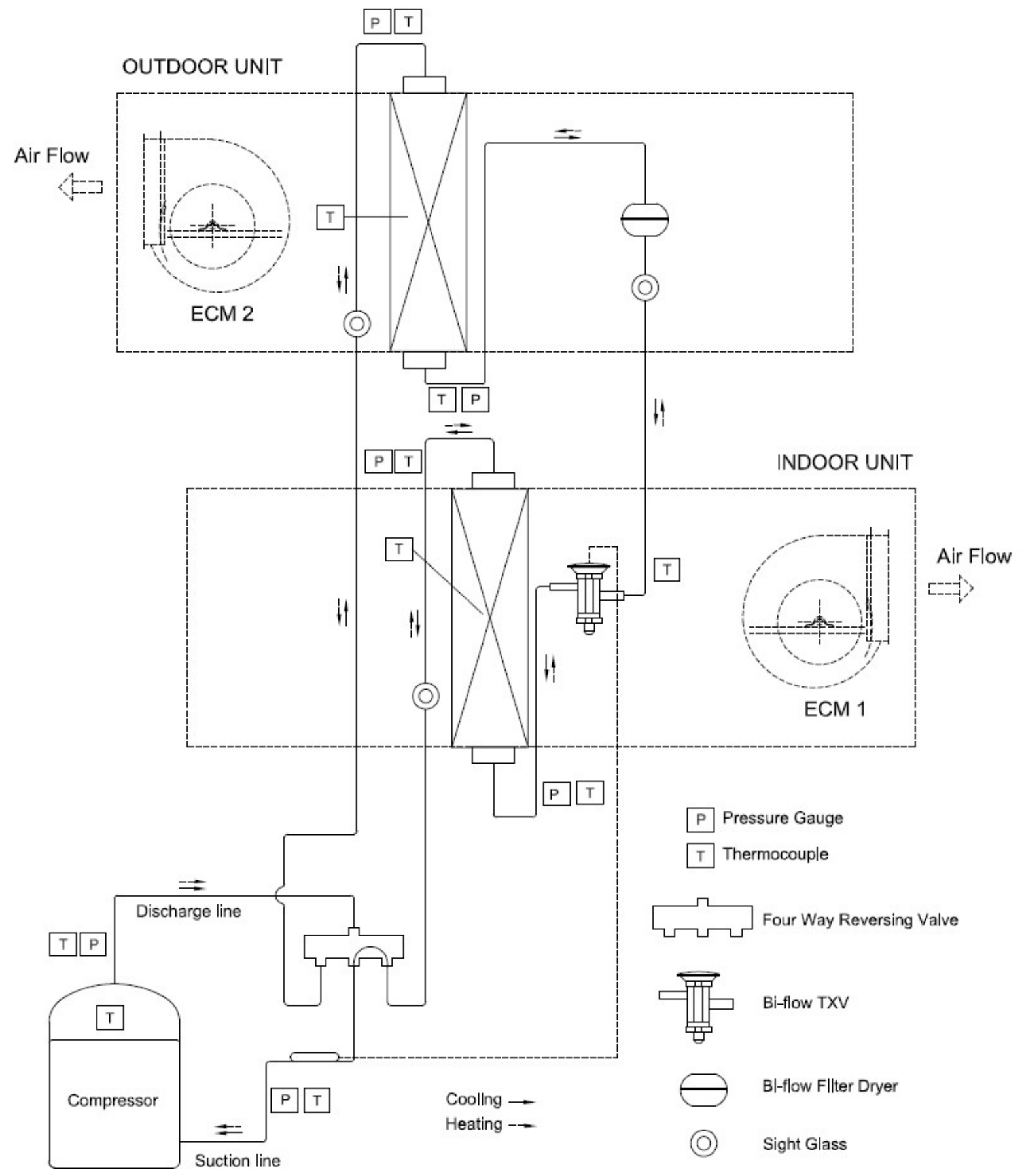

Figure 4-4: Heat pump experimental set-up layout 
Two high efficiency electronic fans, which have their speed modulated by potentiometers, were installed in the indoor and outdoor units. In addition, as shown in the schematic, six pressure gauges were installed to monitor the pressure of suction and discharge lines at the inlet and outlet of each coil, and the temperatures at critical points of the refrigerant lines. The heat pump unit was equipped with two variable speed blower fans.

\subsubsection{Compressor}

The heart of the heat pump is the compressor since it pumps the refrigerant in the system. Its function is to receive the superheated low pressure and temperature refrigerant vapour from the evaporator and compress it into high side pressure and temperature. The compressor used in the unit is a hermetic fixed speed R-290 reciprocating compressor with a constant RPM and displacement of $15.6 \mathrm{cc}$ manufactured by Tecumseh (Model \# AK4482U-XA3B). Its specifications are shown in Table 4-5. The compressor is equipped with a high start torque motor, spark proof relay, start and run capacitors with 115 -volt power supply at $60 \mathrm{~Hz}$.

Table 4-5: Specifications of the R-290 compressor Model AK4482U-XA3B (Tecumseh Products Company LLC, n.d.)

\begin{tabular}{|l|l|}
\hline Type & Hermetic, Single Speed Reciprocating \\
\hline Nominal Capacity & $2.4 \mathrm{~kW}(8240 \mathrm{BTU} / \mathrm{hr})$ \\
\hline Displacement $(\mathrm{cc})$ & 15.63 \\
\hline Oil Type & Polyolester \\
\hline Oil Charge $(\mathrm{cc})$ & 512 \\
\hline Viscosity $(\mathrm{cSt})$ & 32 \\
\hline Motor type & $\mathrm{CSR}, 115 \mathrm{~V} / 60 \mathrm{~Hz}$ \\
\hline
\end{tabular}


The nominal cooling capacity of the selected compressor is rated at $2.4 \mathrm{~kW}(8238 \mathrm{Btu} / \mathrm{h})$ based on the performance under ASHRAE and ARI test conditions (Tecumseh Products Company LLC, n.d.). Table 4-6 depicts the manufacturer compressor performance data sheet.

Table 4-6: Compressor performance data (Tecumseh AK4482U-XA3B)

\begin{tabular}{|c|c|c|c|c|c|}
\cline { 3 - 6 } \multicolumn{2}{c|}{} & \multicolumn{3}{c|}{ Refrigeration Capacity } & Input Power \\
\hline Condition & Test Voltage & Btu/h & $\mathrm{kcal} / \mathrm{h}$ & $\mathrm{W}$ & W \\
\hline ASHRAE & $115 \mathrm{~V} \sim 60 \mathrm{HZ}$ & 8238 & 2076 & 2414 & 840 \\
\hline ASHRAE & $100 \mathrm{~V} \sim 50 \mathrm{HZ}$ & 6700 & 1688 & 1963 & 692 \\
\hline ARI & $115 \mathrm{~V} \sim 60 \mathrm{HZ}$ & 7834 & 1974 & 2295 & 839 \\
& & & & & \\
\hline
\end{tabular}

The performance rating of positive displacement compressors can be determined from the following polynomial equation. The model and constants $\mathrm{C} 1$ to $\mathrm{C} 10$ were obtained from the manufacturer data sheet. These rating calculations are representative of the tabular data for the tests performed in the AHRI Handbook of Low GWP Refrigerants Appendix B (AHRI, 2015).

$$
\begin{aligned}
\mathrm{X}= & \mathrm{C}_{1}+\mathrm{C}_{2}\left(\mathrm{~T}_{\text {evap }}\right)+\mathrm{C}_{4}\left(\mathrm{~T}_{\text {evap }}\right)^{2}+\mathrm{C}_{7}\left(\mathrm{~T}_{\text {evap }}\right)^{3} \\
& +\left(\mathrm{C}_{3}+\mathrm{C}_{5}\left(\mathrm{~T}_{\text {evap }}\right)+\mathrm{C}_{8}\left(\mathrm{~T}_{\text {evap }}\right)^{2}\right)\left(\mathrm{T}_{\text {cond }}\right) \\
& +\left(\mathrm{C}_{6}+\mathrm{C}_{9}\left(\mathrm{~T}_{\text {evap }}\right)\left(\mathrm{T}_{\text {cond }}\right)^{2}+\mathrm{C}_{10}\left(\mathrm{~T}_{\text {cond }}\right)^{3}\right.
\end{aligned}
$$

where:

$$
\begin{aligned}
& \mathrm{C}_{1}-\mathrm{C}_{10}=\text { Equation coefficient, represents compressor performance; } \\
& \mathrm{T}_{\text {evap }} \quad=\text { Evaporator Temperature }\left({ }^{\circ} \mathrm{C},{ }^{\circ} \mathrm{F}\right) ; \\
& \mathrm{T}_{\text {cond }} \quad=\text { Condenser Temperature }\left({ }^{\circ} \mathrm{C},{ }^{\circ} \mathrm{F}\right) ; \text { and }
\end{aligned}
$$

$\mathrm{X}=$ compressor performance (mass flow rate, capacity, power and COP).

The capacity, power input, mass flow rate and coefficient of performance (COP) of the compressor under different operating conditions were obtained from the compressor manufacturer based on the compressor performance equation.

The data was developed in Microsoft Excel. As shown in Figure 4-5, the compressor capacity continues to decline over the evaporating and condensing temperature period. 


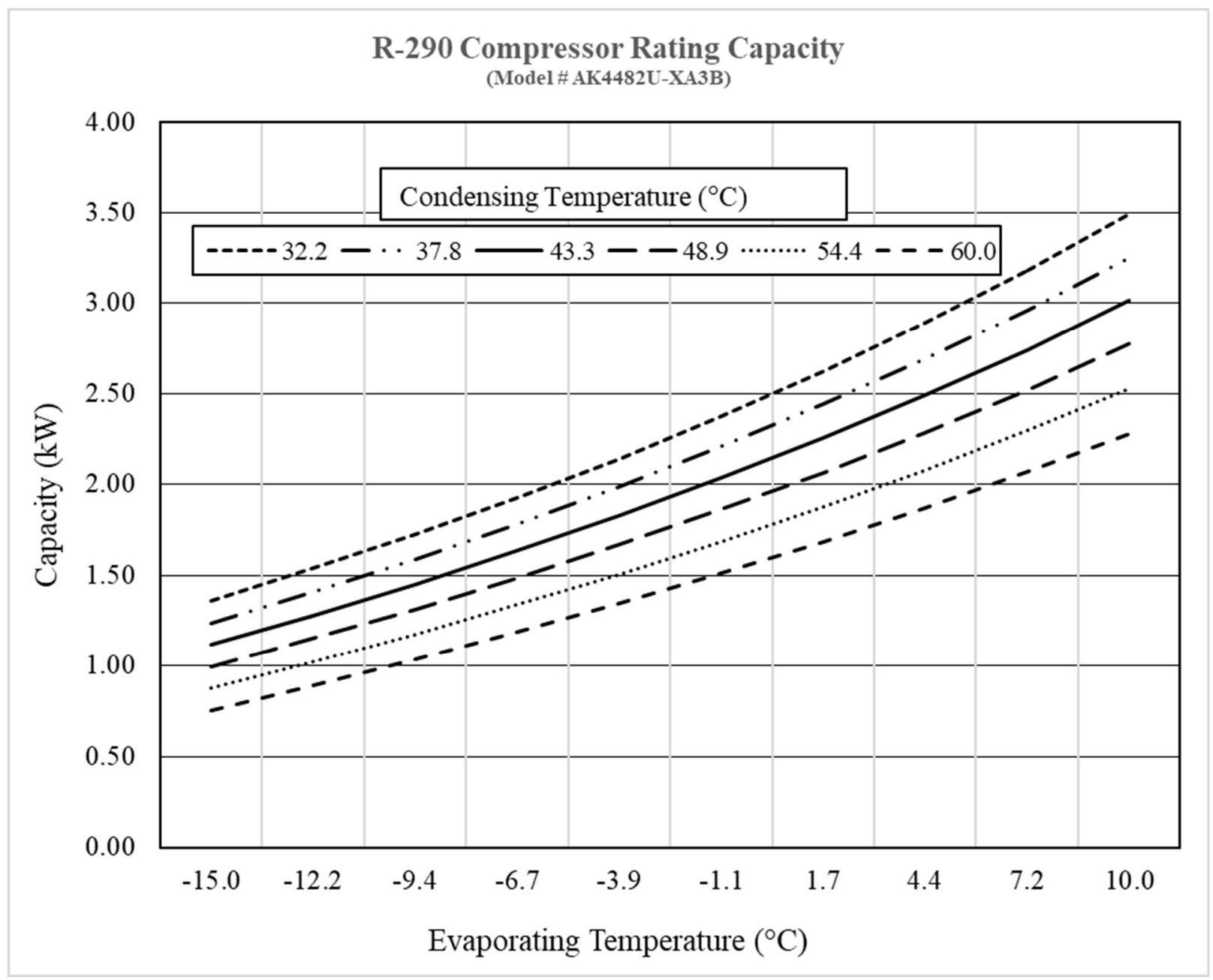

Figure 4-5: Effect of condensing and evaporating temperatures on R-290 compressor capacity

\subsubsection{Thermostatic Expansion Valve (TXV)}

The purpose of the TXV in any refrigeration system is to reduce the pressure of the refrigerant and to regulate the flow of refrigerant to the evaporator by maintaining a nearly constant superheat at the evaporator outlet. A TXV can actively regulate the refrigerant flow by varying its opening extent according to feedback from a sensing bulb installed on the suction line at the outlet of evaporator. The changing pressure from high to low in a TXV is an isenthalpic throttling (constant enthalpy) process (Han, Qu, Ma, Song, \& Ma, 2017). The selected thermostatic valve for the test unit is a bi-flow TXV from Sporlan Valve manufacturer. The model ERVE-1/2-G was 
selected from Sporlan valve selection software which is compatible with R-290 refrigerant. The rating condition and the output of the software is shown in Appendix A, Figure A-1.

\subsubsection{Heat exchangers}

Two fin and tube heat exchangers (aluminum fins/copper tubes) were installed up steams of blower fans in outdoor and indoor units. The nominal tube size of heat exchangers is $5 / 16$ ". In the case of the evaporator or condenser, a 2-phase flow with phase change occurs in the tubes. In cooling and heating modes, refrigerant (R-290) enters the tubes through a distributor and capillary tubes from the lower end of the evaporator and exits from the top end collector tube. Figure 4-6 shows a picture of indoor and outdoor coils.

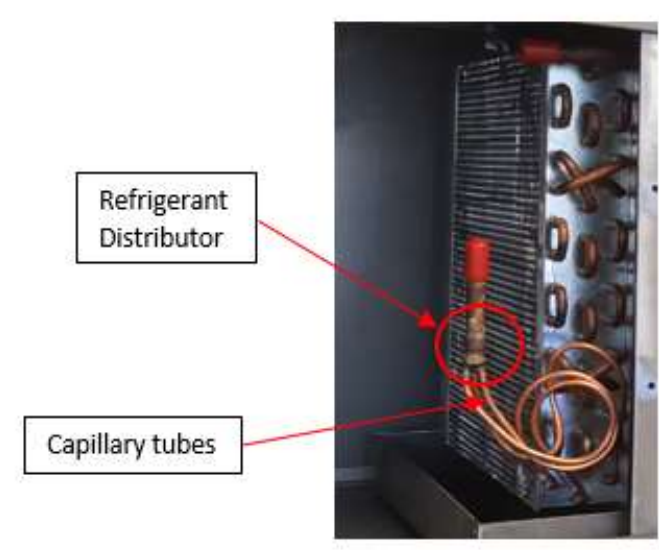

Figure 4-6: Picture of the heat pump heat exchanger 
In the condenser, hot gas propane enters the tubes from the top end and condensed refrigerant leaves from the bottom end of the tubes. Table 4-7 shows the specifications of the heat exchangers. Both heat exchangers were designed with three circuits to minimize the pressure drop across the coils. Refrigerant distributors feed R-290 equally into the passageway to each evaporator circuit.

Table 4-7: Specifications of heat exchangers

\begin{tabular}{|l|l|}
\hline Type & Finned and tube coil \\
\hline Tube material & Copper \\
\hline Fin material & Aluminum \\
\hline Fin thickness (mm) & 0.2 \\
\hline Tube OD (outer diameter) $(\mathrm{mm})$ & 8.2 \\
\hline Tube ID (inner diameter) $(\mathrm{mm})$ & 6.8 \\
\hline Number of tube row & 3 \\
\hline Number of tubes per row & 14 \\
\hline Number of circuits & 3 \\
\hline
\end{tabular}

\subsubsection{Refrigerant piping and accessories}

Refrigerant piping consists of vapour and liquid lines with copper tubes. The copper pipe which transports the liquid refrigerant from the outdoor coil to the indoor coil via a TXV is called the "liquid line" while the pipe which carries the superheated refrigerant from heat exchangers to the compressor is called the "vapour line". Two vapour lines were located in the low-pressure side and the high-pressure side separately. The liquid line is in the high-pressure side. The vapour line has a larger copper tube size as it needs to accommodate larger volumes of refrigerant than the liquid line. A 3/8" O.D. pipe was used for the vapour line while a 1/4" O.D. pipe serves as the liquid line. Refrigerant tubing has been connected by brazing joints to all major components and refrigerant line accessories, i.e., the bi-flow filter dire, three sight glasses, service valves, and access ports. Pressure gauges were connected to piping systems by threaded joints. Special care was taken while installing the pressure gauges as they came with a threaded fitting. Threaded fittings are more susceptible to leaks when high pressure is involved. A layer of Teflon tape was applied over the male joint to prevent potential leaks.

A four-port reversing valve was installed in the lower section of the test unit near the compressor to reverse the direction of flow between cooling and heating mode by a 120 -volt 
solenoid coil. Three sight glasses were installed in the vapour and liquid lines for refrigerant flow observation and indicating the moisture inside the system. A filter drier was also installed in the liquid line to absorb the moisture and contaminants from the refrigerant. Two service valves with gauge service ports were installed in the suction and discharge sides of the compressor for purposes of pressure testing, evacuation, and refrigerant charging.

\subsubsection{Electrical, Controllers and Instrumentation}

The heat pump was equipped with an electrical enclosure at the compressor section. The compressor motor and blower fans were protected with circuit breakers. The compressor motor has an external thermal protector and is protected by high- and low-pressure switches. A potential relay, run and start capacitors were also connected to the compressor motor. Both indoor and outdoor motors are variable speed and their speed can be adjusted by potentiometers that were installed on the electrical panel door.

The heat pump is equipped with a main controller (TC940Ri plus). Three temperature and humidity sensors monitor the condition of air before and after the indoor coil and at the inlet of the outdoor coil. An energy log meter monitors the total power consumption of the heat pump. A selective switch was installed for the manual and automatic start up. In the manual mode, the blower motors, compressor, and solenoid coil of the reversing valve can be energized manually by $\mathrm{ON}$ and OFF switches. An emergency stop was installed on the electric panel for safety. Appendix A, Figure A-2 shows the electrical diagram of the heat pump.

Pressure gauges were installed at the inlet and outlet of each coil, and suction and discharge sides of the compressor to monitor refrigerant line pressures. Standard service ports were installed at the critical points of the refrigerant line for the installation of pressure transducers in the future. Thermocouples with pipe clamp probes were considered for refrigerant line temperature measurement. Electrical components, controllers, and instruments are listed in Table 4-8. 
Table 4-8: Specifications of electrical components, controllers, and instrumentation.

\begin{tabular}{|l|l|}
\hline Controllers & value \\
\hline Main heat pump controller & TC940Ri plus, Ambient and evaporator temperature sensors \\
\hline $\begin{array}{l}\text { Digital controller and indicator } \\
\text { of temperature and humidity }\end{array}$ & $\begin{array}{l}\text { MT-530e Super controller with Humidity and temperature } \\
\text { sensors }\end{array}$ \\
\hline Energy meter & $\begin{array}{l}\text { Energy LOG plus for measuring total Ampere, Voltage and } \\
\text { Power }\end{array}$ \\
\hline Electrical and safety & Modulation variable speed, 120 v input, EC motors RREuG9 \\
\hline Indoor and outdoor fan motors & 120-Volt AC \\
\hline Reversing Valve coil & $\begin{array}{l}\text { Manual/ Auto switch, Heat/Cool Switch, Compressor and fan } \\
\text { switches }\end{array}$ \\
\hline Selective and ON/ OFF switches & Adjusting the speed of EC motors \\
\hline Potentiometer & Disconnect all major loads \\
\hline Emergency stop switch & Potential relay, 4P/DT relays, control relays \\
\hline Relays & Start and Run capacitors \\
\hline Capacitors & $\begin{array}{l}\text { High- and low-pressure switches, Low Side (28 psig, cut in), } \\
\text { High Side (150 psig, cut in) }\end{array}$ \\
\hline Compressor pressure switches \\
\hline Instrumentation & Dwyer / SGY-D11042N \\
\hline Pressure gauges & Pipe clamp adaptor \\
\hline Portable thermocouple &
\end{tabular}

\section{3. $\quad$ Air Side System Design}

The air side of the heat pump was designed for energy recovery in cooling and heating modes. As mentioned earlier, the capacity and COP of the ASHP decreases during the winter when the outdoor temperature drops. It is possible to raise the inlet air through the evaporator in the winter by mixing the cold ambient air with warmer air such as building exhaust air or preheated outdoor air from renewable energy sources. A thermal solar air system, a BIPV/T system, and a thermal energy storage system can be connected to the ASHP as renewable energy systems to enhance the performance of the heat pump in summer and winter. For this purpose, two air dampers were installed at the inlet of the indoor and outdoor sections to connect the unit to the other air sources. 


\subsection{1. $\quad$ Air side system components}

The air side of the prototype unit is included in two sections, the indoor and outdoor units. Both sections were separated from each other by double-wall insulated panels. The components of each unit were the same: two air dampers, a pleated air filter, a fin and tube coil with a condensate pan, and a blower fan assembly. Figure 4-7 shows a picture of the blower fan assembly and the fan outlet. Both blower fans consist of backward blades with modulating EC motors. The speed of the fans can be adjusted by the potentiometers installed on the control panel.

The blower fans present an average volumetric airflow rate of $500 \mathrm{cfm}(850 \mathrm{~m} 3 / \mathrm{h})$ at the static pressure of 1.2 in-WC (300 Pa). Based on the fan curves, with the above air flow and static pressure, each motor consumes only 60 Watts. The inclusion of variable speed fans is beneficial as it allows for testing the heat pump performance under different flow rates for the indoor and outdoor sections. The components of the indoor and outdoor sections are listed in Table 4-9.

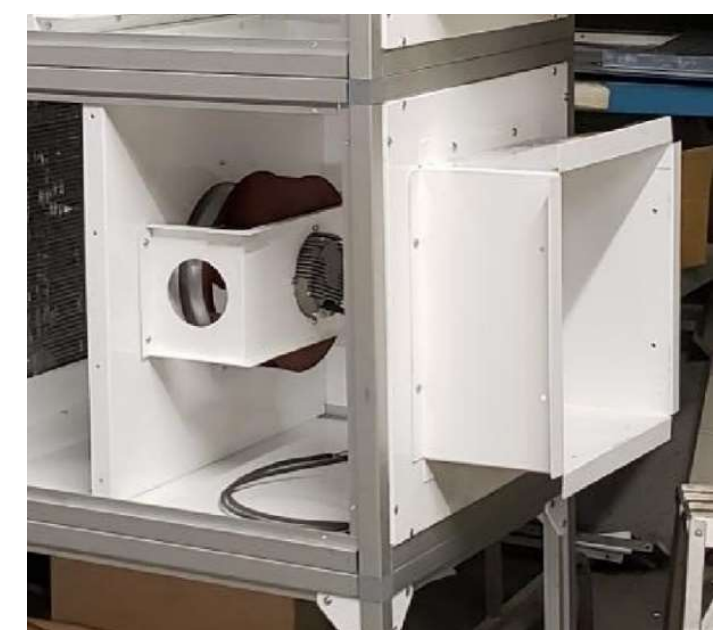

Figure 4-7: Picture of the blower fan, EC motor and fan outlet 
Table 4-9: Specifications of the air side components of the of the tested ASHP.

\begin{tabular}{|c|c|}
\hline Indoor and outdoor units & Value \\
\hline Blower fans (RREuG9) & Backward curve fans, variable speed EC motors \\
\hline Fan opening & 12 x 12 " size connections \\
\hline Indoor and outdoor Coils & $\begin{array}{l}\text { Fin \& tube coils, condensate drain pans and drain pipe } \\
\text { connections }\end{array}$ \\
\hline Air dampers & $\begin{array}{l}12 " \times 12 " \text { size, aluminum parallel blades capable to } \\
\text { connect actuators }\end{array}$ \\
\hline Air filter & Pleated filter size: 18 " x $20 "$ \\
\hline
\end{tabular}

\subsubsection{Heat recovery design}

The design of the air system and inlet dampers provides the advantage of recovering wasted heat from the building's stale air. This will enhance the efficiency of the heat pump. Fresh air can also be distributed throughout the building, while polluted air is exhausted, increasing indoor air quality and comfort. The design of the air duct system allows for bypass of the heat pump and use of only renewable energy sources when the temperature is warm enough to supply the air directly to the building. 


\subsubsection{Example of heat pump Installation}

The prototype ASHP can be installed and connected to the building integrated photovoltaic and solar thermal (BIPV/T) system. Figure 4-8 illustrates the installation of the heat pump unit and air duct connections. The system introduces fresh air from outside to inside the building while simultaneously exhausting the same volume of stale air. The duct system was designed to bypass the $\mathrm{BIPV} / \mathrm{T}$ in the summer.

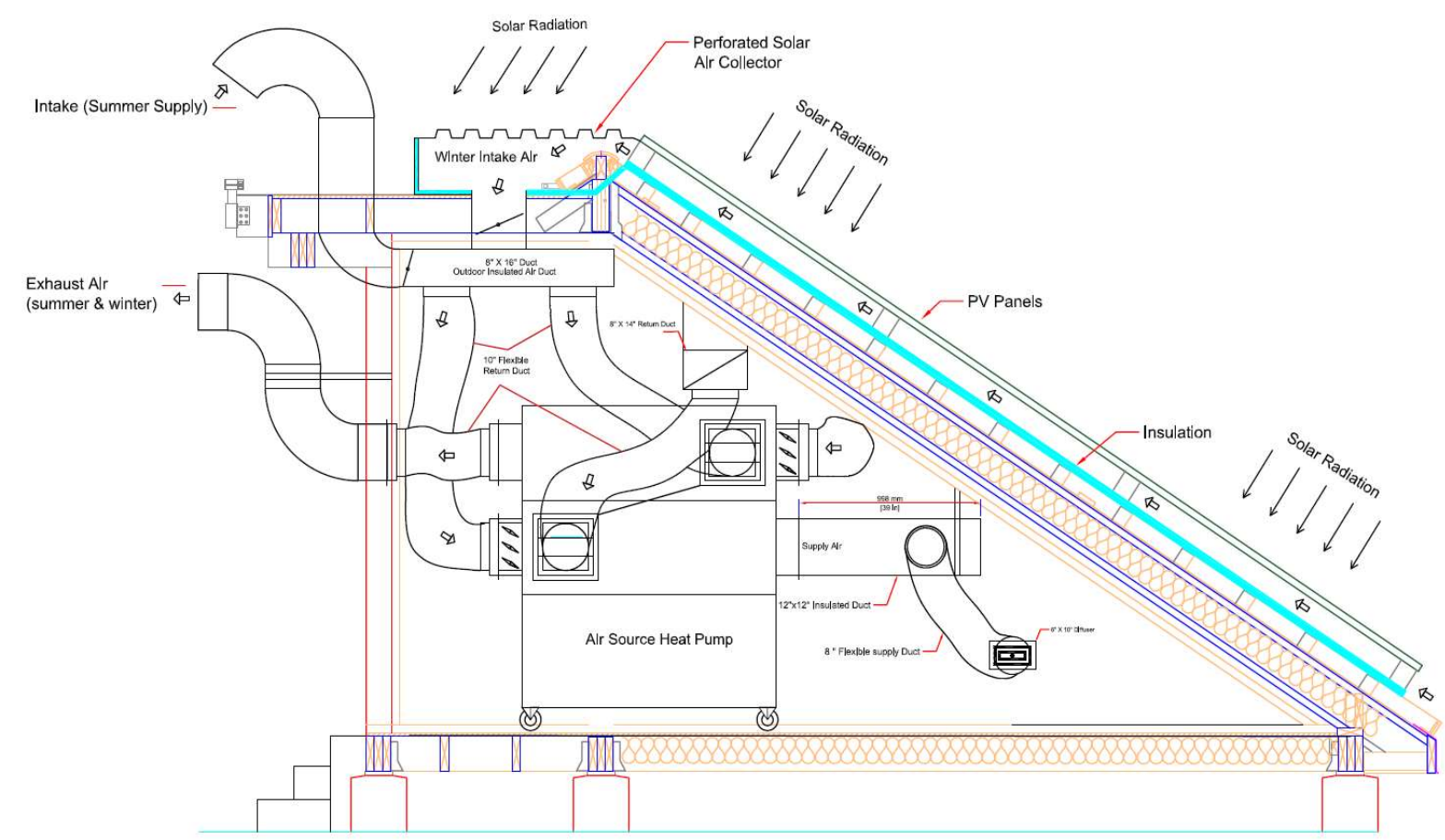

Figure 4-8: Connecting the ASHP prototype to a (BIPV/T) system 


\subsection{Photographic Overview - Construction of the Heat Pump}

The pictures of Figure 4-9 and Figure 4-10 show the construction of the tested heat pump.
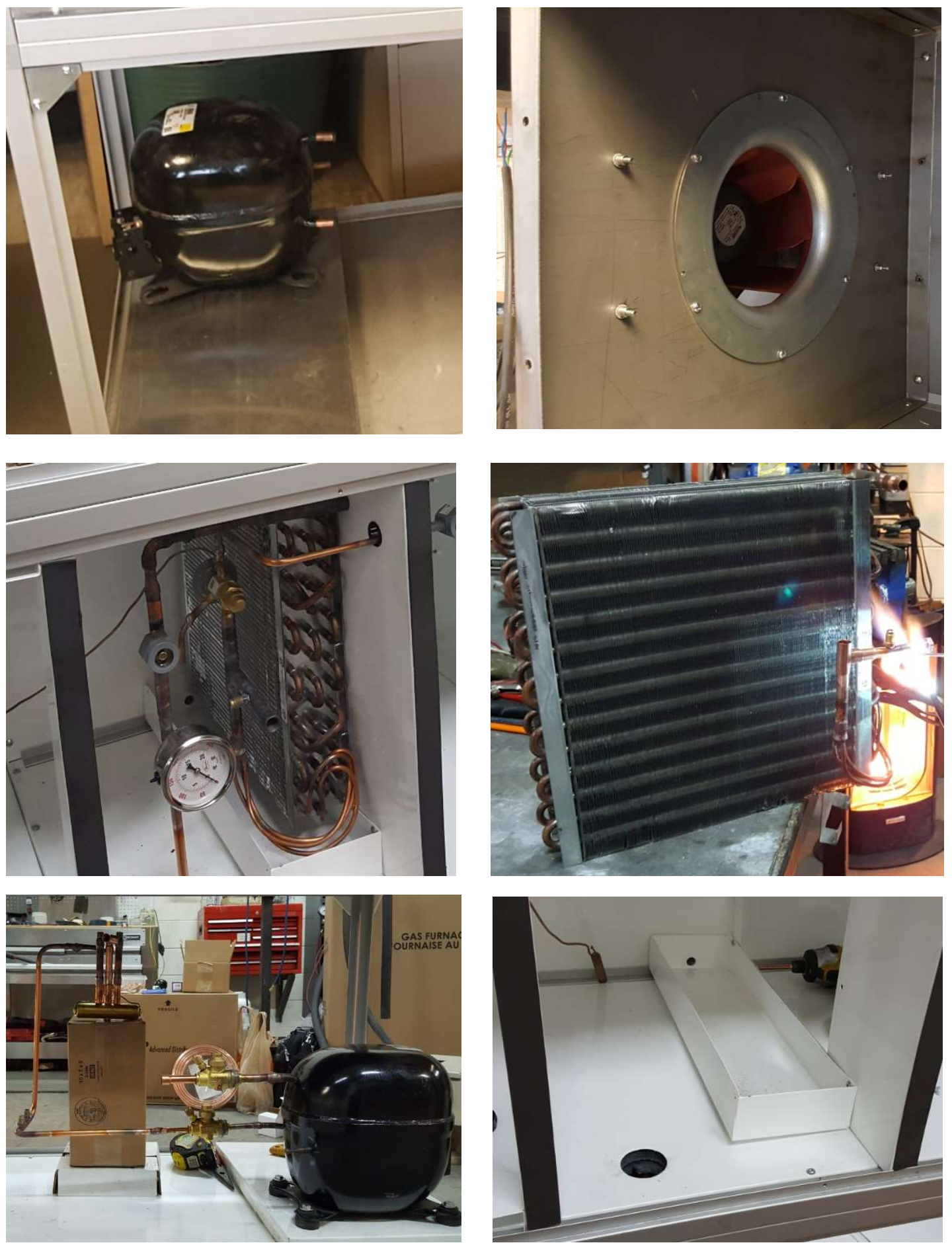

Figure 4-9: Heat Pump Construction - Pictures 1 to 6 

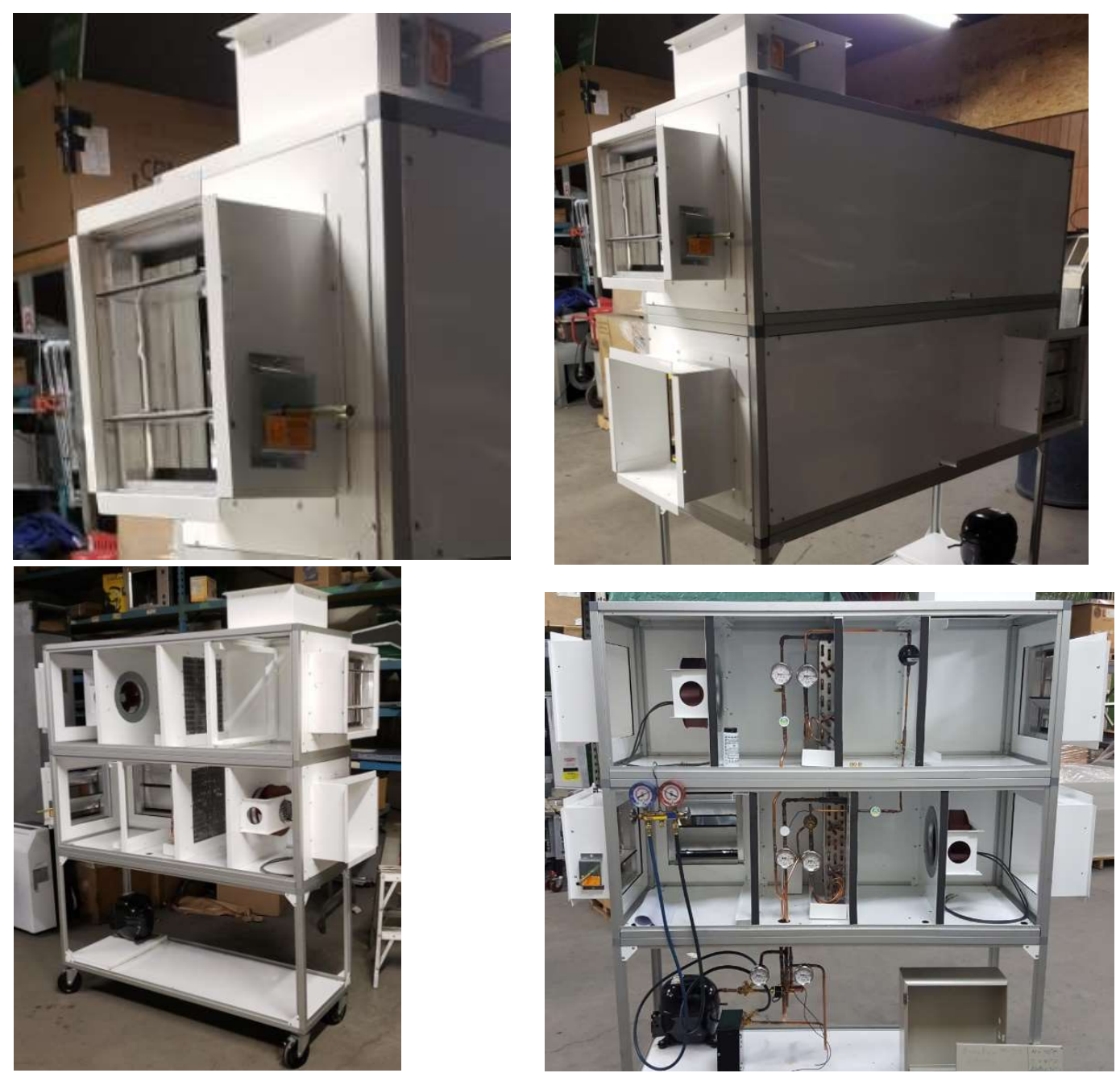

Figure 4-10: Heat Pump Construction - Pictures 7 to 10 


\subsection{Starting Up and Testing the Prototype ASHP}

This section includes reviewing the start up of the tested heat pump unit and explanation of the test procedure and results. The tests of the air conditioning and heat pump units need to be set up at standard rating conditions based on AHRI Standard 210/240 (AHRI, 2017) and ASHRAE standard 37 (ASHRAE, 1978). A psychrometric chamber needs to be connected to the tested unit to supply control dry and wet bulb air temperatures of the indoor and outdoor unit. As of the date of this report, a climatic chamber was not available, and it is not possible to conduct the standard rating conditions. Testing of the ASHP was performed under different evaporating and condensing temperatures of R-290 for both heating and cooling modes. The cooling conditions reflect normal air-conditioning conditions during summer, and an electric heater was used to increase the inlet air of the indoor coil (evaporator). While in the heating mode, conditions reflect normal heat pumping conditions during winter, and the cold ambient air conditions were artificially decreased by reducing the air flow through the outdoor coil (evaporator). Other conditions were performed while changing the air flow of indoor and outdoor fans.

\subsection{Start-Up of the Tested Device}

Because of the flammability issue of the propane refrigerant, starting up and charging the heat pump must be done in a well-ventilated lab. As previously mentioned, the amount of the refrigerant in an ASHP is an important parameter for the energy efficiency. The system was tested with 150 psig pressure of nitrogen before charging R-290. All joints were tested for leaks with spray soapy water and an electronic leak detector. Then the system was evacuated down to 300 microns for 30 minutes. Refrigerant R-290 is a pure fluid and needs to be charged from the vapour side of the refrigerant cylinder. Refrigerant was charged from the suction side of the compressor and the optimum amount of the charge maintained with the subcooling method. The constant superheat was controlled simultaneously by the expansion valve. Charging of the prototype unit was done in the cooling mode when both indoor and outdoor fans were running at the maximum speed. During the charge, the air inlet temperature of the evaporator was set to $26^{\circ} \mathrm{C}$ and the inlet air temperature of the condenser was set to $35^{\circ} \mathrm{C}$. According to AHRI Standard 210/240, the 
blower fans were selected on maximum speed to achieve full air flow with the minimum external static pressure. The indoor airflow rate was measured at the value of $575 \mathrm{cfm}$. The amount of the charge was weighted using a scale. Refrigerant was added to maintain the constant subcooling of $5.6{ }^{\circ} \mathrm{C}\left(10^{\circ} \mathrm{F}\right)$. The refrigerant flow in the liquid line was also observed through the sight glass to check the quality of refrigerant vapour bubbles. The total amount of the charge was recorded at 225 grams. A combustible gas leak detector was used to ensure there were no immediate safety hazards. The operation of the reversing valve was also tested. The reversing valve can be energized by a selector switch installed on the control panel and the heat pump will be operated on the heating mode.

\subsection{Description of Test Setup}

The unit was installed and tested inside the building and the outdoor unit connected to the ambient air by flexible insulated air ducts. Two metal boxes were constructed and connected to the flexible ducts at the inlet of the outdoor unit air damper and the outlet of the blower fan section. Insulated air ducts carried the outside air as the source of heat form the inlet of outdoor unit to the outside. Figure 5-1 shows the ASHP unit during the test. The air flow and temperature through the indoor and outdoor coils were controlled by variable speed fans. An electric heater maintains the required air temperature at the inlet of the indoor coil.

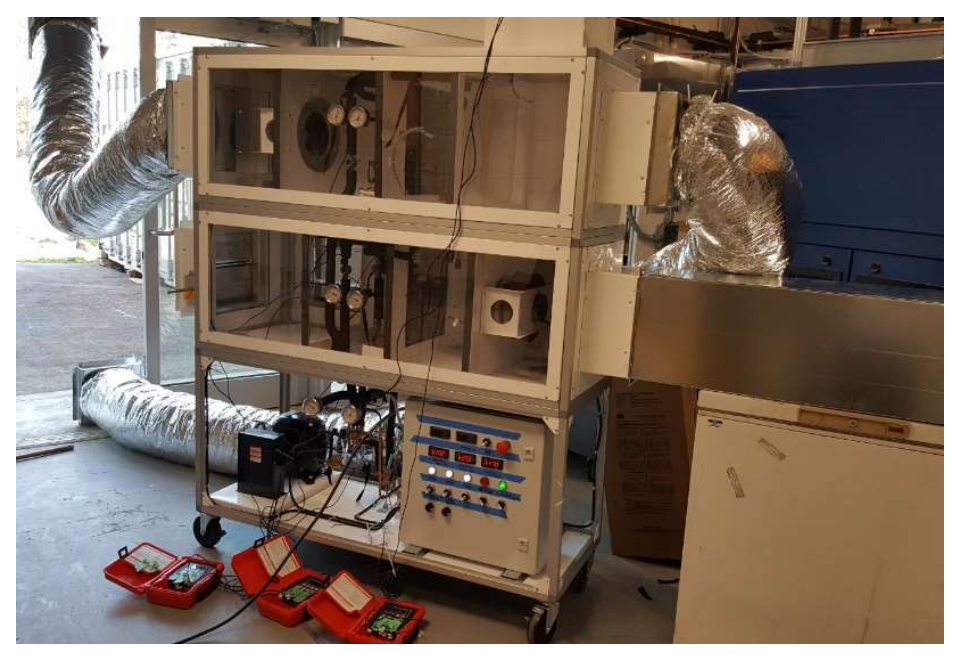

Figure 5-1: Flexible air ducts connecting outdoor unit and thermocouples connected to refrigerant pipes and air side of heat exchangers 
The outside air temperature and electric heater allowed for the attainment of a maximum refrigerant saturation temperature of $55^{\circ} \mathrm{C}$ and a minimum temperature of $-10{ }^{\circ} \mathrm{C}$ at the time of testing. The metrics measured and recorded include suction and discharge pressure levels, refrigerant saturation temperatures of heat exchangers, compressor discharge and suction temperatures, evaporator and condenser inlet and outlet temperatures, air flow, and indoor and outdoor air temperatures.

\subsubsection{Temperature and pressure measurements}

Air and refrigerant side temperatures were measured using digital multi-temperature thermistor instrumentation clamp type probe sensors were installed on critical points of the refrigerant piping and attached to the temperature controller devices. The suction and discharge pressures were measured by a manifold pressure gauge connected to the suction and discharge side of the compressor. Pressure gauges were also installed at the inlet and outlet of each coil and measured the pressure of refrigerant line. The pipe strap probes were tightened to the surface of the refrigerant pipe to measure temperatures. The location of instrumentation is shown in Table 5-1. With the measured pressure and temperature at selected points, the enthalpies and refrigerant properties can be calculated from NIST REFPROP 9.1 (Lemmon et al., 2013) for propane refrigerant.

Table 5-1: Specifications and location of temperature sensors

\begin{tabular}{|l|r|r|l|}
\hline Type of Sensor & $\begin{array}{r}\text { Temperature } \\
\text { Range }\end{array}$ & Accuracy & Location \\
\hline Thermistor Pipe Strap probe & $-25^{\circ}$ to $212^{\circ} \mathrm{F}$ & $\pm 2^{\circ} \mathrm{F}$ & Compressor inlet \\
\hline Thermistor Pipe Strap probe & $-25^{\circ}$ to $212^{\circ} \mathrm{F}$ & $\pm 2^{\circ} \mathrm{F}$ & Compressor outlet \\
\hline Thermistor Pipe Strap probe & $-25^{\circ}$ to $212^{\circ} \mathrm{F}$ & $\pm 2^{\circ} \mathrm{F}$ & Outdoor coil inlet \\
\hline Thermistor Pipe Strap probe & $-25^{\circ}$ to $212^{\circ} \mathrm{F}$ & $\pm 2^{\circ} \mathrm{F}$ & Outdoor coil outlet \\
\hline Thermistor Pipe Strap probe & $-25^{\circ}$ to $212^{\circ} \mathrm{F}$ & $\pm 2^{\circ} \mathrm{F}$ & Indoor coil inlet \\
\hline Thermistor Pipe Strap probe & $-25^{\circ}$ to $212^{\circ} \mathrm{F}$ & $\pm 2^{\circ} \mathrm{F}$ & Indoor coil outlet \\
\hline Thermistor Air Probe $(10 \mathrm{~K})$ & $-40^{\circ}$ to $300^{\circ} \mathrm{F}$ & $\pm 0.3^{\circ} \mathrm{F}$ & Outdoor coil inlet (Air side) \\
\hline Thermistor Air Probe $(10 \mathrm{~K})$ & $-40^{\circ}$ to $300^{\circ} \mathrm{F}$ & $\pm 0.3^{\circ} \mathrm{F}$ & Indoor coil inlet (Air side) \\
\hline Thermistor Air Probe $(10 \mathrm{~K})$ & $-40^{\circ}$ to $300^{\circ} \mathrm{F}$ & $\pm 0.3^{\circ} \mathrm{F}$ & Indoor coil outlet (Air side) \\
\hline
\end{tabular}




\subsubsection{Test procedure}

The general test procedures for air conditioning and heat pump systems are considered based on the standard rating conditions for the determination of heating capacity, cooling capacity, and energy performance. The rating conditions for different climate areas were listed in AHRI 210/240 (AHRI, 2017). In this report, general test conditions similar to AHRI were utilized. In the cooling mode, the inlet temperature of the indoor unit was generated by an electric heater and changing the speed of the blower fan. The different conditions of the heating tests were performed on a cool day. To determine the heat pump performance, all tests have been performed in the steady state. The base case test was started in the cooling mode after charging with the R-290 refrigerant. The temperatures and pressures were recorded after establishing stable conditions. For steady state operation, the measured operating parameters are typically obtained in the last 20 minutes.

The general test procedure was performed, yielding information based on the influence of the different evaporating and condensing temperatures on the system performance. The amounts for the enthalpies, superheat, subcooling and COPs were calculated by NIST REFPROP 9.1 (Lemmon et al., 2013) for propane refrigerant. The heat pump was tested in eight different conditions in the heating mode and five conditions in the cooling mode. The results of the test calculations are shown in Appendix B, Table B-1 and Table B-2 for the cooling mode heat pump tests and for the heating mode tests respectively. In Figure 5-2, the variation in evaporating and condensing temperatures for the tests are plotted in both heating and cooling modes. 


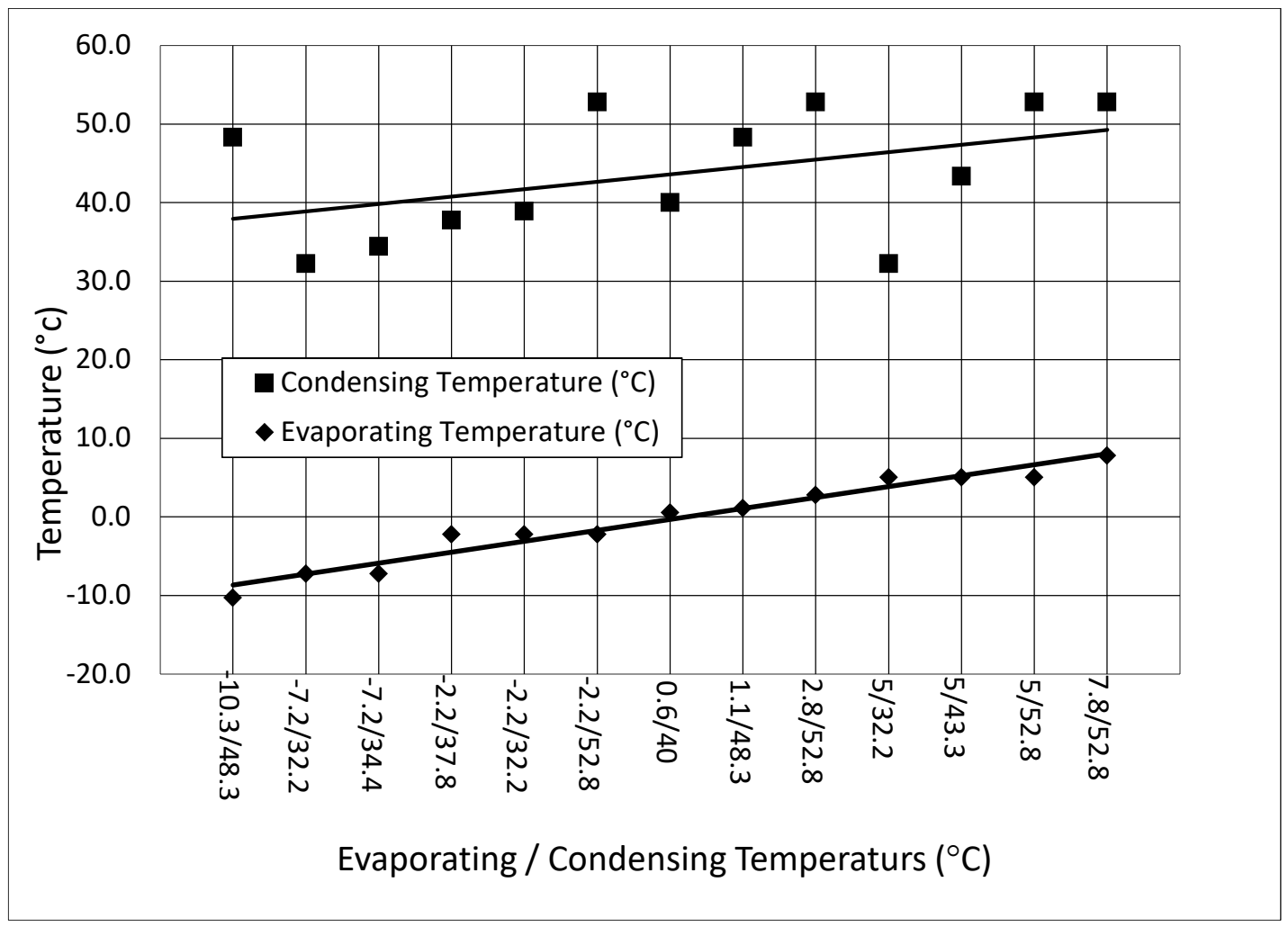

Figure 5-2: R-290 Refrigerant saturation temperatures of the ASHP test unit 


\subsection{Discussion and Results}

\subsubsection{Heating and cooling performance}

The variations of $\mathrm{COP}$ as a function of evaporating and condensing temperatures are shown in Figure 5-3 for heating and cooling modes. The average COPs were calculated at 4.96 for the heating mode and 3.9 for the cooling mode. As mentioned earlier in this report, when outdoor air temperature decreases in the winter, the evaporating temperature and performance of the ASHP decreases. However, the optimum COP depends on both evaporating and condensing temperatures. Figure 5-3 indicates that even in the lower evaporating conditions, maintaining the moderate condensing temperatures will improve the efficiency of the ASHP in winter. This is made possible by mixing the air with the other air sources such as building exhaust air before the heat exchangers.

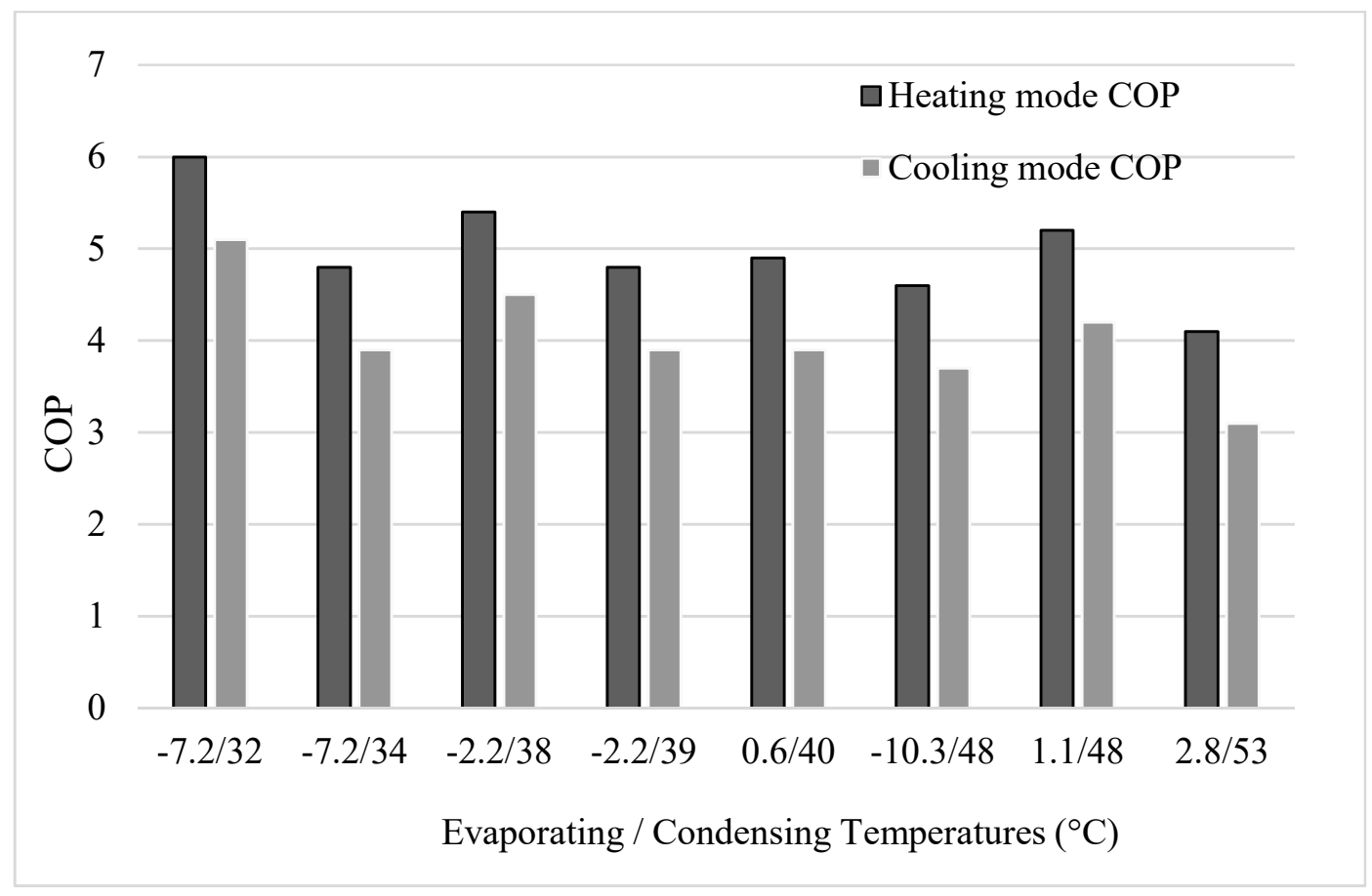

Figure 5-3: Heating and cooling COPs vs. evaporating and condensing temperatures 


\subsubsection{Subcooling and superheat analysis}

A certain amount of superheat and subcooling in the refrigerant line is required for compressor safety and stable operation of the TXV. The TXV controls the degree of superheat at the evaporator outlet by using a sensing bulb. A few degrees of subcooling at the exit of the condenser can improve the performance of the heat pump. In order to analyze the superheat and subcooling of the prototype heat pump unit, thermodynamic calculations were carried out for R290 based on each test series. In the heating mode, the amount of the superheat at the outlet of the evaporator was measured at $4.1^{\circ} \mathrm{C}$ to $6{ }^{\circ} \mathrm{C}$. In the cooling mode, the superheat was measured at 1.1 to $5.6^{\circ} \mathrm{C}$. The average amounts of subcooling were calculated at $8.4{ }^{\circ} \mathrm{C}$ in the cooling mode and $11.9^{\circ} \mathrm{C}$ in the heating mode.

The measurements of superheat and subcooling from the conducted heating tests are presented in Figure 5-4. It can be observed for the R290 system that large superheat and subcooling degrees can have an optimum effect on system performance.

Figure 5-4: Variation of Heating mode COP vs. superheat and subcooling

Superheat \& Subcooling vs. COP

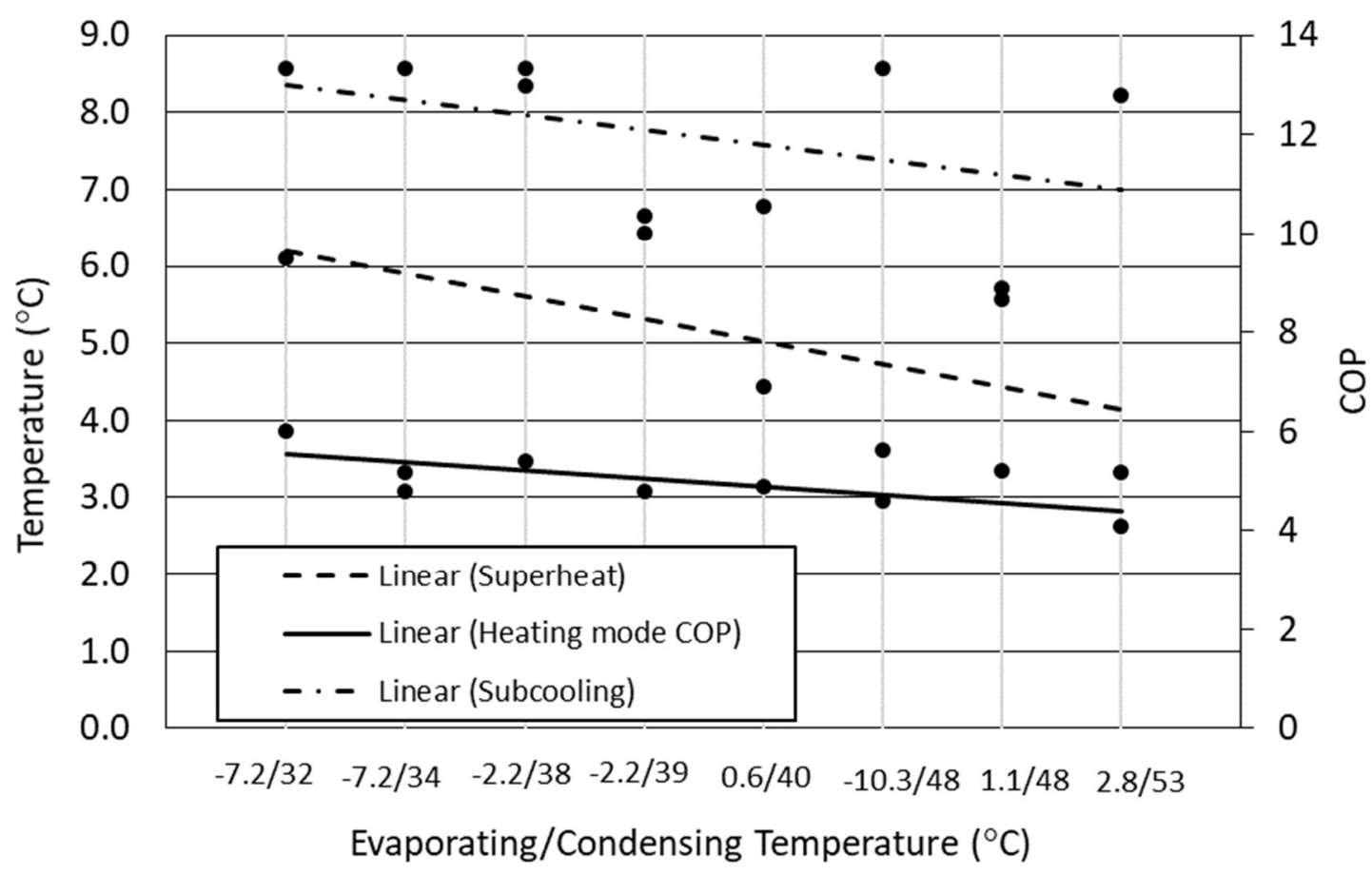




\subsubsection{Compressor performance and discharge temperature effect}

In an ASHP, the capacity of the compressor is as important as COP in an ASHP. Figure 5-5 shows the R-290 compressor capacities under different heating and cooling test series. The compressor used in the test unit is a hermetic reciprocating type compressor which has been originally designed to operate with refrigerant R-290. As seen in Figure 5-5, compressor capacities varied from 1.5 to $2.5 \mathrm{~kW}$. The capacity of the compressor increases as the condensing and evaporating temperatures increase. In Figure 5-6 the compressor discharge temperatures of R-290 were compared with the compression ratio of each test condition. The life time of the compressor and the stability of the refrigerant lubricant can be examined by measuring the compressor discharge temperature.

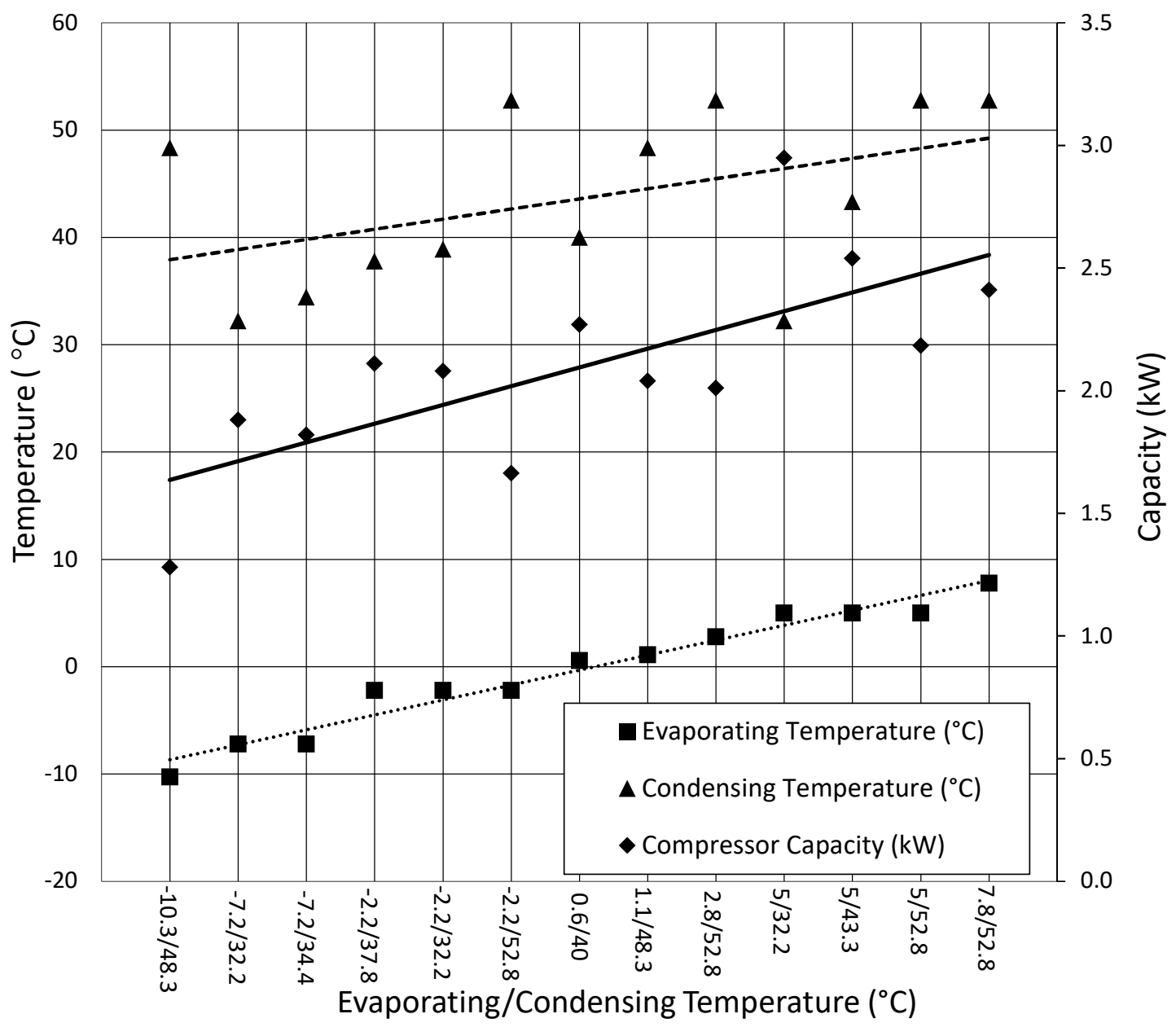

Figure 5-5: R-290 Compressor Capacities of the test unit 


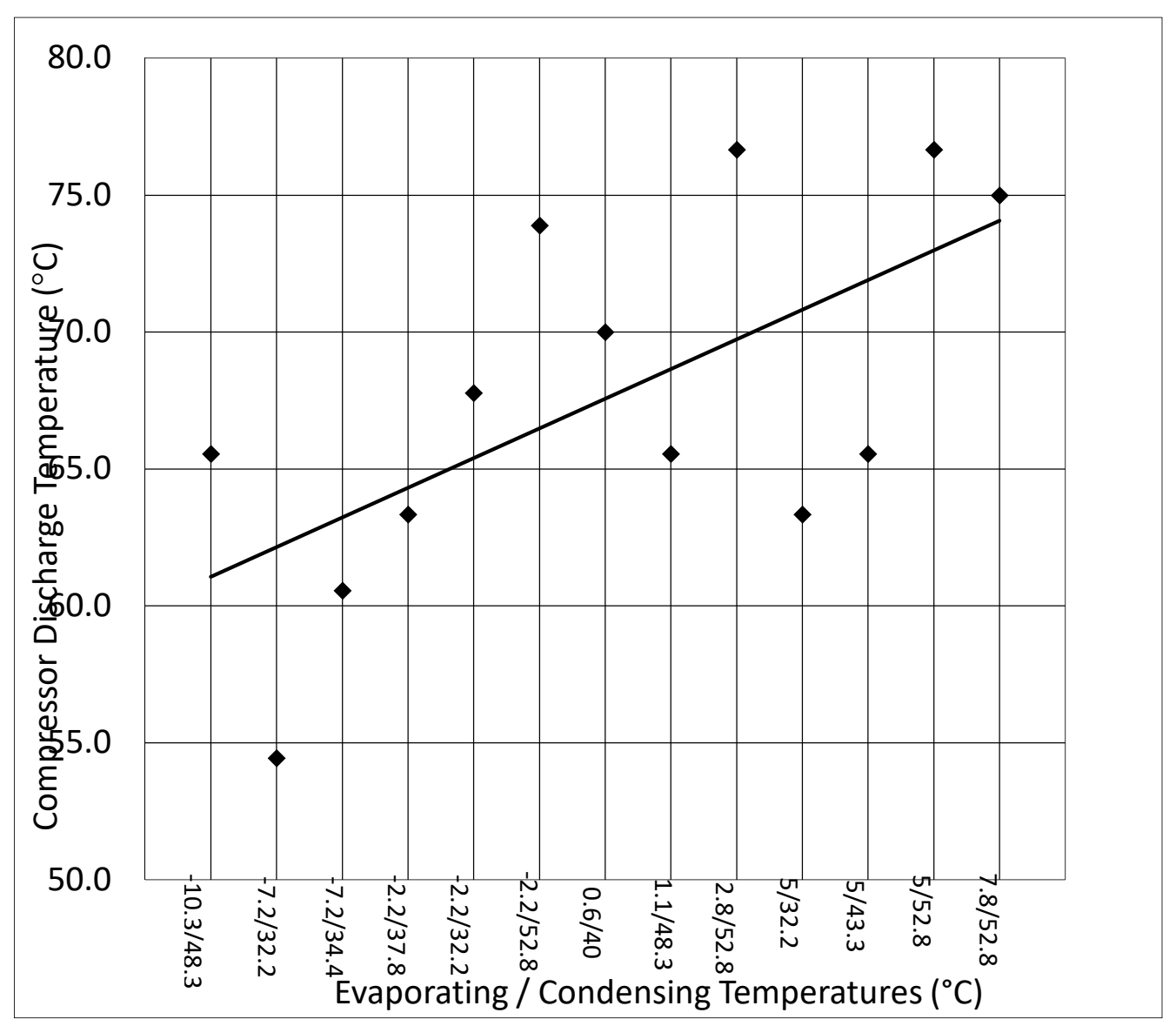

Figure 5-6: Compressor discharge temperatures vs. pressure ratios 


\subsection{Future Work and Recommendation}

Further efforts are needed in order to improve the operation and efficiency of the heat pump test unit. As proposed work, it is recommended to further develop the efficiency with a variable speed R-290 compressor. This will allow the heat pump to modulate the capacity of the compressor by using temperature sensors on the supply side or exhaust side of the indoor and outdoor units. The other option is installing an inverter to the existing compressor for load modulation, which would enhance the COPs. The mass flow rate of refrigerant can also be improved by using electronic expansion valves (EEV).

In order to collect more accurate data from the testing laboratory, the test unit should be equipped with more instrumentation such as temperature, humidity and pressure transducers, and a refrigerant mass flow meter, as well as a control strategy that integrates with the ASHP system. Climatic chambers are also needed to supply the standard testing conditions for indoor and outdoor units

The presented air-side design of the ASHP would be provided additional opportunities by installing and testing the system in a BIPV/T coupled ASHP building exhaust air system for energy efficient homes. 


\subsection{Conclusion}

The objective of this work was to apply and evaluate the possibilities of using low GWP natural R-290 refrigerant in an ASHP and improving the efficiency by using an energy recovery system in a cold climate city such as Toronto. The experiments were conducted in the cooling and heating mode of the test unit to evaluate the thermodynamic performance of the R-290 refrigerant. The experimental testing and theoretical analyses of propane show that this natural refrigerant is suitable for use in ASHPs. The theoretical results showed the capacity and COP of the R-290 refrigerant as equal to or higher than those of other existing HFC and HCFC refrigerants. In addition, the amount of the refrigerant charge and mass flow rate of the propane is significantly lower than for other candidate refrigerants. A major concern about R-290 arises from its flammability, causing risks which must be taken seriously. The risks caused by the flammability of the propane can be reduced by utilizing certain system design elements such as designing it for minimum charge of refrigerant, using low volume heat exchangers, careful leak detection during production and service, using the minimum number of threaded connections, use of spark-proof electric components, and proper ventilation (Palm et al, 2008).

In this project the heat pump test unit was designed, constructed, started up, and tested with propane refrigerant. The amount of the charge was about 225 grams. In the experimental test of the heat pump, evaporating and condensing pressures and temperatures were investigated by considering the Pressure-Enthalpy (PE) chart of propane. The heating and cooling performance and total superheat and subcooling were calculated. Cooling and heating COPs were evaluated based on different rating conditions of evaporating and condensing temperatures. The experimental results showed the average COP of 4.96 for the heating mode and 3.9 for the cooling mode. Based

on the tests, the larger amount of superheat and subcooling degrees can have an optimum effect on system performance. From the view of compressor performance and discharge temperature results, the capacity of the R-290 compressor was calculated at $1.5-2.5 \mathrm{~kW}$. The compressor discharge gas temperatures were measured at $55-77^{\circ} \mathrm{C}$, which is close to the theoretical calculations.

The study shows the viability of the natural R-290 refrigerant ASHP for use in cold temperatures and considers areas for future work to enhance its performance. 


\section{APPENDIX A - ASHP SYSTEM DESIGN}

Table A-1: Suction and Discharge Temperature Condition

(AHRI Handbook of low GWP Refrigerants, 2015)

Table 5.SI: Test Conditions for Compressors and Compressor Units Used In Air Conditioners and Heat Pumps $s^{1,2,4,5}$

\begin{tabular}{|c|c|c|c|c|c|}
\hline \multirow[t]{2}{*}{$\begin{array}{l}\text { Rating } \\
\text { Test } \\
\text { Point }\end{array}$} & \multirow[t]{2}{*}{ Intended Use } & $\begin{array}{l}\text { Suction Dew Point } \\
\text { Temperature }\end{array}$ & $\begin{array}{l}\text { Discharge Dew } \\
\text { Point Temperature }\end{array}$ & $\begin{array}{l}\text { Return Gas } \\
\text { Temperature }\end{array}$ & \multirow[t]{2}{*}{$\begin{array}{l}\text { Capacity } \\
\text { Setting } \\
\text { (Note } 3 \text { ) }\end{array}$} \\
\hline & & ${ }^{\circ} \mathrm{C}$ & ${ }^{\circ} \mathrm{C}$ & ${ }^{\circ} \mathrm{C}$ & \\
\hline A & $\begin{array}{l}\text { Air Source } \\
\text { (Cooling) }\end{array}$ & 7.2 & \begin{tabular}{|c|}
54.4 (standard) $^{6}$ \\
57.2 (high ambient)
\end{tabular} & 18 & MAX \\
\hline B & $\begin{array}{l}\text { Air Source } \\
\text { (Cooling) }\end{array}$ & 7.2 & 46.1 & 18 & MAX \\
\hline $\mathrm{C}$ & $\begin{array}{l}\text { Air Source } \\
\text { (Cooling \& } \\
\text { Heating) }\end{array}$ & 7.2 & 37.8 & 18 & MIN. \\
\hline D & \begin{tabular}{|l}
$\begin{array}{l}\text { Air Source } \\
\text { (Heating) }\end{array}$ \\
\end{tabular} & -1.1 & 43.3 & 10 & MAX \\
\hline $\mathrm{E}$ & $\begin{array}{l}\begin{array}{l}\text { Air Source } \\
\text { (Heating) }\end{array} \\
\end{array}$ & -15 & 35 & 3.9 & MAX \\
\hline $\mathrm{F}$ & $\begin{array}{l}\text { Air Source } \\
\text { (Cooling) }\end{array}$ & 7.2 & 27 & 18 & MIN. \\
\hline $\mathrm{G}$ & $\begin{array}{l}\text { Air Source } \\
\text { (Heating) }\end{array}$ & 1.7 & 32 & 13 & MIN. \\
\hline $\mathrm{H}$ & $\begin{array}{l}\text { Water Source } \\
\text { (Cooling \& } \\
\text { Heating) }\end{array}$ & 7.2 & 48.9 & 18 & $\begin{array}{l}\text { MAX } \\
\& \text { MIN }\end{array}$ \\
\hline \multicolumn{6}{|c|}{$\begin{array}{l}\text { NOTE: } \\
\text { 1) Allowable ambient temperature range surrounding compressors during performance } \\
\text { evaluation testing is to be } 21.1^{\circ} \mathrm{C} \text { to } 35^{\circ} \mathrm{C} \text {. Ambient temperature surrounding the compressor } \\
\text { during baseline testing and low-GWP refrigerants testing is to be within } \pm 3.9^{\circ} \mathrm{C} \text { in all cases. } \\
\text { 2) If airflow across the compressor is used to determine ratings, it shall be specified by the } \\
\text { compressor manufacturer. } \\
\text { 3) The maximum and minimum capacity setting is the highest and lowest displacement capacity } \\
\text { obtainable by the compressor or compressor unit. } \\
\text { 4) } 8.3 \mathrm{~K} \text { degrees of subcooling } \\
\text { 5) Table values are the target operating conditions. } \\
\text { 6) Two discharge dew point temperatures are applied to rating point A. } 54.4^{\circ} \mathrm{C} \text { is the standard } \\
\text { rating condition, and } 57.4^{\circ} \mathrm{C} \text { is the added high ambient condition. }\end{array}$} \\
\hline
\end{tabular}

Performance maps for the baseline and alternative refrigerants shall be created from data obtained during the calorimeter tests and shall be provided with the test results. The polynomial equation that shall be used to represent the tabular data is a third degree equation of ten coefficients in the form of: 
Table A-2: Comparison of $R-22, R-410 A, R-134 A$ and $R-290$

Refrigerants under different condition

\begin{tabular}{|l|r|r|r|r|r|r|r|r|r|r|}
\hline & \multicolumn{9}{|c|}{ R-134a } & \multicolumn{5}{|c|}{ R410a } \\
\hline Evaporator Temperature $\left({ }^{\circ} \mathrm{C}\right)$ & 4.44 & 7.22 & -6.67 & -17.78 & -31.67 & 4.44 & 7.22 & -6.67 & -17.78 & -31.67 \\
\hline Condenser Temperature $\left({ }^{\circ} \mathrm{C}\right)$ & 37.78 & 54.44 & 43.33 & 43.33 & 40.56 & 37.78 & 54.44 & 43.33 & 43.33 & 40.56 \\
\hline Evaporator Outlet Superheat $\left({ }^{\circ} \mathrm{C}\right)$ & 5.56 & 5.56 & 5.56 & 5.56 & 5.56 & 5.56 & 5.56 & 5.56 & 5.56 & 5.56 \\
\hline Compressor Suction Superheat $\left({ }^{\circ} \mathrm{C}\right)$ & 5.56 & 11.11 & 11.11 & 5.56 & 22.22 & 5.56 & 11.11 & 11.11 & 5.56 & 22.22 \\
\hline Subcooling $\left({ }^{\circ} \mathrm{C}\right)$ & 5.56 & 8.33 & 0.00 & 0.00 & 0.00 & 5.56 & 8.33 & 0.00 & 0.00 & 0.00 \\
\hline Suction Pressure (bar) & 3.43 & 3.77 & 2.28 & 1.46 & 0.78 & 9.17 & 9.98 & 6.42 & 4.34 & 2.51 \\
\hline Discharge Pressure (bar) & 9.57 & 14.71 & 11.10 & 11.10 & 10.32 & 22.91 & 33.88 & 26.20 & 26.00 & 24.52 \\
\hline Pressure Ratio & 2.79 & 3.90 & 4.86 & 7.61 & 13.25 & 2.50 & 3.39 & 4.08 & 6.04 & 9.76 \\
\hline $\begin{array}{l}\text { Compressor Discharge Superheat } \\
\left({ }^{\circ} \mathrm{C}\right)\end{array}$ & 61.25 & 86.00 & 79.40 & 80.20 & 105.41 & 72.71 & 102.65 & 97.78 & 103.15 & 136.19 \\
\hline Cooling Efficiency (COP) & 4.98 & 3.22 & 2.69 & 2.05 & 1.44 & 4.63 & 2.58 & 2.45 & 1.89 & 1.34 \\
\hline Heating Efficiency (COP) & 6.16 & 4.42 & 3.87 & 3.12 & 2.64 & 5.78 & 4.05 & 3.62 & 2.96 & 2.51 \\
\hline
\end{tabular}

\begin{tabular}{|l|r|r|r|r|r|r|r|r|r|r|}
\hline & \multicolumn{9}{|c}{ R-22 } & \multicolumn{5}{c|}{ R-290 } \\
\hline Evaporator Temperature $\left({ }^{\circ} \mathrm{C}\right)$ & 4.44 & 7.22 & -6.67 & -17.78 & -31.67 & 4.44 & 7.22 & -6.67 & -17.78 & -31.67 \\
\hline Condenser Temperature $\left({ }^{\circ} \mathrm{C}\right)$ & 37.78 & 54.44 & 43.33 & 43.33 & 40.56 & 37.78 & 54.44 & 43.33 & 43.33 & 40.56 \\
\hline Evaporator Outlet Superheat $\left({ }^{\circ} \mathrm{C}\right)$ & 5.56 & 5.56 & 5.56 & 5.56 & 5.56 & 5.56 & 5.56 & 5.56 & 5.56 & 5.56 \\
\hline Compressor Suction Superheat $\left({ }^{\circ} \mathrm{C}\right)$ & 5.56 & 11.11 & 11.11 & 5.56 & 22.22 & 5.56 & 11.11 & 11.11 & 5.56 & 22.22 \\
\hline Subcooling $\left({ }^{\circ} \mathrm{C}\right)$ & 5.56 & 8.33 & 0.00 & 0.00 & 0.00 & 5.56 & 8.33 & 0.00 & 0.00 & 0.00 \\
\hline Suction Pressure (bar) & 5.73 & 6.25 & 3.98 & 2.67 & 1.53 & 5.42 & 5.88 & 3.85 & 2.64 & 1.57 \\
\hline Discharge Pressure (bar) & 14.53 & 21.46 & 16.61 & 16.61 & 15.55 & 13.00 & 18.85 & 14.77 & 14.77 & 13.87 \\
\hline Pressure Ratio & 2.53 & 3.43 & 4.17 & 6.22 & 10.19 & 2.40 & 3.21 & 3.84 & 5.59 & 8.83 \\
\hline $\begin{array}{l}\text { Compressor Discharge Superheat } \\
\left({ }^{\circ} \mathrm{C}\right)\end{array}$ & 75.90 & 106.30 & 102.69 & 109.46 & 145.13 & 51.80 & 74.00 & 64.64 & 61.82 & 78.93 \\
\hline Cooling Efficiency (COP) & 4.92 & 3.20 & 2.73 & 2.10 & 1.50 & 7.02 & 4.50 & 3.77 & 2.88 & 2.04 \\
\hline Heating Efficiency (COP) & 6.00 & 4.38 & 3.85 & 3.15 & 2.64 & 8.25 & 5.84 & 5.05 & 3.98 & 3.33 \\
\hline
\end{tabular}


Table A-3: R-290 Compressor Performance Sheet

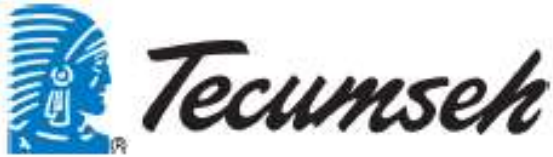

Performance Data Sheet

\section{AK4482U-XA3B}

\section{General Information}

\begin{tabular}{|l|l|l|l|}
\hline Model & AK4482U-XA3B & Refrigerant & R-280 \\
\hline Test Condition & ARI & Performance Test Voltage & $115 \mathrm{~V} \sim 60 \mathrm{HZ}$ \\
\hline Return Gas & $18.3^{\circ} \mathrm{C}\left(65^{\circ} \mathrm{F}\right)$ RETURN GAS & Motor Type & CSR \\
\hline
\end{tabular}

\section{Performance Information}

\begin{tabular}{|c|c|c|c|c|c|c|c|}
\hline \multirow{2}{*}{ Evap Temp ('F) } & \multicolumn{7}{|c|}{ Condensing Temperature $\left({ }^{\circ} \mathrm{F}\right)$} \\
\hline & & 90 & 100 & 110 & 120 & 130 & 140 \\
\hline \multirow{4}{*}{5} & Btuh & 4540 & 4230 & 3620 & 3400 & 2960 & 2570 \\
\hline & Watts & 488 & 515 & 537 & 554 & 567 & 577 \\
\hline & Amps & 5.12 & 5.35 & 5.55 & 5.74 & 5.92 & 6.10 \\
\hline & Loh & 31.0 & 29.4 & 27.9 & 26.3 & 24.5 & 22.6 \\
\hline \multirow{4}{*}{10} & Btulh & 5240 & 4810 & 4370 & 3930 & 3490 & 3050 \\
\hline & Watts & 508 & SAD & 566 & 589 & 609 & 627 \\
\hline & Amps & 5.33 & 5.58 & 5.82 & 6.05 & 6.28 & 6.51 \\
\hline & Loh & 35.1 & 33.6 & 32.0 & 30.4 & 28.6 & 26.6 \\
\hline \multirow{4}{*}{15} & Etuh & 5890 & 5420 & 4960 & 4490 & 4020 & 3540 \\
\hline & Watts & 526 & 562 & 594 & 623 & 649 & 674 \\
\hline & Amps & 5.50 & 5.79 & 6.07 & 6.34 & 6.62 & 6.90 \\
\hline & Lbh & 39.5 & 37.9 & 36.4 & 34.7 & 32.9 & 30.9 \\
\hline \multirow{4}{*}{20} & Btuh & 6580 & 6080 & 5580 & 5070 & 4560 & 4050 \\
\hline & Watts & 542 & 582 & 620 & 654 & 687 & 719 \\
\hline & Amps & 5.64 & 5.96 & 6.28 & 6.60 & 6.93 & 7.27 \\
\hline & Loh & 44.2 & 42.7 & 41.1 & 39.4 & 37.5 & 35.4 \\
\hline \multirow{4}{*}{25} & Etwh & 7310 & 6780 & 6240 & 5690 & 5140 & 4590 \\
\hline & Watts & 556 & 601 & 643 & 684 & 723 & 762 \\
\hline & Amps & 5.75 & 6.11 & 6.47 & 6.84 & 7.22 & 7.61 \\
\hline & LDin & 49.3 & 47.8 & 46.1 & 44.3 & 424 & $\Delta 0.2$ \\
\hline \multirow{4}{*}{30} & Btuh & 8110 & 7530 & 6940 & 6350 & 5750 & 5150 \\
\hline & Watts & 567 & 616 & 664 & 710 & 756 & 803 \\
\hline & Amps & 5.84 & 6.24 & 6.64 & 7.05 & 7.49 & 7.94 \\
\hline & Loh & 54.9 & 53.3 & 51.6 & 49.7 & 47.6 & 45.3 \\
\hline \multirow{4}{*}{35} & Btwh & 8960 & 8330 & 7690 & 7050 & 6400 & 5750 \\
\hline & Watts & 575 & 629 & 682 & 734 & 787 & 841 \\
\hline & Amps & 5.91 & 6.34 & 6.79 & 7.25 & 7.74 & 8.25 \\
\hline & Lbin & 60.9 & 59.2 & 57.4 & 55.5 & 53.3 & 50.8 \\
\hline \multirow{4}{*}{40} & Btuh & 9870 & 9190 & 8500 & 7800 & 7090 & 6380 \\
\hline & Watts & 581 & 640 & 697 & 756 & 815 & 876 \\
\hline & Amps & 5.96 & 6.43 & 6.92 & 7.43 & 7.98 & 8.55 \\
\hline & Loh & 67.5 & 65.7 & 63.8 & 61.7 & 59.4 & 56.8 \\
\hline
\end{tabular}


Table A-3: R-290 Compressor Performance Sheet (Continued)

\begin{tabular}{|c|c|c|c|c|c|c|c|}
\hline \multirow{4}{*}{45} & Etwh & 10900 & 10100 & 9360 & 8600 & 7830 & 7060 \\
\hline & Watts & 585 & 647 & 710 & 774 & 840 & 908 \\
\hline & Amps & 5.96 & 6.50 & 7.03 & 7.60 & 8.20 & 8.84 \\
\hline & Lbin & 74.6 & 72.7 & 70.7 & 68.5 & 66.0 & 63.2 \\
\hline \multirow{4}{*}{50} & Btwh & 11900 & 11100 & 10300 & 9460 & 8620 & 7780 \\
\hline & Watts & 585 & 652 & 720 & 790 & 862 & 937 \\
\hline & Amps & 5.99 & 6.55 & 7.13 & 7.75 & 8.41 & 9.11 \\
\hline & Lbin & 82.3 & 80.3 & 78.1 & 75.8 & 73.1 & 70.2 \\
\hline \multirow{4}{*}{55} & Btun & 13000 & 12200 & 11300 & 10400 & 9470 & 8550 \\
\hline & Watts & 582 & 654 & 727 & 803 & 881 & 964 \\
\hline & Amps & 5.98 & 6.59 & 7.22 & 7.89 & 8.61 & 9.38 \\
\hline & Loh & 90.6 & 88.5 & 86.2 & 83.6 & 80.8 & 77.7 \\
\hline
\end{tabular}

\begin{tabular}{|c|c|c|c|c|}
\hline COEFFICIENTS & CAPACITY & POWER & CURRENT & MASS FLOW \\
\hline$C 1$ & $7.577640 E+03$ & $-1.051296 E+02$ & $1.073960 E+00$ & $4.855348 E+01$ \\
\hline$C 2$ & $1.287379 E+02$ & $2.558157 E+00$ & $4.643514 E-02$ & $5.209864 E-01$ \\
\hline$C 3$ & $-3.811768 E+01$ & $1.109983 E+01$ & $7.128838 E-02$ & $-3.608257 E-01$ \\
\hline$C 4$ & $1.575882 E+00$ & $-3.368044 E-02$ & $-9.481062 E-04$ & $7.329594 E-03$ \\
\hline$C 5$ & $-1.265212 E-01$ & $-3.955976 E-02$ & $-4.441752 E-04$ & $3.978254 E-03$ \\
\hline$C 6$ & $-1.187911 E-02$ & $-6.266037 E-02$ & $-4.031337 E-04$ & $2.277810 E-03$ \\
\hline$C 7$ & $6.041071 E-03$ & $-1.606336 E-04$ & $2.624856 E-06$ & $5.623314 E-05$ \\
\hline$C 6$ & $-1.048816 E-02$ & $-2.652819 E-05$ & $2.765958 E-06$ & $-3.305625 E-05$ \\
\hline$C 9$ & $-9.136068 E-04$ & $6.884581 E-04$ & $5.428134 E-06$ & $-1.662154 E-05$ \\
\hline$C 10$ & $3.300543 E-05$ & $1.115359 E-04$ & $9.125369 E-07$ & $-7.683025 E-06$ \\
\hline
\end{tabular}

Value $=\mathrm{C}_{1}+\mathrm{C} 2^{*} \mathrm{Te}+\mathrm{C} 4^{*} \mathrm{Te}^{\wedge} 2+\mathrm{C} 7^{*} \mathrm{Te}^{\wedge} 3+\left(\mathrm{C} 3+\mathrm{C} 5^{*} \mathrm{Te}+\mathrm{C} 8^{*} \mathrm{Te}^{\wedge} 2\right)^{*} \mathrm{Tc}+\left(\mathrm{C} 8+\mathrm{C} 9^{*} \mathrm{Te}^{\wedge} \mathrm{Tc}^{\wedge} 2+\mathrm{C} 10^{*} \mathrm{Tc} c^{\wedge}\right.$

Te = Evaporator Temperature

Tc = Condensing Temperature

THERMOSTATIC EXPANSION VALVE SELECTION DATA

(Using NIST RefProp DLL)

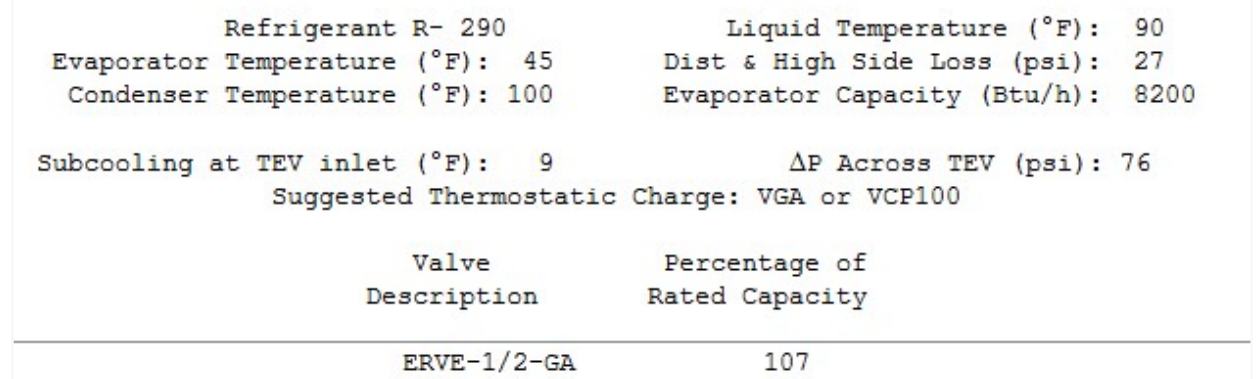

Figure A-1: TXV selection (Sporlan Valve selection program v5) 


\section{ASHP ELECTRICAL SCHEMATIC}

Controllers
\begin{tabular}{|c|l|l|c|}
\hline & Itern & \multicolumn{1}{|c|}{ Functlon } & QTY \\
\hline 1 & TC-940IL Plus & Maln Heat pump Controller & 1 \\
\hline 2 & MT-530 E Super & Humldity \& temperature Dlsplay & 3 \\
\hline 3 & Energy Log Plus & Energy MonHor Dlsplay & 1 \\
\hline 4 & TCP -485 WIFI & RS 485 Interface & 1 \\
\hline
\end{tabular}

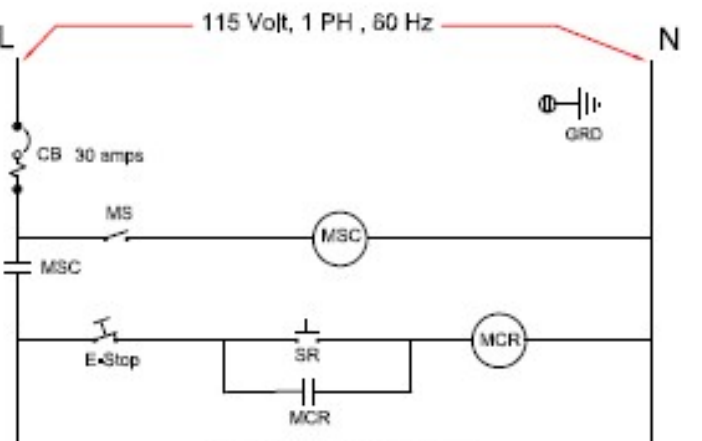

LEGEND

\begin{tabular}{|c|c|}
\hline MS & ON/OFF Maln Power Swtich \\
\hline MSC & Maln Swleh Contractor \\
\hline MCR & Maln Swltch Relay (4PDT) \\
\hline$E-s t o p$ & Emergency Stop \\
\hline SR & Pushbutton NO with LED \\
\hline Comp & Compressar \\
\hline RV & Reversing valve \\
\hline IFM & Indoor Fan Motor \\
\hline OFM & Outdose Fan Mator \\
\hline RVS & Heat / Cool Selective switch \\
\hline $\mathrm{c}$ & Compressor relay \\
\hline SR & Selectlve Relay ( $4 \rho d v 120$ volt) \\
\hline IFR & Indoor Fan Relay \\
\hline OFR & Outdoor Fan Relay \\
\hline cs & Compressor Start Swltch \\
\hline SR1-4 & Selectlve relay contacts \\
\hline IFS & Indoor Fan Swlich \\
\hline OFS & Outdoor Fan Swltch \\
\hline $\mathrm{CH}$ & Crankcase heater \\
\hline HP & Hlgh pressure Swl:ch \\
\hline LP & Low pressure Swlich \\
\hline P3S & Manual / Auto Selectlve swltch \\
\hline GN & Green Lamp \\
\hline $\mathrm{RD}$ & Red Lamp \\
\hline $\mathrm{CB}$ & Clrcult Breaker \\
\hline
\end{tabular}

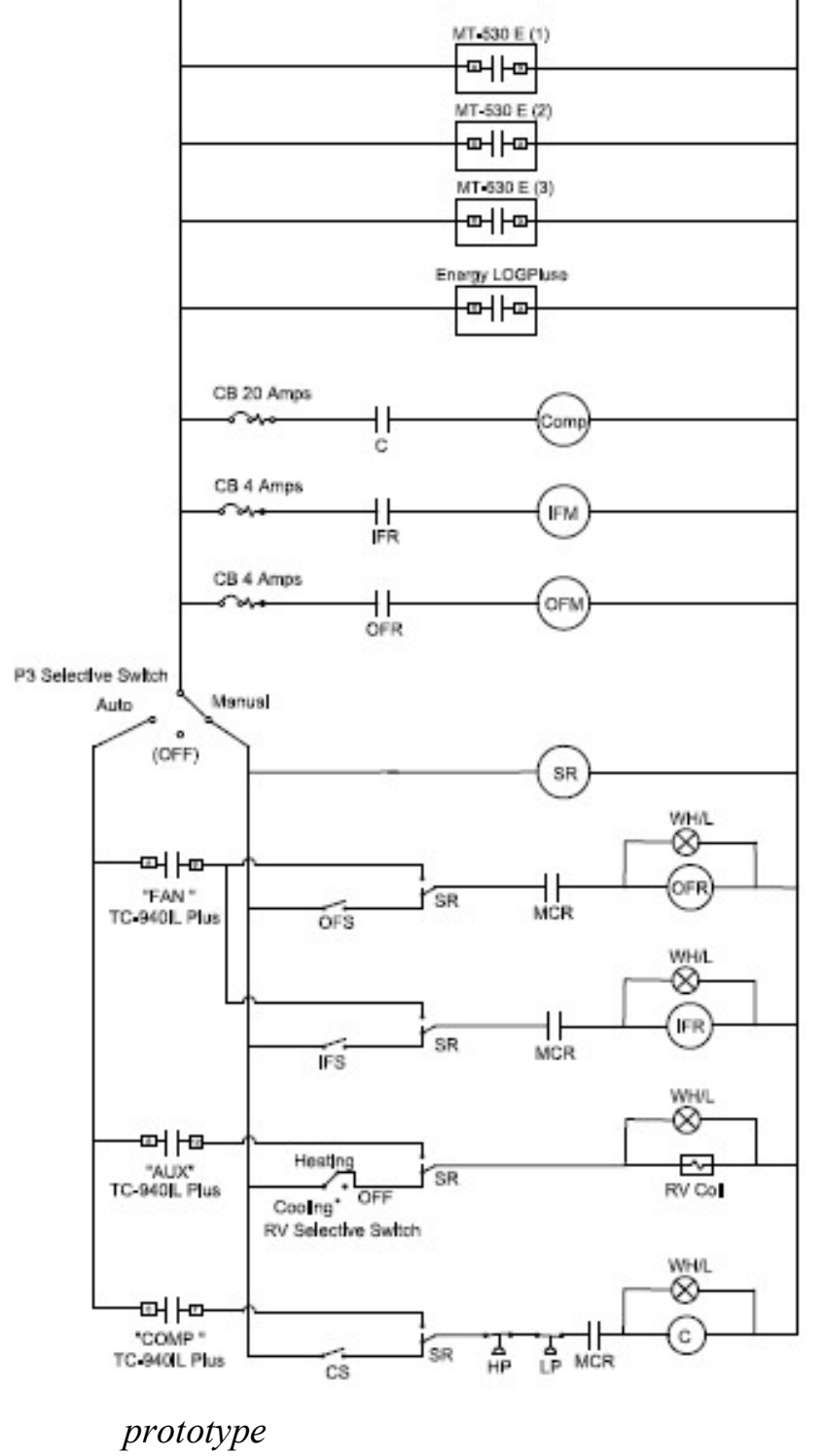

Figure A-2: Electrical Diagram of the heat pump prototype 


\section{APPENDIX B - ASHP TEST RESULTS AND CONDITIONS}

Table B-1. Cooling performance of the test heat pump with R290 working fluids

\begin{tabular}{|c|c|c|c|c|c|c|c|c|c|c|}
\hline \multirow[b]{3}{*}{ Refrigerant and air side data } & \multicolumn{10}{|c|}{ Cooling Performance (IP Units) } \\
\hline & \multicolumn{2}{|c|}{ TEST 1} & \multicolumn{2}{|c|}{ TEST 2} & \multicolumn{2}{|c|}{ TEST 3} & \multicolumn{2}{|c|}{ TEST 4} & \multicolumn{2}{|c|}{ TEST 5} \\
\hline & $\mathrm{T}\left({ }^{\circ} \mathrm{F}\right)$ & $P$ (psig) & $\mathrm{T}\left({ }^{\circ} \mathrm{F}\right)$ & $P$ (psig) & $\mathrm{T}\left({ }^{\circ} \mathrm{F}\right)$ & P (psig) & $\mathrm{T}\left({ }^{\circ} \mathrm{F}\right)$ & $\mathrm{P}$ (psig) & $\mathrm{T}\left({ }^{\circ} \mathrm{F}\right)$ & $P$ (psig) \\
\hline Compressor Suction & 41 & 65 & 41 & 65 & 41 & 65 & 46 & 72 & 28 & 50 \\
\hline Compressor Discharge & 90 & 150 & 110 & 200 & 127 & 250 & 127 & 250 & 127 & 250 \\
\hline Condenser Inlet & 137 & & 142 & & 161 & & 158 & & 152 & \\
\hline Condenser Outlet & 80 & & 102 & & 118 & & 123 & & 116 & \\
\hline Subcooling & 10 & & 8 & & 9 & & 4 & & 11 & \\
\hline Evaporator Inlet & 46 & & 46 & & 48 & & 52 & & 30 & \\
\hline Evaporator Outlet & 61 & & 58 & & 55 & & 61 & & 30 & \\
\hline Evaporator Superheat & 20 & & 17 & & 14 & & 15 & & 2 & \\
\hline Compressor inlet (RGT) & 66 & & 66 & & 63 & & 67 & & 46 & \\
\hline Compressor outlet & 146 & & 150 & & 170 & & 167 & & 165 & \\
\hline Suction line Superheat & 5 & & 8 & & 8 & & 6 & & 16 & \\
\hline Indoor air inlet & 70 & & 66 & & 74 & & 75 & & 41 & \\
\hline Indoor air outlet & 60 & & 56 & & 56 & & 60 & & 66.5 & \\
\hline Air temperature Difference & 10 & & 10 & & 18 & & 15 & & & \\
\hline Outdoor air Inlet & 60 & & 52 & & 58 & & 57 & & 57 & \\
\hline Enthalpy $1^{*}$ (Compressor inlet) & 260.39 & & 260.39 & & 259.1 & & 260.05 & & 253.63 & \\
\hline Enthalpy 2 (Compressor outlet) & 289.22 & & 286.76 & & 292.81 & & 291.15 & & 290.05 & \\
\hline Enthalpy 2a (Condenser inlet) & 284.78 & & 282.56 & & 287.82 & & 286.15 & & 282.77 & \\
\hline Enthalpy 3 (Condenser outlet) & 116.01 & & 130.73 & & 141.92 & & 145.57 & & 140.47 & \\
\hline Enthalpy 4 (Evaporator inlet) & 116.01 & & 130.73 & & 141.92 & & 145.57 & & 140.47 & \\
\hline Enthalpy 1a (Evaporator outlet) & 258.24 & & 256.96 & & 255.67 & & 257.45 & & 247.02 & \\
\hline Condenser effect (CE) & 168.77 & & 151.83 & & 145.9 & & 140.58 & & 142.3 & \\
\hline Net refrigerant effect (NRE) & 142.23 & & 126.23 & & 113.75 & & 111.88 & & 106.55 & \\
\hline Heat of Compression (HOC) & 28.83 & & 26.37 & & 33.71 & & 31.1 & & 36.42 & \\
\hline COP (Cooling) & 4.9 & & 4.8 & & 3.4 & & 3.6 & & 2.9 & \\
\hline
\end{tabular}

* btu/hr 
Table B-2: Heating performance of the heat pump with R290 as working fluid

\begin{tabular}{|c|c|c|c|c|c|c|c|c|c|c|c|c|c|c|c|c|}
\hline \multirow[b]{3}{*}{$\begin{array}{l}\text { Refrigerant and air side } \\
\text { data }\end{array}$} & \multicolumn{16}{|c|}{ Heating Performance (IP Units) } \\
\hline & \multicolumn{2}{|c|}{ TEST 1} & \multicolumn{2}{|c|}{ TEST 2} & \multicolumn{2}{|c|}{ TEST 3} & \multicolumn{2}{|c|}{ TEST 4} & \multicolumn{2}{|c|}{ TEST 5} & \multicolumn{2}{|c|}{ TEST 6} & \multicolumn{2}{|c|}{ TEST 7} & \multicolumn{2}{|c|}{ TEST 8} \\
\hline & $\begin{array}{l}\mathrm{T} \\
\left({ }^{\circ} \mathrm{F}\right) \\
\end{array}$ & $\begin{array}{l}\text { P } \\
\text { (psig) } \\
\end{array}$ & $\mathrm{T}\left({ }^{\circ} \mathrm{F}\right)$ & $\begin{array}{l}\text { P } \\
\text { (psig) }\end{array}$ & $\mathrm{T}\left({ }^{\circ} \mathrm{F}\right)$ & $\begin{array}{l}\text { P } \\
\text { (psig) } \\
\end{array}$ & $\mathrm{T}\left({ }^{\circ} \mathrm{F}\right)$ & $\begin{array}{l}\text { P } \\
\text { (psig) }\end{array}$ & $\mathrm{T}\left({ }^{\circ} \mathrm{F}\right)$ & $\begin{array}{l}\text { P } \\
\text { (psig) } \\
\end{array}$ & $\mathrm{T}\left({ }^{\circ} \mathrm{F}\right)$ & $\begin{array}{l}\text { P } \\
\text { (psig) } \\
\end{array}$ & $\mathrm{T}\left({ }^{\circ} \mathrm{F}\right)$ & $\begin{array}{l}\text { P } \\
\text { (psig) }\end{array}$ & $\mathrm{T}\left({ }^{\circ} \mathrm{F}\right)$ & $\begin{array}{l}\mathbf{P} \\
\text { (psig) }\end{array}$ \\
\hline Compressor Suction & 28 & 50 & 33 & 55 & 34 & 57 & 37 & 60 & 13.5 & 35 & 28 & 50 & 19 & 40 & 19 & 40 \\
\hline Compressor Discharge & 102 & 180 & 104 & 185 & 119 & 225 & 127 & 250 & 119 & 225 & 100 & 175 & 94 & 160 & 90 & 150 \\
\hline Condenser Inlet & 140 & & 143 & & 140 & & 157 & & 132 & & 131 & & 122 & & 114 & \\
\hline Condenser Outlet & 84 & & 85 & & 103 & & 104 & & 95 & & 76 & & 70 & & 66 & \\
\hline Expansion Device Inlet & 84 & & 85 & & 103 & & 104 & & 95 & & 76 & & 70 & & & \\
\hline Subcooling & 18 & & 19 & & 16 & & 23 & & 24 & & 24 & & 24 & & 24 & \\
\hline Evaporator Inlet & 32 & & 33 & & 39 & & 39 & & 21 & & 31 & & 15 & & 20 & \\
\hline Evaporator Outlet & 40 & & 41 & & 44 & & 43 & & 20 & & 43 & & 25 & & 30 & \\
\hline Evaporator Superheat & 12 & & 8 & & 10 & & 6 & & 6.5 & & 15 & & 6 & & 11 & \\
\hline Compressor inlet (RGT) & 53 & & 49 & & 53 & & 52 & & 38 & & 52 & & 37 & & 43 & \\
\hline Compressor outlet & 154 & & 158 & & 150 & & 170 & & 150 & & 146 & & 141 & & 130 & \\
\hline Suction line Superheat & 13 & & 8 & & 9 & & 9 & & 18 & & 9 & & 12 & & 13 & \\
\hline Indoor air inlet & 74.5 & & 74 & & 77 & & 77 & & 65 & & 70 & & 69 & & 55 & \\
\hline Indoor air outlet & 89 & & 91 & & 109 & & 112 & & 78 & & 82 & & 78 & & 75 & \\
\hline $\begin{array}{l}\text { Air temperature } \\
\text { Difference }\end{array}$ & 14.5 & & 17 & & 32 & & 35 & & 13 & & 12 & & 9 & & 20 & \\
\hline Outdoor air Inlet & 56.5 & & 57 & & 58 & & 58 & & 48 & & 66 & & 62 & & 45 & \\
\hline Enthalpy* 1 & $\begin{array}{r}256 . \\
54 \\
\end{array}$ & & $\begin{array}{r}254 . \\
3 \\
\end{array}$ & & $\begin{array}{r}255 . \\
75 \\
\end{array}$ & & $\begin{array}{r}254 . \\
98 \\
\end{array}$ & & $\begin{array}{r}252 . \\
1\end{array}$ & & $\begin{array}{r}256 . \\
12 \\
\end{array}$ & & $\begin{array}{r}251 . \\
11\end{array}$ & & $\begin{array}{r}253 . \\
55\end{array}$ & \\
\hline Enthalpy 2 & $\begin{array}{r}290 . \\
64 \\
\end{array}$ & & $\begin{array}{r}288 . \\
15 \\
\end{array}$ & & $\begin{array}{r}284 . \\
3 \\
\end{array}$ & & $\begin{array}{r}292 . \\
81\end{array}$ & & $\begin{array}{r}284 . \\
3 \\
\end{array}$ & & $\begin{array}{r}287 . \\
01\end{array}$ & & $\begin{array}{r}285 . \\
86 \\
\end{array}$ & & $\begin{array}{r}281 . \\
33 \\
\end{array}$ & \\
\hline $\begin{array}{l}\text { Enthalpy 2a (Condenser } \\
\text { inlet) }\end{array}$ & $\begin{array}{r}283 . \\
49 \\
\end{array}$ & & $\begin{array}{r}284 . \\
55 \\
\end{array}$ & & $\begin{array}{r}278 . \\
83 \\
\end{array}$ & & $\begin{array}{r}285 . \\
59 \\
\end{array}$ & & $\begin{array}{r}274 . \\
39 \\
\end{array}$ & & $\begin{array}{r}279 . \\
39 \\
\end{array}$ & & $\begin{array}{r}276 . \\
37 \\
\end{array}$ & & $\begin{array}{r}273 . \\
43 \\
\end{array}$ & \\
\hline $\begin{array}{l}\text { Enthalpy } 3 \text { (condenser } \\
\text { outlet) }\end{array}$ & $\begin{array}{r}118 . \\
62 \\
\end{array}$ & & $\begin{array}{r}119 . \\
28 \\
\end{array}$ & & $\begin{array}{r}131 . \\
38 \\
\end{array}$ & & $\begin{array}{r}132 . \\
03 \\
\end{array}$ & & $\begin{array}{r}125 . \\
92 \\
\end{array}$ & & $\begin{array}{r}113 . \\
41 \\
\end{array}$ & & $\begin{array}{r}109 . \\
55 \\
\end{array}$ & & $\begin{array}{r}107 . \\
01 \\
\end{array}$ & \\
\hline $\begin{array}{l}\text { Enthalpy } 4 \text { (TXV out } \\
\text { /Evap in) }\end{array}$ & $\begin{array}{r}118 . \\
62 \\
\end{array}$ & & $\begin{array}{r}119 . \\
28 \\
\end{array}$ & & $\begin{array}{r}131 . \\
38 \\
\end{array}$ & & $\begin{array}{r}132 . \\
03 \\
\end{array}$ & & $\begin{array}{r}125 . \\
92 \\
\end{array}$ & & $\begin{array}{r}113 . \\
41 \\
\end{array}$ & & $\begin{array}{r}109 . \\
55 \\
\end{array}$ & & $\begin{array}{r}107 . \\
01 \\
\end{array}$ & \\
\hline $\begin{array}{l}\text { Enthalpy 1a } \\
\text { (Evaporator out) }\end{array}$ & $\begin{array}{r}251 . \\
15 \\
\end{array}$ & & $\begin{array}{r}250 . \\
95 \\
\end{array}$ & & $\begin{array}{r}251 . \\
96 \\
\end{array}$ & & $\begin{array}{r}251 . \\
17 \\
\end{array}$ & & $\begin{array}{r}244 . \\
92 \\
\end{array}$ & & $\begin{array}{r}252 . \\
39 \\
\end{array}$ & & $\begin{array}{r}246 . \\
27 \\
\end{array}$ & & $\begin{array}{r}248 . \\
28 \\
\end{array}$ & \\
\hline Condenser effect (CE) & $\begin{array}{r}164 . \\
87 \\
\end{array}$ & & $\begin{array}{r}165 . \\
27 \\
\end{array}$ & & $\begin{array}{r}147 . \\
45 \\
\end{array}$ & & $\begin{array}{r}153 . \\
56 \\
\end{array}$ & & $\begin{array}{r}148 . \\
47 \\
\end{array}$ & & $\begin{array}{r}165 . \\
98 \\
\end{array}$ & & $\begin{array}{r}166 . \\
82 \\
\end{array}$ & & $\begin{array}{r}166 . \\
42 \\
\end{array}$ & \\
\hline $\begin{array}{l}\text { Net refrigerant effect } \\
\text { (NRE) }\end{array}$ & $\begin{array}{r}132 . \\
53 \\
\end{array}$ & & $\begin{array}{r}131 . \\
67 \\
\end{array}$ & & $\begin{array}{r}120 . \\
58 \\
\end{array}$ & & $\begin{array}{r}119 . \\
14\end{array}$ & & 119 & & $\begin{array}{r}138 . \\
98 \\
\end{array}$ & & $\begin{array}{r}136 . \\
72 \\
\end{array}$ & & $\begin{array}{r}141 . \\
27\end{array}$ & \\
\hline $\begin{array}{l}\text { Heat of Compression } \\
(\mathrm{HOC})\end{array}$ & 34.1 & & $\begin{array}{r}33.8 \\
5 \\
\end{array}$ & & $\begin{array}{r}28.5 \\
5 \\
\end{array}$ & & $\begin{array}{r}37.8 \\
3 \\
\end{array}$ & & 32.2 & & $\begin{array}{r}30.8 \\
9 \\
\end{array}$ & & $\begin{array}{r}34.7 \\
5 \\
\end{array}$ & & $\begin{array}{r}27.7 \\
8 \\
\end{array}$ & \\
\hline COP (Heating) & 4.8 & & 4.9 & & 5.2 & & 4.1 & & 4.6 & & 5.4 & & 4.8 & & 6.0 & \\
\hline
\end{tabular}

* btu/hr 


\section{REFERENCES}

Abas, N., Kalair, A. R., Khan, N., Haider, A., Saleem, Z., \& Saleem, M. S. (2018). Natural and synthetic refrigerants, global warming: A review. Renewable and Sustainable Energy Reviews, 90(C), 557-569.

Abdelaziz, O., \& Shrestha, S. S. (2017). Evaluation of Alternative Refrigerants for Mini-Split Air Conditioners. ASHRAE Transactions, 123(1), 147-161.

Afshari, F., Comakli, O., Adiguzel, N., \& Ghasemi Zavaragh, H. (2017). Influence of Refrigerant Properties and Charge Amount on Performance of Reciprocating Compressor in Air Source Heat Pump. Journal of Energy Engineering, 143(1), Retrieved from https://doi.org/10.1061 /(ASCE)EY.1943-7897.0000377

AHRI. (2015). Participants' Handbook: AHRI Low GWP Alternative Refrigerants Evaluation Program. Arlington, VA. Retrieved from http://www.ahrinet.org/App_Content/ahri/files /Research/Participants_Handbook2015-04-17.pdf

AHRI. (2017). AHRI Standard 210/240 Performance Rating of Unitary Air-conditioning and Airsource Heat Pump Equipment. Arlington, VA. Retrieved from http://www.ahrinet.org /App_Content/ahri/files/STANDARDS/AHRI/AHRI_Standard_210-240_2017.pdf

ASHRAE. (1978). ANSI/ASHRAE 37 Methods of Testing for Rating Unitary Air Conditioning and Heat Pump Equipment. Atlanta, GA. Retrieved from https://ashrae.iwrapper.com /ViewOnline/Standard_37-1978

ASHRAE. (2016a). ASHRAE/ANSI Standard 62.1-2016 Ventilation for Acceptable Indoor Air Quality. Atlanta, GA. Retrieved from https://www.ashrae.org/technical-resources/standardsand-guidelines

ASHRAE. (2016b). HVAC Systems and Equipment (2016th ed.). ASHRAE Handbook. Atlanta. Retrieved from https://www.ashrae.org/technical-resources/standards-and-guidelines

ASHRAE. (2017). Fundamentals, Residential cooling and heating load calculation. ASHRAE Handbook 2017. Atlanta, GA. Retrieved from https://www.ashrae.org/technical-resources /standards-and-guidelines 
Beshr, M., Aute, V., Abdelaziz, O., Fricke, B., \& Radermacher, R. (2017). Potential emission savings from refrigeration and air conditioning systems by using low GWP refrigerants. International Journal of Life Cycle Assessment. 22(5), 675-682.

Calm, J. M. (2008). The next generation of refrigerants - Historical review, considerations, and outlook. International Journal of Refrigeration. 31(7), 1123-1133.

Chang, Y. S., Kim, M. S., \& Ro, S. T. (2000). Performance and heat transfer characteristics of hydrocarbon refrigerants in a heat pump system. International Journal of Refrigeration, 23(3), 232-242.

Chen, X., Liu, C., Yang, J., \& Chen, J. (2018). Experimental study on R-22, R-427A, R-161 and R-290 in air-source heat pump for space heating at low ambient temperatures. International Journal of Refrigeration, 96(147-154).

Choi, J.M., \& Kim, Y. C. (2002). The effects of improper refrigerant charge on the performance of a heat pump with an electronic expansion valve and capillary tube. Energy, 27(4), 391-404.

Corberán, J.-M., Martínez-Galván, I., Martínez-Ballester, S., Gonzálvez-Maciá, J., \& Royo-Pasto, R. (2011). Influence of the source and sink temperatures on the optimal refrigerant charge of a water-to-water heat pump. International Journal of Refrigeration, 34(4), 881-892.

CSA. (2012). Determining the Required Capacity of Residential Space Heating and Cooling Appliances F280. Retrieved from http://www.scc.ca/en/standardsdb/standards/26341

Dupont and Honeywell. (2007). DuPont, Honeywell Announce Refrigerants Global Joint Development Agreement. Morris Township, NJ and Wilmington, DE. Retrieved from http://www51.honeywell.com/honeywell/news-events/press-releases-details/10_0520 _Honeywell_Dupont.html

Farzad, M., \& O’Neal, D. L. (1994). The effect of void fraction model on estimation of air conditioner system performance variables under a range of refrigerant charging conditions. International Journal of Refrigeration, 17(2), 85-93.

Fernando, P., Palm, B., Lundqvist, P., \& Granryd, E. (2007). Performance of a Single-Family Heat Pump at Different Working Conditions Using Small Quantity of Propane as Refrigerant. Experimental Heat Transfer, 20(1), 57-71. 
Han, Z., Qu, L., Ma, X., Song, X., \& Ma, C. (2017). Simulation of a multi-source hybrid heat pump system with seasonal thermal storage in cold regions. Applied Thermal Engineering, 116, 292-302.

Hewitt, N. J., Huang, M. J., Anderson, M., \& Quinn, M. (2011). Advanced air source heat pumps for UK and European domestic buildings. Applied Thermal Engineering, 31, 3713-3719.

HFC/PFC Task Force of the Technology and Economic Assessment Panel). Nairobi: UNEP., \& Assessment Panel (UNEP/TEAP). (1999). The Implications to the Montreal Protocol of the Inclusion of HFCs and PFCs in the Kyoto Protocol, October 1999. Nairobi.

Jin, W., Gao, P., \& Zheng, Y. (2017). Experimental Study on Ventilation Effect on Concentration Distribution of R32 Leaking from Floor Type Air Conditioner. Energy Procedia, 105, 46274634.

Johnson, E. P. (2011). Air-source heat pump carbon footprints: HFC impacts and comparison to other heat sources. Energy Policy, 39(3), 1369-1381.

Kamel R, Ekramia, N., Dasha, P., Funga, A., \& Hailub, G. (2015). BIPV/T+ASHP: Technologies for NZEBs. In 6th International Building Physics Conference, IBPC.

Laue, H. J. (1994). The impact of heat pumps on global warming and ozone depletion. Heat Recovery Systems and CHP, 14(3), 323-335.

Lemmon, E. W., Huber, M. L., \& McLinden, M. O. (2013). REFPROP, Version 9.1, Natl Std. Ref. Data Series (NIST NSRDS): Fluid Dynamics and Transport Properties. Natl Std. Ref. Data Series (NIST NSRDS). Retrieved from https://www.nist.gov/publications/nist-standardreference-database-23-reference-fluid-thermodynamic-and-transport

Li, T. (2014). Indoor leakage test for safety of R-290 split type room air conditioner. International Journal of Refrigeration, 40, 380-389.

Maojuan, H., Jinbo, L., Zhe, L., \& Tingxun, L. (2018). Experimental and numerical simulation analysis of R-290 air conditioner leak. International Journal of Refrigeration, 90, 163-173.

National Resources Canada (NRCan). (2004). Heating and Cooling With a Heat Pump. Retrieved from https:/www.nrcan.gc.ca/sites/oee.nrcan.gc.ca/files/pdf/publications /infosource/pub/home/heating-heat-pump/booklet.pdf

National Resources Canada (NRCan). (2017). National Resources Canada: Air-Source Heat Pumps, Section 4 - Heating and Cooling with a Heat Pump. Retrieved from https://www .nrcan.gc.ca/energy/publications/efficiency/heating-heat-pump/6831 
Roth, K., Dieckmann, J., \& Brodrick, J. (2009). Heat Pumps for Cold Climates. ASHRAE Journal, $51(2), 69-72$.

Safa, A. A., Fung, A. S., \& Kumar, R. (2015). Comparative thermal performances of a ground source heat pump and a variable capacity air source heat pump systems for sustainable houses. Applied Thermal Engineering, 81, 279-287.

Schultz, K., Perez-Blanco, M., \& Kujak, S. (2015). Test Report \#56: System Soft-optimization Tests of Refrigerant R-32, DR-5A, and DR-55 in a R-410A 4-ton Unitary Rooftop Heat PumpCooling Mode Performance. Retrieved from http://www.ahrinet.org/App_Content /ahri/files/RESEARCH/AREP_Final_Reports/AHRI_Low_GWP_AREP_Rpt_056.pdf

Solvay Fluor GmbH. (n.d.). Solkane Software 8.0 Technical Data Program. Hannover, Germany. Retrieved from https://solkane-refrigerants.software.informer.com/8.0/

Sporlan. (2011). Bulletin 10-9 Thermostatic Expansion Valves With Selective Thermostatic Charges. Retrieved from https://sporlanonline.com/literature/10/10-10.pdf

Stöben, T., Wesch, S., Jepsen, J. ., \& Jessen, L. . (2016). AHRI Test Report \#61, System Drop-in Tests of DR-3, L-20(R-444B), and R-290 in Air-to-Water Heat Pump-Heating Mode. Arlington, VA.

Tecumseh Products Company LLC. (n.d.). Tecumseh Data Sheet Model: AK4482U-XA3B Product Specifications Performance. Ann Arbor, MI. Retrieved from http://www.tecumseh.com/en/na/products/recip/ak4482u-xa3b?pdf=datasheet

Trane Co. (1965). Trane Air Conditioning Manual.

United Nations Environment Programme (UNEP). (2016). The Kigali Amendment to the Montreal Protocol: HFC Phase-down. Retrieved from https://multimedia. $3 \mathrm{~m} . c 0 m / \mathrm{mws}$ /media/13659240/unep-fact-sheet-kigali-amendment-to-mp.pdf

Vuong, E. (2017). Thermal enhancement of an integrated building integrated photovoltaic/thermal system coupled with an air source heat pump. Ryerson Univesity.

Yu, C. C., \& Teng, T. P. (2014). Retrofit assessment of refrigerator using hydrocarbon refrigerants. Applied Thermal Engineering, 66, 507-518. 